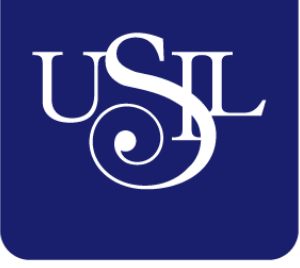

UNIVERSIDAD

SAN IGNACIO

DE LOYOLA

ESCUELA DE POSTGRADO

Maestría en Educación con mención en

Psicopedagogía de la Infancia

\title{
HABILIDADES SOCIALES EN LOS ESTUDIANTES DE SEXTO GRADO DE PRIMARIA DE DOS INSTITUCIONES EDUCATIVAS DEL CALLAO, 2019
}

Tesis para optar el grado de Maestro en Educación con Mención en Psicopedagogía de la Infancia

LILIANA CELEDONIA HUAMÁN PRETELL

Asesor:

ROBERTO SANTIAGO BELLIDO GARCÍA

Lima - Perú 
Página del Jurado

\section{Presidente}

Secretario

Vocal 


\section{Dedicatoria}

A mis hijos Susi, Jorge y Renzo quienes

son y serán siempre la motivación de mi superación profesional. 


\section{Agradecimiento}

Un sincero agradecimiento al convenio entre las autoridades de la Región Callao y la Universidad San Ignacio de Loyola, que me permitió alcanzar uno de los logros en mi desarrollo profesional. 


\section{Índice de Contenido}

Portada

Portadilla

Dedicatoria

Agradecimiento

Índice de Contenido $\quad$ V

Índice de Tablas vii

Índice de Figuras $\quad$ ix

Resumen $\quad x$

Abstract $\quad x i$

$\begin{array}{lr}\text { Introducción } & 1\end{array}$

$\begin{array}{ll}\text { Problema de investigación } & 1\end{array}$

$\begin{array}{ll}\text { Planteamiento } & 1\end{array}$

Formulación 3

Justificación 4

Fundamentación teórica $\quad 5$

$\begin{array}{ll}\text { Antecedentes } & 5\end{array}$

Marco teórico $\quad 8$

$\begin{array}{lr}\text { Objetivos e Hipótesis } & 27\end{array}$

$\begin{array}{ll}\text { Objetivos } & 27\end{array}$

$\begin{array}{ll}\text { Hipótesis } & 27\end{array}$

Marco metodológico

$\begin{array}{ll}\text { Tipo y diseño de la investigación } & 29\end{array}$

$\begin{array}{ll}\text { Variables } & 29\end{array}$

Definición conceptual 30

Definición operacional $\quad 30$ 
Población y muestra

$\begin{array}{ll}\text { Técnica e instrumento de recolección de datos } & 31\end{array}$

Procedimientos

33

Resultados

Discusión, Conclusiones y Sugerencias

$\begin{array}{ll}\text { Discusión } & 48\end{array}$

$\begin{array}{ll}\text { Conclusiones } & 51\end{array}$

$\begin{array}{ll}\text { Sugerencias } & 53\end{array}$

Referencias

Anexos

Anexo 1: Matriz de consistencia

Anexo 2: Instrumento de recolección de datos

Anexo 3: Certificado de validez

Anexo 4: Matriz de datos

Anexo 5: Otras evidencias 


\section{Índice de Tablas}

$\begin{array}{lll}\text { Tabla } 1 & \text { Operacionalización de la variable habilidades sociales } & 17\end{array}$

Tabla $2 \quad$ Baremos de la variable habilidades sociales 20

$\begin{array}{lll}\text { Tabla } 3 & \text { Frecuencia de habilidades sociales } & 21\end{array}$

Tabla $4 \quad$ Frecuencia de habilidades básicas de interacción social 22

Tabla $5 \quad$ Frecuencia de habilidades para hacer amigos y amigas 23

$\begin{array}{lll}\text { Tabla } 6 & \text { Frecuencia de habilidades conversacionales } & 24\end{array}$

Tabla $7 \quad$ Frecuencia de habilidades relacionadas con las emociones, $\begin{array}{ll}\text { sentimientos y opiniones } & 25\end{array}$

Tabla $8 \quad$ Frecuencia de habilidades de solución de problemas interpersonales 26

$\begin{array}{lll}\text { Tabla } 9 & \text { Frecuencia de habilidades para relacionarse con adultos } & 27\end{array}$

$\begin{array}{lll}\text { Tabla } 10 & \text { Prueba de normalidad } & 28\end{array}$

Tabla 11 Estadístico prueba U Mann Whitney para el desarrollo de habilidades $\begin{array}{ll}\text { sociales } & 29\end{array}$

Tabla 12 Estadístico prueba U Mann Whitney para el desarrollo de habilidades básicas de interacción social 30

Tabla 13 Estadístico prueba U Mann Whitney para el desarrollo de habilidades sociales para hacer amigos y amigas

Tabla 14 Estadístico prueba U Mann Whitney para el desarrollo de habilidades conversacionales

Tabla 15 Estadístico prueba U Mann Whitney para el desarrollo de habilidades Relacionadas con emociones, sentimientos y opiniones

Tabla 16 Estadístico prueba U Mann Whitney para el desarrollo de habilidades para la solución de problemas interpersonales

Tabla 17 Estadístico prueba U Mann Whitney para el desarrollo de habilidades para relacionarse con los adultos 


\section{Índice de Figuras}

Figura 1 Marco de referencia para habilidades cognitivas, sociales y emocionales

Figura 2 Interacciones dinámicas entre las habilidades cognitivas, emocionales y sociales

Figura $3 \quad$ Estilos de relación interpersonal 24

Figura $4 \quad$ Nivel de habilidades sociales $\quad 34$

Figura $5 \quad$ Nivel de habilidades básicas de interacción social 35

Figura $6 \quad$ Nivel de habilidades para hacer amigos y amigas 36

$\begin{array}{lll}\text { Figura } 7 & \text { Nivel de habilidades conversacionales } & 37\end{array}$

Figura $8 \quad$ Nivel de habilidades relacionadas con emociones, sentimientos y

$\begin{array}{ll}\text { opiniones } & 38\end{array}$

Figura $9 \quad$ Nivel de habilidades para la solución de problemas interpersonales $\quad 39$

Figura $10 \quad$ Nivel de habilidades para relacionarse con adultos 40 


\section{Resumen}

El presente estudio tuvo como objetivo comparar las diferencias en el desarrollo de las habilidades sociales en dos instituciones educativas del Callao. Como investigación fue del tipo básica, de nivel descriptivo comparativo, de enfoque cuantitativo; de diseño no experimental transversal. Su muestra censal tuvo conformada por 96 estudiantes. La técnica que empleó fue la encuesta y el instrumento de recolección de datos fue el Cuestionario de habilidades de interacción social (Monjas, 1994). Se arribó a las siguientes conclusiones: (a) existen diferencias significativas en el desarrollo de las habilidades sociales, habilidades para hacer amigos y amigas, habilidades relacionadas con emociones, sentimientos y opiniones, y habilidades para relacionarse con los adultos, (b) no existen diferencias significativas en el desarrollo de habilidades básicas de interacción social, habilidades conversacionales y habilidades de solución de problemas interpersonales.

Palabras claves: habilidades sociales, clima escolar, inteligencia emocional. 


\begin{abstract}
This study aimed to compare the differences in the development of social skills in two educational institutions in Callao. As research it was of the basic type, of comparative descriptive level, of quantitative approach; of non-experimental transversal design. Its census sample had 96 students. The technique he used was the survey and the data collection instrument was the Social Interaction Skills Questionnaire (Monjas, 1994). The following conclusions were reached: (a) there are significant differences in the development of social skills, abilities to make friends, emotions-related abilities, feelings and opinions, and abilities to interact with adults, (b) they do not exist significant differences in the development of basic social interaction skills, conversational skills and interpersonal problem solving skills.

Keywords: social skills, school climate, emotional intelligence.
\end{abstract}




\section{Introducción}

Se constata día a día un progresivo incremento de los problemas de interacción social que presentan los niños y niñas en los distintos contextos en los que viven. Es decir, hay una escasa habilidad para relacionarse con los demás o falta de desarrollo de las habilidades sociales.

Las habilidades sociales juegan un papel fundamental en el desarrollo integral de la persona, porque a través de ellas, la persona obtiene importantes refuerzos sociales del entorno más inmediato (familia, escuela) que favorecen su adaptación al mismo. La carencia de estas habilidades puede provocar rechazo, aislamiento, menor satisfacción personal y, en definitiva, niveles inferiores de calidad de vida.

El niño no nace socialmente hábil, sino que cada persona en su interacción con el medio y el entorno interpersonal va aprendiendo un comportamiento social adecuado, siendo la familia y la escuela los responsables de este aprendizaje.

La familia y la escuela tienen gran responsabilidad en el desarrollo de estas habilidades sociales. La familia como primer ente socializador es la encargada de transmitir un ambiente apropiado que permita que el niño se desarrolle en un mundo social que le permita un crecimiento psicológico y moral adecuado. Mientras que en la escuela el comportamiento interpersonal de los niños juega un papel vital en la adquisición de reforzamiento sociales. Este estudio permitirá aportar nuevos conocimientos sobre un problema de aprendizaje que afecta a las escuelas de la región Callao.

\section{Problema de investigación}

\section{Planteamiento.}

Las habilidades sociales están constituidas por cogniciones, emociones y conductas que ayudan al sujeto a entablar relaciones positivas y a convivir satisfactoria y eficazmente con sus pares (Monjas, 2009). Como conductas que son, se adquieren principalmente por medio del aprendizaje, se ponen en práctica en situaciones interpersonales, y se maximizan con el refuerzo social. Son valiosas para la construcción de la autoestima y el bienestar personal, así como para la adopción de roles y las competencias profesionales. 
Según la Encuesta Nacional de Relaciones Sociales (INEI, 2015) cerca del 75\% de los estudiantes ha sufrido una agresión de sus compañeros, por lo menos en una oportunidad, aproximadamente el $40 \%$ o 50\% de las víctimas de la agresión no solicitan ayuda, y entre el $25 \%$ y $35 \%$ de compañeros se niega a ayudarlos o son indiferentes frente a estos actos. Hace algunos años, la Oficina de Tutoría y Prevención Integral (2003), como se citó en Verde (2019), encontró que el 31,3\% de los escolares del nivel secundario mostraban preocupantes deficiencias en sus habilidades sociales (Ministerio de Educación, 2003). Un bajo nivel de desarrollo de habilidades sociales podría ser uno de los factores que ayude a comprender la violencia en el Perú actual. Escasa tolerancia a la frustración, inexistencia de contención frente a impulsos primarios, la casi normalización de que la agresión es la mejor manera de arreglar las cosas son conductas, y la falta de empatía son manifestaciones de un problema no solo por estudiar, sino también por resolver.

A nivel internacional, según el National Research Council y la National Academy of Sciences de los Estados Unidos (como se citó en García, 2018), las habilidades sociales -junto a otras habilidades interpersonales como la habilidad de comunicación, la sensibilidad cultural y el trabajo en equipo- son algunas de las habilidades que el ciudadano del siglo XXI deberá ir adquiriendo, si desea desempeñarse exitosamente en diversos ámbitos de la vida personal, laboral y social. Por su parte, la Organización de las Naciones Unidas para la Educación, Ciencia y Cultura (Unesco, 2016) señala como una de las habilidades para un mundo cambiante a la interacción con grupos heterogéneos. En otras palabras, desde una perspectiva global de ciudadano competente en lo social, es indispensable aprender a relacionarse bien con los demás, a estar predispuestos a la cooperación y al trabajo en equipo, a la gestión y resolución de conflictos.

La presente investigación se centró en dos instituciones educativas, en donde la ficha integral del estudiante fue el insumo principal para caracterizar a la población. Por un lado, un colegio donde predomina en los padres la actividad laboral mal remunerada y, en varios casos, al margen de la ley, el absentismo frente a las convocatorias del tutor y de los docentes, bajo rendimiento académico, conducta agresiva e irrespeto frecuente a las figuras de autoridad. Por otro lado, un colegio donde padres y madres tienen una mejor condición socioeconómica, debido a su empleabilidad en el sector público y privado, buen nivel de asistencia cuando el tutor o los docentes los convocan para informar del progreso del estudiante. En ambos casos, una característica compartida es la disfuncionalidad familiar y la pubertad de sus estudiantes. Estos rasgos no son poca 
cosa, ya que un hogar disfuncionalidad cuenta con un menor tiempo de acompañamiento y/o supervisión para el hijo, mientras que la pubertad es una transición hacia la adolescencia, marcada por situaciones conflictivas (Salvat, 2004).

Como se evidencia, las habilidades sociales son parte importante del desarrollo socioemocional del individuo, se aprenden socialmente y constituyen una de las habilidades más requeridas en el ámbito educativo, familiar y laboral. Esto lleva a buscar como propósito identificar y comparar las diferencias de dos grupos de estudiantes de la región Callao, en cuanto a su nivel de progreso de las habilidades sociales en el 2019.

\section{Formulación.}

\section{Pregunta general.}

¿Cuáles son las diferencias en el desarrollo de habilidades sociales en los estudiantes de sexto grado de dos instituciones educativas del Callao, 2019?

\section{Preguntas específicas.}

¿Cuáles son las diferencias en el desarrollo de habilidades básicas de interacción social en los estudiantes de sexto grado de dos instituciones educativas del Callao, 2019?

¿Cuáles son las diferencias en el desarrollo de habilidades para hacer amigos y amigas en los estudiantes de sexto grado de dos instituciones educativas del Callao, 2019?

¿Cuáles son las diferencias en el desarrollo de habilidades conversacionales en los estudiantes de sexto grado de dos instituciones educativas del Callao, 2019?

¿Cuáles son las diferencias en el desarrollo de habilidades relacionadas con las emociones, sentimientos y opiniones en los estudiantes de sexto grado de dos instituciones educativas del Callao, 2019?

¿Cuáles son las diferencias en el desarrollo de habilidades de solución de problemas interpersonales en los estudiantes de sexto grado de dos instituciones educativas del Callao, 2019? 
¿Cuáles son las diferencias en el desarrollo de habilidades para relacionarse con los adultos en los estudiantes de sexto grado de dos instituciones educativas del Callao, $2019 ?$

\section{Justificación.}

\section{Justificación teórica.}

La presente investigación permitió conocer en mayor medida el comportamiento de la variable habilidades sociales por medio de una investigación descriptiva comparativa. Según diversos estudios las habilidades sociales inciden en la autoestima, adopción de roles, autorregulación del comportamiento y en el rendimiento académico. El autor base para la definición conceptual y operacional de dicha variable fue Inés Monjas.

\section{Justificación práctica.}

Los resultados del estudio serán de utilidad para las autoridades de las instituciones educativas, dado que se les proporcionará un diagnóstico objetivo en base al cual se puedan generar estrategias, programas, talleres que sean beneficiosos para la población estudiantil, potenciando el desarrollo de habilidades sociales, de modo que se estimule su desarrollo integral, y se les brinde más oportunidades que les permitan afrontar con éxito diversas situaciones en el ámbito social, escolar y familiar. Asimismo, el estudio será útil para la Dirección Regional de Educación del Callao, ya que proporcionará información relevante acerca de un posible bajo nivel de desarrollo de habilidades sociales, con el propósito de implementar estrategias de reducción de la violencia y el manejo de la resolución de conflictos en el ámbito educativo, creando un clima escolar idóneo para el aprendizaje.

\section{Justificación metodológica.}

El presente estudio se valió del Cuestionario de habilidades sociales de interacción social para contribuir al estudio de dicha variable en dos instituciones educativas del Callao. Por ese motivo, se confirma la pertinencia de dicho instrumento para el estudio de las habilidades sociales en una población escolar. 


\section{Fundamentación Teórica}

\section{Antecedentes.}

\section{Antecedentes internacionales.}

Holst, Galicia, Gómez y Degante (2017) se propusieron como objetivo obtener la validez de constructo de la Escala de Habilidades Sociales y reseñar las diferencias que, al respecto, tengan 400 estudiantes universitarios provenientes de tres instituciones de México. Un análisis factorial exploratorio permitió obtener una escala válida y confiable ( $\alpha=0.707$ ), mientras que se halló que: (a) los estudiantes de Ciudad Universitaria UNAM cuentan con mayores habilidades que los de la Facultad de Estudios Superiores Zaragoza, (b) los varones tienen mayores habilidades de comunicación que las mujeres, (c) en esa misma habilidad los estudiantes de Psicología obtuvieron un puntaje más alto que los de Ingeniería Química.

Barrientos (2016), en su tesis doctoral, se planteó como objetivo establecer si las habilidades sociales y emocionales del profesorado de educación infantil están relacionadas con la gestión del clima de aula. Su muestra estuvo compuesta por 68 maestros tutores y 1493 estudiantes de la Comuna de Madrid (España). Sus instrumentos de medición fueron: Emotional Quotient Inventory (BarOn, 1997), Classroom Assessment Scoring System (CLASS, Hamre \& Pianta, 2005), y Early Environmental Rating Scale, (ECERS-R, Harms, Clifford \& Cryer, 1980). Su hallazgo más destacado es que no necesariamente existe relación entre las variables en estudio, puesto que son varios casos en donde la primera variable mejora o empeora, pero no siempre ocurre eso en la segunda variable. Por ejemplo: no hay relación entre inteligencia emocional y apoyo emocional ( $r=0.133$; sig.=0.280), al igual que entre la inteligencia emocional y la organización de la clase $(r=0.176$; sig.=0.150), y entre inteligencia emocional 2y apoyo pedagógico ( $r=0.102$; sig.=0.407).

Carrillo (2015), en su tesis doctoral, se interesó por elaborar y validar un programa lúdico para la mejora de las habilidades sociales en niños cuyas edades estén entre los 9 y 12 años. Por ello, realizó una investigación aplicada, de nivel explicativo, de enfoque cuantitativo; de diseño cuasi experimental. Su muestra estuvo compuesta por 112 estudiantes de un colegio público de Granada (España). Los instrumentos de medición fueron la "Escala de comportamiento asertivo para niños" (CABS por sus siglas en inglés, 
Wood, Michelson \& Flynn, 1978), "Escala de conducta asertiva del niño para maestros" (TRCABS por sus siglas en inglés, Wood et al., 1978), y "Cuestionario de interacción social para niños" (CISO-NIII, Caballo, Arias et al., 2011). El resultado más destacado fue que el programa en mención logró los efectos deseados en el grupo experimental, por lo que disminuyó el número de comportamientos no asertivos, al igual que la ansiedad social. Todo lo anterior fue percibido por los estudiantes y por los docentes que participaron en el estudio.

Losada (2015), en su tesis doctoral, se planteó como objetivo la adaptación del "Social Skills Improvement System-rating Scales" (SSIR-RS, Gresham \& Elliot, 2008) al contexto sociocultural español, en particular el de la educación primaria. Dicho proceso de adaptación se hizo acatando los lineamientos técnicos de la Comisión Internacional de Tests (Hambleton, 2009). Consistió en una investigación aplicada, una muestra de 751 estudiantes, y se exploraron evidencias de validez, por medio del análisis de las relaciones del Sistema de Evaluación de las Habilidades Sociales-Alumno (SEHS-A) con otras variables de las que se presupone una relación, por ejemplo, competencia social, problemas emocionales y de conducta, entre otros. El resultado principal fue que la adaptación del SEHS-A mostró una consistencia interna y una validez apropiadas. Por tanto, se cuenta con un instrumento más al servicio de la investigación educativa, orientado a determinar déficits y carencias en el área de las habilidades sociales.

Caballo, Salazar, Irurtia, Olivares y Olivares (2014), se interesaron por la relación entre las habilidades sociales con la ansiedad social y los estilos/trastornos de la personalidad. Su muestra estuvo compuesta por 537 sujetos (la mayoría estudiantes universitarios españoles) con una edad promedio de 22 años. Los instrumentos de medición fueron: "Cuestionario de habilidades sociales" (CHASO-I, Caballo, Salazar, Olivares, Irurtia y Olivares, 2014), "Inventario de asertividad de Rathus" (RAS, Rathus, 1973), "Inventario de aserción" (Gambrill \& Richey, 1975), "Escala de autoexpresión universitaria" (CSES, Galassi et al., 1974), "Cuestionario de ansiedad social para adultos" (CASO-A30, Caballo, Salazar, Irurtia et al., 2012), "Escala de ansiedad social de Liebowitz-versión de autoinforme" (Liebowitz, 1987), y el "Cuestionario exploratorio de personalidad-III" (CEPER-III, Caballo, Guillen, Salazar e Irurtia, 2011). Se concluyó que: (a) hay una relación inequívoca e inversa entre la ansiedad social y las habilidades sociales, en otras palabras, a mayor habilidad social menor ansiedad social y viceversa, (b) la Interacción con el sexo opuesto de la variable ansiedad social tiene relaciones moderadas (de $r=-$ 
0.40 a $r=-0.47)$ con su contrapartida de las habilidades sociales en los cuestionarios donde se le incluye (CHASO-I, RAS y CSES).

\section{Antecedentes nacionales.}

Ibarra (2018) realizó una investigación con una muestra censal de 59 estudiantes del VI ciclo de una institución educativa de Lima. Como instrumentos de medición empleó la Escala de Habilidades Sociales (Gonzáles, 2000) y la Escala de Clima Social en el Centro Escolar (Moos, Bernice, Moos \& Trickett, 1984). El resultado más relevante al que arribó fue demostrar que, entre las variables en estudio, existe una relación moderada ( $r=$ 0.658; sig.=0.000).

Jara (2018) realizó una investigación descriptiva correlacional. Su muestra censal, ya que trabajó con toda la población, estuvo conformada por 210 estudiantes del VI ciclo de educación secundaria en Huacho (provincia de Huaura). Sus instrumentos de medición fueron el Cuestionario de las Habilidades Sociales (Minedu, 2005), Cuestionario de las habilidades comunicativas (Jara, 2016), y el Inventario de Estilos de Manejo de Conflictos (Rodríguez, 2016). Su principal resultado fue que las tres variables estudiadas tienen una relación moderada y positiva $(r=0.664)$.

Zelada (2018) llevó a cabo una investigación del tipo básica, de nivel descriptivo correlacional, de enfoque cuantitativo; de diseño no experimental transversal. Su población estuvo conformada por 150 estudiantes y su muestra fue de 100 estudiantes de una institución educativa de La Victoria (Lima Metropolitana). Su instrumento de recolección de datos fue de su autoría y se tituló "Cuestionario de Habilidades sociales y Competencia en gestión de proyectos de emprendimiento económico y social”. El hallazgo más destacado fue la correlación positiva, directa y moderada entre las variables en estudio $(r=0.63)$.

Huertas (2017) realizó una investigación básica, de nivel descriptivo explicativo, de enfoque cuantitativo; de diseño no experimental transversal. Empleó una muestra censal compuesta por 35 estudiantes de 4 años de edad de una institución educativa de Piura. El instrumento de medición elegido fue "Lista de chequeo de habilidades sociales para preescolares" cuyas siglas son LCHS-PE (McGinnis \& Goldstein, 1990). El principal hallazgo fue que los niños han desarrollado habilidades sociales en diversos niveles de logro. En un nivel denominado competente se encontró a las primeras habilidades 
sociales, habilidades relacionadas con la escuela, habilidades para hacer amigos, y habilidades relacionadas con los sentimientos. En un nivel promedio se encontró a las habilidades alternativas a la agresión y las habilidades frente al estrés.

López (2016) llevó a cabo una investigación básica, de nivel descriptivo correlacional, de enfoque cuantitativo; de diseño no experimental transversal. Su muestra censal estuvo compuesta por 100 estudiantes de primaria de una institución educativa de Miraflores (Lima Metropolitana). Para sus variables empleó los instrumentos "Escala del Clima Social en Familia" (Moos \& Trickett, 2001) y "Lista de chequeo y evaluación de habilidades sociales" (Goldstein, Sprafkin, Gershaw \& Klein, 1989). El hallazgo más resaltante fue la relación significativa, muy alta y positiva entre las dos variables en estudio $(r=0.861 ; p<0.01)$.

\section{Marco teórico.}

La presente investigación adopta la definición de habilidades sociales de Monjas y González (1998), por la que estas son una serie de destrezas y conductas aprendidas y necesarias para la ejecución competente de una tarea interpersonal, por ejemplo, pedir algo, contestar a un saludo, ser empático con alguien que necesita soporte emocional, y decir cosas asertivamente a los demás. Se trata de conductas que se hacen, piensan y dicen, que se aprenden, son específicas en tanto que expresan una respuesta a otras circunstancias específicas, se producen en relación a otras personas, son comportamientos de muy distinta complejidad, Para Caballo y Verdugo (2005), las habilidades sociales tienen componentes conductuales, cognitivos y fisiológicos (figura 1). Los componentes cognitivos se refieren a lo que la persona piensa, dice e imagina; los componentes emocionales se relacionan con lo que se siente y las sensaciones corporales, y por último, los componentes conductuales comprenden lo que se dice y lo que se hace.

La adquisición de estas destrezas es importante porque le ayudan al sujeto a evitar la ansiedad en situaciones tensas e inesperadas, además de facilitar la comunicación emocional y la resolución de problemas (Minedu, 2004). Asimismo, son parte imprescindible de la actividad cotidiana al punto que impactan en la autoestima, la adopción de roles y la autorregulación del comportamiento (Lacunza \& Contini, 2011).

Otras definiciones de interés han provenido de: 
Morales y Olsa (2001). Las habilidades sociales son conductas aprendidas, que se pueden observar en momentos donde es necesaria la interacción, siendo el ambiente un factor que influye de manera directa, al igual que la cultura y la personalidad de la persona.

Gil (como se citó en Valles y Valles, 1996) considera que las habilidades sociales son conductas que se exteriorizan en situaciones interpersonales; dichas conductas se pueden aprender y eso quiere decir que tendrán la misma facilidad para poder enseñarse. También son comportamientos a ser reforzados por la sociedad, es decir, se les debe considerar como las normas elementales dentro del contexto donde se encuentre y de la misma manera se debe tener en cuenta la moralidad.

Caballo (1993). Conjunto de conductas interpersonales que posibilitan la comunicación eficaz con los demás, bajo el principio del respeto mutuo.

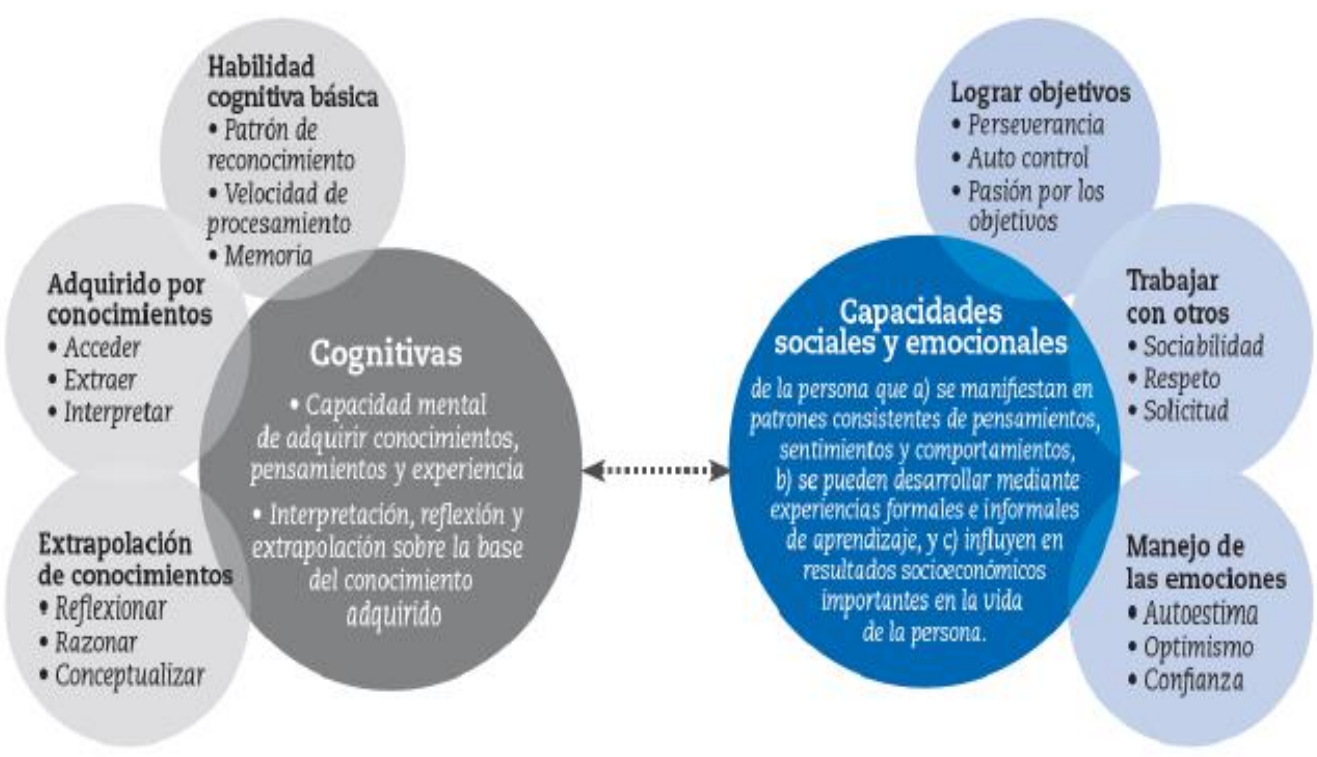

Figura 1. Marco de referencia para las habilidades cognitivas, sociales y emocionales. El desarrollo de las habilidades sociales es una necesidad que debe ser satisfecha por la formación escolar, debido a sus diversas implicancias en la futura vida laboral y la convivencia saludable. Tomado de "Habilidades para el progreso social: el poder de las habilidades sociales y emocionales" por Instituto de Estadística de la Unesco (2016), p. 34.

Por lo expuesto hasta el momento, establecer una definición única de las habilidades sociales es difícil dada su multidimensionalidad y su afinidad con otros conceptos. En la 
revisión de la literatura ha sido frecuente encontrar expresiones relacionadas con competencia social, inteligencia social, habilidades adaptativas, competencia interpersonal, habilidades de interacción social, destrezas sociales, conductas de intercambio social, habilidades para la interacción, etc. Fernández (1994) señala que hay un consenso entre los especialistas respecto a lo difícil que es precisar el significado de una habilidad social. Iruarrizaga, Gómez, Criado, Zuazo y Sastre (1999) señalan que el problema radica en que una definición está ligada a una serie de fenómenos sociales, educativos, psicológicos, etc. De igual manera, se debe considerar que cada persona tiene a su alcance diversos recursos o estrategias, entre ellos aquellos que cognitivamente formarán parte de su individualidad al manifestar sus habilidades sociales.

Caballo (1993) consideró muy difícil llegar a una sola definición de habilidad social, debido a tres tipologías: en primer lugar, el número de estudios en donde frecuentemente se han utilizado numerosos y variados términos para referirse a un mismo concepto. En segundo lugar, la relación entre los comportamientos y el contexto social no siempre es la misma (Meichenbaum, Butler \& Grudson, 1981). Es muy recomendable tener en cuenta el marco cultural, es decir, cómo las culturas se encuentran inmersas en contextos más amplios. Al analizar las interacciones al interior de una sociedad, a los niveles social, económico y educativo se suman las singularidades de la capacidad cognitiva, los sentimientos y la jerarquía de valores, lo que hace que sea casi imposible determinar un razonamiento específico para señalar qué es una habilidad o qué son las habilidades sociales. De esta manera, los individuos pueden tener comportamientos diferentes en una misma circunstancia social y, a su vez, tener diversas maneras de responder ante una misma situación y considerar que su forma de comportarse es igual de efectiva (Lacunza \& Contini, 2011).

Gresham (1988) ha señalado que, en relación a la infancia aún tienen vigencia tres definiciones de habilidades sociales. Primero, definición de aceptación de iguales por la que se considera como niños socialmente hábiles a aquellos que son aceptados o disfrutan de popularidad en la escuela o en la comunidad, pero el reparo estriba en que no se identifican los comportamientos específicos relacionados con la aceptación de sus pares. Segundo, definición conductual que asume a las habilidades sociales como los comportamientos específicos que pueden maximizar la probabilidad de conservar el reforzamiento o disminuir la probabilidad de castigo. La aceptación y difusión de esta definición se debe a las facilidades que brinda para la identificación y operacionalización 
de antecedentes y las consecuencias de determinados comportamientos con la finalidad de evaluar e intervenir. Empero, la definición en mención no asegura que los comportamientos que se hayan identificado para la intervención sean en la práctica socialmente hábiles o socialmente importante. Tercero, definición de validación social que implica que las habilidades sociales son las conductas hasta cierto punto predictoras de los resultados que un niño pueda lograr respecto a aceptación, popularidad o juicios significativos de quienes le rodean. Bajo esa lógica, las habilidades sociales brindan indicios acerca del ajuste y adaptación social del niño a mediano y largo plazo (figura 2).

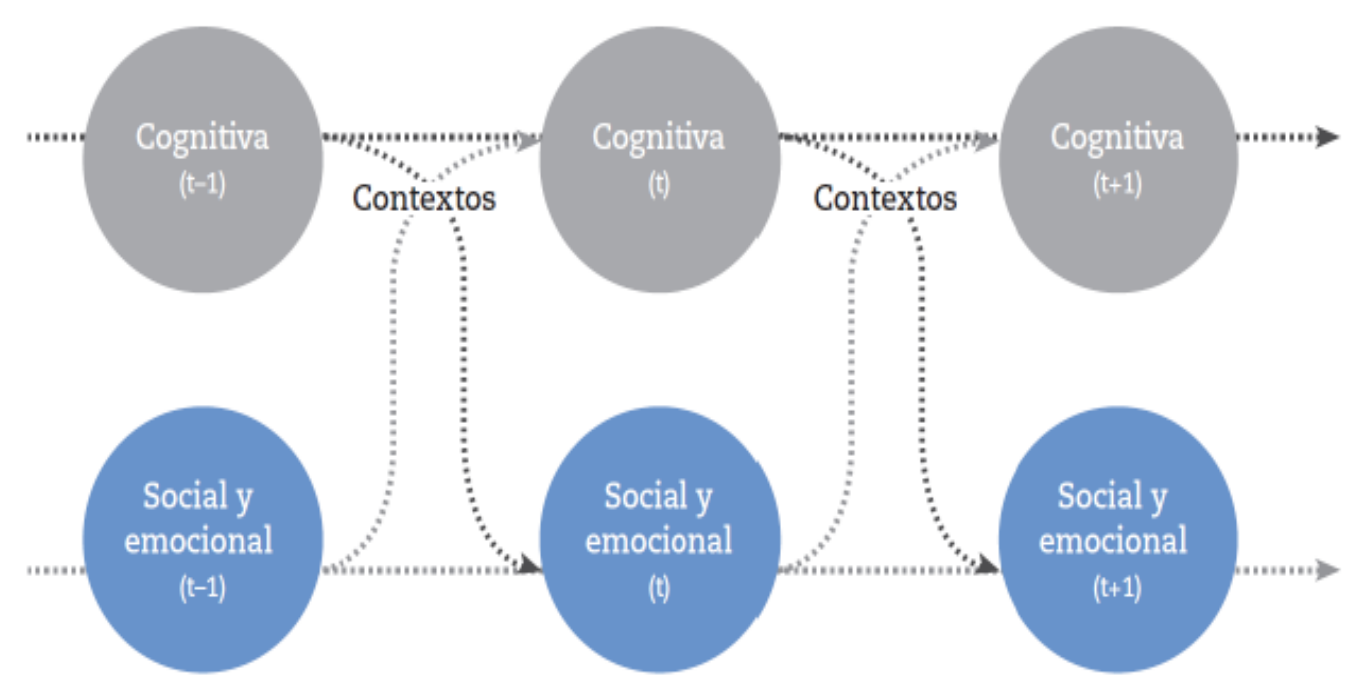

Figura 2. Interacciones dinámicas entre las habilidades cognitivas, emocionales y sociales. Las habilidades adquiridas determinarán hasta dónde los individuos se beneficiarán con nuevas inversiones provenientes de sus familias, escuelas y comunidad. Tomado de "Habilidades para el progreso social: el poder de las habilidades sociales y emocionales" por Instituto de Estadística de la Unesco (2016), p. 40.

Promover las habilidades sociales en la Educación Básica Regular es una necesidad impostergable que requiere de una preparación por parte del docente. Los maestros interactúan con decenas o incluso cientos de alumnos todos los días. En el aula, su tarea principal es indudablemente el desarrollo de capacidades. Sin embargo, para poder apoyar el aprendizaje de los alumnos en el aula, los maestros brindan comentarios, alientan y confortan a sus alumnos. Además, es importante tratar (o preferiblemente prevenir) los desafíos de comportamiento de los alumnos, como el comportamiento fuera de la tarea o, a veces, incluso el comportamiento agresivo. Por lo tanto, la contribución de los maestros para ayudar a los estudiantes a colaborar entre ellos y participar en 
actividades de aprendizaje es esencial. Los maestros necesitan educación continua para poder promover una interacción social ideal en el aula. En conclusión, la interacción del maestro al respecto es diversa y durante el día escolar los maestros necesitan varias habilidades para mantener una interacción exitosa en la escuela.

También es importante que un maestro sepa qué habilidades deben usarse en cada situación. Hamre, Hatfield, Pianta y Jamil (2014) dividieron las interacciones de los maestros en el aula en elementos generales y específicos del dominio. Los elementos específicos del dominio incluyen el manejo proactivo y las rutinas de los maestros, el apoyo motivacional y cognitivo facilitación. Los elementos generales incluyen características específicas de la enseñanza receptiva, como la detección de señales, la respuesta contingente y la participación activa. Se sugirió que ambos elementos en las interacciones efectivas y específicas son necesarios para contribuir al aprendizaje y desarrollo de los niños (Hamre et al., 2014). Por lo tanto, los maestros competentes varían sus formas de interactuar de acuerdo con las necesidades de crecimiento de los alumnos.

Las formas hábiles de los maestros de interactuar con los miembros de la comunidad escolar no son relevantes solo por la interacción misma. Los maestros también son modelos a seguir cuyas conductas interactivas muestran a los alumnos cuán respetuosos son los adultos cuando se comunican entre sí y se ocupan de los problemas (Durlak, Weissberg, Dymnicki, Taylor \& Schellinger, 2011). Así, al observar a los adultos, los alumnos determinan la idoneidad del comportamiento (Bandura, 1977). Para el crecimiento de un alumno, ese ejemplo puede ser positivo o negativo (Hurd, Zimmerman \& Xue, 2009). Además, mediante el uso de habilidades de interacción, los maestros crean un clima de apoyo autónomo en el aula y promueven una atmósfera para que los estudiantes se sientan incluidos (Leroy, Bressoux, Sarrazin \& Trouilloud, 2007). Por ejemplo, escuchar a los alumnos sobre sus dificultades, en lugar de dar respuestas directas, les ayuda a resolver sus propios problemas y, por lo tanto, a regular su propio aprendizaje. Para concluir, la necesidad de las habilidades de interacción social de los docentes es enorme, para permitir ocuparse de todas las tareas que exige la profesión docente.

Ha habido una mayor investigación en educación sobre cómo se desarrollan las habilidades de regulación emocional, las habilidades de cognición social y los comportamientos comunicativos positivos (Brophy, Lee, Nievar \& Stollak, 2007). Además, 
hay investigaciones disponibles sobre programas de interacción en la escuela, pero la mayor parte se centra en los estudiantes (Lintunen, 2006). La investigación activa en el área de habilidades de interacción social se proporciona en ciencias de la salud, educación médica y de comunicación. Según una revisión sistemática de la literatura a cargo de Aspegren (1999), las habilidades de comunicación se pueden enseñar y aprender durante los cursos, pero se olvidan fácilmente si no se practican habitualmente. También se descubrió que las habilidades básicas pueden ser aprendidas durante un corto período de entrenamiento. Sorprendentemente, existe poca investigación sobre cómo los maestros desarrollan y mejoran las habilidades sociales y emocionales necesarias para que colaboren entre sí y faciliten comportamientos pro-sociales con sus estudiantes.

\section{Teoría científica de las habilidades sociales.}

Teoría sociocultural.

La teoría sociohistórica parte de la premisa de que las habilidades de un individuo se producen en el ámbito social. Esta teoría brinda la posibilidad de analizar las diferentes formas en que un niño logra aprender a través de la conexión de los diferentes procesos históricos, culturales, individuales y sociales. Esboza el origen doble que se presenta en los procesos psicológicos, manifestando que el desarrollo infantil surge en dos momentos; en primera instancia se da entre las personas y en segunda surge el interior del individuo (Vygotsky, 1978). No se refiera a un aprendizaje netamente de índole académico, por el contario se centra en un sentido más amplio, como lo es el aprendizaje cultural; el cual puede ser concebido como todas las herramientas que se tiene a disposición para solventar los problemas que se presentan en la vida cultural. Se puede decir que la interacción social se transforma en un motor para lograr el desarrollo integral de las personas.

Esta teoría señala lo vital que resulta el aprendizaje de los sujetos desde temprana edad, basado en las relaciones que entabla con sus padres, quienes son las personas más inmediatas, y que a su vez también se encuentran los compañeros con los que comparte día a día. Ha mostrado gran interés en el aprendizaje desarrollado a través de la educación directa o la organización continua de las costumbres que favorecen el aprendizaje de los demás, sin embargo, su teoría además ampara las otras maneras de aprendizaje cultural. 
Teoría del aprendizaje social.

Para Bandura (1977), la correlación que se da entre la persona y el ambiente se encuentra influenciada por los procesos de aprendizaje, referente a lo que es modelado y moldeamiento los cuales permiten instruir a la persona con el fin de que pueda desenvolverse de manera socialmente competente. Esta teoría hace énfasis en la influencia que se genera en el aprendizaje para la lograr adquirir un desempeño social adecuado. Este aspecto debe ser complementado considerando los elementos biológicos tales como el temperamento. De igual manera la psicología social destaca lo importante que resulta la atracción, la percepción y la comunicación interpersonal, en el proceso de adquisición de habilidades sociales. Del mismo modo la terapia de conducta hace referencia a todas las conductas y mediaciones psicológicas concernientes a la noción de desempeño socialmente aceptable. En función de ello, se recalca como herramientas básicas el uso de ensayo de conducta, refuerzo positivo y moldeamiento y las estrategias de role-playing para así poder garantizar la consolidación de las habilidades sociales necesarias.

La teoría del aprendizaje social sostiene que el desempeño psicológico, y a su vez el desarrollo social, están condicionados por diversos factores individuales, circunstanciales y conductuales de la persona. Estos brindan la posibilidad de alcanzar un aprendizaje del comportamiento social adecuado. Por tanto, es posible argumentar que los factores que actúan en el proceso de desarrollo de las habilidades sociales son ambientales e individuales tales como:

- Factores ambientales: cuando se decide realizar un estudio de las habilidades sociales, es necesario considerar el ámbito natural en donde se va a desarrollar la persona.

- Factores individuales: estos factores interactúan en conjunto con los factores de tipo ambiental para poder generar como efecto la conducta social del individuo. Dentro de los factores individuales se encuentran las variaciones constitucionales como lo son el temperamento, género y atractivo personal y las variables psicológicas entre las que se tiene a los aspectos cognitivos, afectivos y conductuales. 
Teoría del desarrollo social de Erickson.

Para Erickson (1982) el ser humano a lo largo de su vida desarrolla determinadas competencias y una de las más importantes es la socialización, sobre todo cuando los niños requieren de esta para ir construyendo su identidad personal de una manera sana. Si lo consigue experimentará lo que se conoce como la sensación de dominio denominada también como fuerza del ego. Su adquisición permitirá una sensación de suficiencia que le será útil al niño cuando tenga que afrontar los retos en las próximas etapas de su vida. La teoría de Erickson también destaca porque considera que en cada etapa de la vida se da un conflicto que, al ser resuelto, fomenta el crecimiento psicológico. Como no podía ser de otra manera, así como el conflicto entraña un potencial para el desarrollo también podría ofrecer lo mismo pero para el fracaso. Según Pérez (2008) la filiación psicoanalítica de Erickson ayuda a explicar su interés por las inquietudes y aspiraciones de la persona, así como de su satisfacción con la sociedad. Todo esto se refleja en los ocho momentos o etapas por las que atraviesa una persona donde la oposición de extremos es una constante:

- Comparación entre confianza y desconfianza.

- Comparación de autonomía con vergüenza y duda.

- Comparación entre iniciativa y sentimiento de culpabilidad.

- Comparación entre industriosidad e inferioridad.

- Comparación entre identidad y confusión de identidad.

- Comparación entre intimidad y aislamiento.

- Comparación entre creatividad y estancamiento.

- Comparación entre integridad y desesperación.

Conductismo de Skinner.

De acuerdo con Skinner (1938) la conducta es influenciada por las derivaciones del entorno en el que se desenvuelve un comportamiento en particular. Refiere que la estructura de cómo se aprende es la siguiente: estímulo, respuesta, consecuencia y considerando que está última pueden ser positivas o negativas. De acuerdo con esta estructura, la conducta está precedida de acuerdo con unas referencias y unos resultados que, si son positivos, fortalecen la conducta. En función de esta teoría las habilidades sociales se logran a través de estímulos positivos y directos de las experiencias. Del mismo modo, se obtienen a través de aprendizaje vicario u observacional, por medio de 
la retroalimentación interpersonal y a través del desarrollo de perspectivas cognoscitivas referentes a las circunstancias interpersonales para mejorar de manera significativa los procesos enseñanza-aprendizaje.

Teoría de habilidades sociales de Goldstein.

Goldstein et al. (2002) puntualiza que las habilidades sociales son un conjunto de comportamientos eficaces en las relaciones interpersonales. De acuerdo con este autor, dichos comportamientos son asimilados, y favorecen la relación que se pueda establecer con los otros, la demanda de los derechos personales, sin hacer caso omiso de los derechos de otros, evade la ansiedad en circunstancias dificultosas o nuevas, favorecen la comunicación y la solución de inconvenientes. En ese sentido, se está consciente de que hay habilidades sociales básicas y otras que son más complejas: concernientes con los sentimientos, superpuestos a la agresión, a la confrontación del estrés y habilidades de planificación entre otras.

De igual manera se puede indicar la presencia de varias de ellos en las relaciones que establecen los niños de la calle diariamente. Existen reglas y jerarquías determinadas que tienen que ser respetadas. Si se solicita contar algunas rutinas diarias, se podrá observar cuántas de dichas habilidades son utilizadas. Se puede decir que las habilidades sociales son conductas asimiladas y autocontroladas, cuyos objetivos se centran en lograr un reconocimiento con la intención de ser beneficioso para ambos, lo cual requiere, a su vez, de ser empáticos y colocarse en el lugar de la persona, es decir, tratar de entender su conducta y forma de reaccionar frente al mismo con eficiencia y eficacia. En esa línea argumental, hay conductas que pueden ser clasificadas como:

Habilidades sociales básicas: (a) comenzar un diálogo, (b) oír con atención, (c) lograr mantener una conversación, (d) realizar una pregunta, (e) agradecer, (f) presentarse ante otras personas y decir halagos.

Habilidades sociales avanzadas: (a) solicitar ayuda, (b) ser participe en las actividades, (c) dar indicaciones, (d) seguimiento de instrucciones, (e) pedir disculpas, (f) persuadir a los demás.

Habilidades relacionadas con los sentimientos: (a) tener conocimiento de los propios sentimientos, (b) manifestar los sentimientos, (c) entender los sentimientos 
de otras personas, (d) confrontarse con el enfado de otro, (e) manifestar afecto, (f) solventar el miedo y (g) auto-recompensarse.

Habilidades alternativas a la agresión: (a) solicitar permiso, (b) compartir con otros algo, (c) brindar ayuda a otros, (d) llegar a acuerdos, (e) comenzar a tener auto-control, (f) ser garante de los derechos personales, (g) dar respuestas a las bromas, (h) evadir los problemas con otros y (i) evitar ser parte de las peleas.

Habilidades para hacer frente al estrés: (a) expresar una inconformidad, (b) dar respuesta a una queja, (c) mostrar actitud deportiva luego de un juego, (d) darle solución a la vergüenza, (e) solventar cuando esté sin ayuda, (f) proteger a un amigo, (g) dar respuesta a la sugestión (h) poder dar respuesta a la frustración, (i) confrontarse a las respuestas contrarias, (j) dar respuesta frente a una acusación, (k) tomar medidas para enfrentar una conversación dificultosa, (l) poder enfrentar las presiones del grupo donde se desenvuelva.

Habilidades de Planificación: (a) considerar la toma de decisiones realistas, (b) comprender el origen de un problema, (c) plantearse un objetivo, (d) prescribir cuáles son las propias destrezas, (e) acopiar la información necesaria, (f) solventar los diferentes problemas de acuerdo con su nivel de importancia, (g) tomar decisiones efectivas y eficaces y (h) mantener la concentración en una tarea.

Se considera que la capacidad social sostiene una gran importancia en el manejo eficiente del presente y del futuro proceso de desarrollo de la persona. Se piensa que las habilidades sociales son significativas en cuanto a lo relacionado con las relaciones interpersonales, así como con el instante de acordonar roles y normas sociales. Hay un consenso en torno a que los individuos viven en un proceso de desarrollo y aprendizaje constante a través del cual participa su codificación genética, así como su ámbito social. Por ello, como por naturaleza el hombre es un ser social y requiere de su ambiente para desenvolverse de forma integral, resulta vital adquirir y desarrollar las habilidades que den la posibilidad de relaciones interpersonales saludables.

\section{Características de las Habilidades sociales.}

De acuerdo con Caballo y Verdugo (2005), son un conjunto de conductas que le facilitan a la persona el desenvolvimiento en un determinado contexto de forma individual e 
interpersonal, pudiendo expresar necesidades y emociones según la situación. Dichos comportamientos serán importantes para desarrollarse internamente al relacionarse con otras personas donde cada individuo pueda y sea capaz de transmitir sus pensamientos, sentimientos y emociones de una manera adecuada y gratificante, sin afectar a los demás.

Caballo (1993) señaló que las habilidades sociales se caracterizan porque son: (a) conductas adquiridas por medio del aprendizaje. No son parte inherente de la personalidad humana, ya que a lo largo del ciclo vital pueden sufrir variaciones; (b) se aplican en contextos interpersonales, son recíprocas y dependerán también de la conducta de sus pares; (c) tienen componentes visibles y verbales. Los componentes verbales surgen a partir de la emisión y recepción de mensajes entre las personas que establecen una comunicación, sin embargo, una gran cantidad de estos provienen del lenguaje no verbal, como la postura corporal, movimientos del cuerpo, señas, expresiones del rostro; (d) en última instancia, están condicionadas por un contexto sociocultural. Toda conducta que una persona exprese dependerá del lugar, de un momento en particular y de las normas socialmente aceptadas. Por este motivo, para que las conductas puedan ser pertinentes, será necesario que la comunicación verbal y no verbal sea correctamente percibida.

\section{Adquisición de las habilidades sociales.}

La interacción social con su entorno es el medio por el cual el niño adquiere las habilidades sociales. Para Ramírez (2012) las instituciones educativas -en tanto encargadas de la formación de los estudiantes-deben contribuir a la solución de sus problemas ya sean personales o sociales. De allí la importancia de trabajar con criterio pedagógico las destrezas necesarias y, a su vez, diseñar un modelo social-educativo. Por esto último se entiende aquella construcción curricular donde se establece una relación entre el niño y sus pares con la finalidad de alcanzar propósitos significativos que incluyen qué duda cabe el estudio, pero sobre todo la práctica de los valores sociales y la resolución no violenta de los problemas.

De acuerdo con González (2009), numerosas investigaciones han verificado que una apropiada competencia social en la escuela trae consigo éxito académico y aceptación social. En realidad, esto no debe sorprender a nadie porque un rendimiento exitoso implica también una gestión idónea de las frustraciones. Por ello, hay que aprender de 
ello y estar convencido de que alcanzar la meta es meritorio pero mucho más meritorio sea ir tras ella. En consecuencia, las habilidades sociales son competencias conductuales que hacen posible establecer relaciones sociales positivas.

Las conductas socialmente hábiles necesitan de tres componentes: conductual (habilidades sociales), situacional y personal. Los tres componen requieren ser entrenados a través de la observación de quienes realizan de manera adecuada las conductas. Estas solo podrán irse perfeccionado si se brindan reforzamientos por las acciones correctas, y se van practicando en situaciones distintas y reales en la medida de lo posible. Este adiestramiento debe concretarse en dos fases: planificación y aplicación (González, 2009).

\section{Evaluación de las Habilidades sociales.}

Caballo (2005) al igual que Monjas y González (1998) determinaron que la finalidad de la evaluación de las habilidades sociales es poder identificar conductas o comportamientos deseables en el ámbito interpersonal, y consta de un proceso de tres etapas: el diagnostico, después de la intervención y, por último, la evaluación de los efectos de la intervención. La primera estimación permite identificar cuáles son los niños que tienen dificultades para poder relacionarse con sus iguales o con los adultos que son hábiles socialmente. Lograr identificar comportamientos específicos permite delimitar metas y objetivos en el periodo de intervención. En un segundo periodo, la intervención para la evolución de la habilidad social es permanente, ya que facilita información sobre las variaciones en el comportamiento y la posibilidad de transferencia de dichas habilidades a otros contextos. Por último, la evaluación final busca determinar la certeza de la enseñanza y el entrenamiento en las habilidades sociales más adecuadas para la adaptación del niño.

Para Sendín (2000), la evaluación está determinada por ciertas características: (a) individualidad: considera paulatinamente la evolución, el factor cultural, lo característico del niño y sus necesidades, (b) interacción y contexto: no solo es evaluada la manera de comportarse el niño, sino que también se tiene en cuenta el contexto en el que se dan las interacciones, como también los sujetos que van interviniendo y los momentos interpersonales que son relevantes, (c) informativa: en base al actual nivel de déficits y de habilidades específicas. 
Hernández, Pozo y Alonso (2004) sostienen que estas características suponen el beneficio de una perspectiva multimetódica que sirva para evaluar la competencia social. Dicho enfoque multimétodo refleja que la unión de técnicas cuantitativas y cualitativas son útiles para comprender de una manera adecuada los fenómenos sociales. Partiendo de esta perspectiva, se tiene a aumentar la certeza del diagnóstico con respecto a las habilidades sociales en un niño, debido a la utilización de distintos instrumentos y métodos o modalidades para hacer la evaluación.

Si bien es cierto, se ha logrado desarrollar una gran variedad de instrumentos para evaluar las habilidades sociales, la gran mayoría todavía lo para adultos o adolescentes (Sanz, Gil \& García, 1998). Dichos instrumentos se aplican a base de escalas o cuestionarios y se le suman evaluaciones de amplio espectro como las entrevistas, que agregan cierta información sobre las maneras de interacción a pesar de no ser su objetivo básicamente. Sin embargo, en la etapa de la niñez no son muy amplios los recursos instrumentales especialmente para las habilidades sociales, debido a la dificultad al elaborar pruebas apropiadas a la evolución de parámetros y los diversos contextos que no facilitan la homogeneidad. Por ello, la necesidad de recurrir a nuevas vías que posibiliten una adecuada y certera evaluación de las habilidades sociales en los niños.

\section{Habilidades sociales y adaptación cultural.}

Diversos grupos a menudo demuestran habilidades sociales de manera única en diversos entornos y contextos, destacando la especificidad cultural del comportamiento social (Cartledge y Loe, 2001; Jack, Garrod, Yu, Caldara y Schyns, 2012; Gendron, Roberson, van der Vyver, \& Barrett, 2014; Harrison, Long, Tommet y Jones, 2017). La variabilidad entre culturas está bien documentada en la cantidad y el tipo de contacto visual, la expresividad y el reconocimiento facial, las interpretaciones y el uso de señales y lenguaje no verbales, los tipos de juegos y objetos utilizados durante el juego y la expresión de emoción (Marsh, Elfenbein y Ambady, 2003; Carter et al., 2005; Yuki, Maddux y Masuda, 2007; Zebrowitz, Kikuchi y Fellous, 2010; Elfenbein, 2013; Norbury \& Sparks, 2013; Ember y Cunnar, 2015).

Esta variabilidad cultural en el comportamiento social tiene una relevancia particular para los TEA. En las culturas asiáticas, se puede percibir que el contacto visual directo es grosero o irrespetuoso, lo que significa que la falta de contacto visual puede no ser una 
"señal de alerta" social significativa para el TEA. Del mismo modo, los niños chinos se socializan para inhibir la expresión emocional (Ho, 1986); Como resultado, la falta de expresión facial puede verse como socialmente deseable en lugar de desadaptativa (como en las culturas occidentales). El uso de gestos también varía significativamente entre culturas de maneras que pueden afectar directamente el reconocimiento del uso de gestos no verbales en ASD. Por ejemplo, algunas culturas no permiten señalar con el dedo índice como un intento de comunicación para compartir la atención, por lo que es un comportamiento menos relevante socialmente que en las culturas occidentales. Con respecto a las primeras señales de alerta para el autismo, las madres latinas son menos propensas que las familias blancas a expresar preocupaciones sobre las dificultades de habilidades sociales en niños pequeños con TEA (Ratto, Reznick y Turner-Brown, 2016; Blacher, Cohen y Azad, 2014). En general, la consideración de posibles diferencias interculturales tanto en la demostración como en la interpretación de los comportamientos sociales es importante para comprender el deterioro social en los TEA y para desarrollar intervenciones culturalmente competentes.

La mayoría de las intervenciones basadas en evidencia (EBI), incluidas las intervenciones de habilidades sociales, se desarrollaron originalmente para familias de habla inglesa con antecedentes de mayoría racial / étnica. Como tal, a menudo se encuentran barreras al diseminar estas intervenciones a comunidades étnicamente diversas o internacionales (Kumpfer, Magalhães y Xie, 2017). Barrera, Berkel y Castro (2017) describieron las barreras comunes abordadas por la adaptación cultural: dificultades con la utilización inicial del servicio, adherencia a los procedimientos de intervención, asistencia (por ejemplo, cantidad de sesiones asistidas), compromiso (por ejemplo, participación en la sesión o uso del programa habilidades en el hogar) y retención (p. ej., finalización del tratamiento). Nation et al. (2003) determinaron que la relevancia del programa de intervención es una función directa del grado en que las normas, creencias y prácticas culturales de una comunidad se han integrado en el contenido, la entrega y la evaluación del programa. Las disparidades de tratamiento entre poblaciones diversas pueden reducirse si se percibe que las intervenciones son más relevantes y aplicables desde la perspectiva de familias étnicamente diversas (Barrera, Castro, Strycker y Toobert, 2013). La adaptación cultural de las prácticas e intervenciones basadas en evidencia es un modelo emergente en el área de educación especial y discapacidad (Wang y Lam, 2017). 
En el campo de intervención más amplio, las adaptaciones culturales se definen como la modificación sistemática de una intervención para considerar el lenguaje, cultura y contexto de una manera que sea compatible con los patrones, significados y valores culturales de un individuo (Bernal et al., 2009). Kreuter y Skinner (2000) abogaron porque pueda haber una distinción establecida entre la terminología a menudo sinónima "dirigida" y "adaptada" en la investigación de adaptación cultural. La "adaptación cultural" captura la consolidación de dos enfoques: (a) un enfoque universal dirigido que considera el contenido de una intervención original como aplicable a todos los grupos subculturales y que no necesita alteraciones, y (b) un enfoque específico de cultura adaptado que enfatiza culturalmente contenido basado en los valores únicos, creencias, tradiciones y prácticas de un grupo subcultural particular (Falicov, 2009). Más específicamente, el término "dirigido" se refiere a una intervención diseñada para un grupo subcultural particular basado en características comunes a sus miembros (Kreuter y Skinner 2000). Los enfoques culturalmente "personalizados" identifican factores culturales que influyen en los resultados del cliente (por ejemplo, creencias religiosas, contextos de vecindario, etc.), miden las diferencias individuales en esos factores y ofrecen estrategias individualizadas que abordan esos factores (Kreuter et al., 2003).

Para reducir la ambigüedad, los investigadores han comenzado a explorar cómo estructurar adaptaciones culturales específicas en la investigación en salud e intervención conductual. Butler y Titus (2015) conceptualizaron las consideraciones culturales como dos grandes categorías: estructura superficial y estructura profunda. Las adaptaciones culturales de la estructura superficial incluyen metodologías que hacen coincidir las personas o el idioma con las características raciales / étnicas observables de la población (Butler y Titus, 2015), mientras que las adaptaciones culturales de estructura profunda incluyen estrategias de contenido que incorporan aspectos culturales, sociales, históricos, ambientales o psicológicos, aspectos que influyen en el comportamiento del grupo minoritario objetivo (Butler y Titus, 2015; Resnicow, Baranowski, Ahluwalia y Braithwaite, 1999). Del mismo modo, Kreuter et al. (2003) presentaron parámetros organizativos estrechos para posibles consideraciones culturales: (a) estrategias periféricas que manipulan materiales de intervención para emparejarlos visualmente con las culturas de los participantes, (b) estrategias lingüísticas que alteran el lenguaje de la intervención, (c) estrategias de evidencia que incluyen información que resalta la relevancia de la intervención para el grupo étnico de los participantes (por ejemplo, útil para la aceptación inicial con cuidadores o adolescentes), (d) estrategias que involucran a los constituyentes que incorporan los conocimientos y experiencias pasadas de los participantes, y (e) 
sociocultural estrategias que refuerzan los valores culturales, creencias y comportamientos de los participantes. Dentro de esta revisión, las adaptaciones culturales se conceptualizarán como enfoques culturalmente específicos que incluyen modificaciones de estructuras superficiales y/o profundas.

\section{Habilidades sociales y cultura organizacional.}

Es posible encontrar algunas referencias que han arrojado algo de luz sobre los componentes que influyen en el desarrollo del potencial de las organizaciones y los empleados y nos hace comprender mejor estos tres casos. Cada vez más, Bisquerra y Escoda exponen que somos conscientes de que en el marco laboral implementado en las empresas, junto con su énfasis en la flexibilidad, los grupos de trabajo y la gran orientación hacia los servicios, las habilidades emocionales son cada vez más críticas para alcanzar la calidad superior en cualquier tipo de trabajo y en cualquier país del mundo (2007). Según Bisquerra, el concepto de competencia incluye "el conjunto de conocimientos, habilidades, capacidades y actitudes necesarias para realizar diversas actividades con un cierto nivel de calidad y eficiencia" (2003, p. 22). Algunos años después, Bisquerra y Escoda revisaron y actualizaron el constructo de acuerdo con las habilidades emocionales y la "inteligencia interpersonal" relacionada (Gardner, 1983) a "competencia social" como la "capacidad de mantener buenas relaciones con otras personas. Esto implica dominar las habilidades sociales: la capacidad de establecer una comunicación efectiva, respeto, actitudes pro-sociales, asertividad, etc." (2007, p. 72).

El beneficio del desarrollo de la competencia social en el mundo profesional es muy claro debido a la efectividad y rendimiento que implica. Por ello, la competencia comunicativa social es objeto de un renovado interés y se le define como esa capacidad específica para establecer una comunicación adecuada y promover relaciones sociales como el estilo asertivo, la empatía y el consenso o la participación democrática. En una situación cooperativa, las personas buscan obtener los resultados que son beneficiosos para ellos y para todos los demás miembros del grupo. Esto sucede más cuando estas empresas se encuentran en una situación de multiculturalismo o logran, gracias a esto, la interculturalidad. 
Asertividad, inteligencia emocional y autoestima.

A pesar de que en un inicio la asertividad y las habilidades sociales eran tomados como dos términos distintos eso ha cambiado en las últimas décadas. Según Camazón (2012) hoy la asertividad es un concepto que se incluye dentro de habilidades sociales. Una conducta de ese tipo equivale a un estilo o forma de interactuar. Olivera (2005) lo entiende como la conducta que supone expresar directamente los sentimientos propios y defender los derechos de los demás. Ser asertivo implica la capacidad de autoafirmación de los propios derechos, impidiendo la manipulación y rehusándose a manipular a los demás. Una decisión autónoma de ese tipo encuentra un contexto personal favorable cuando la persona adopta un estilo asertivo para sus interacciones sociales. Por el contrario, si se optase por el estilo agresivo o pasivo se dificultaría enormemente la interacción satisfactoria con los demás (figura 3).
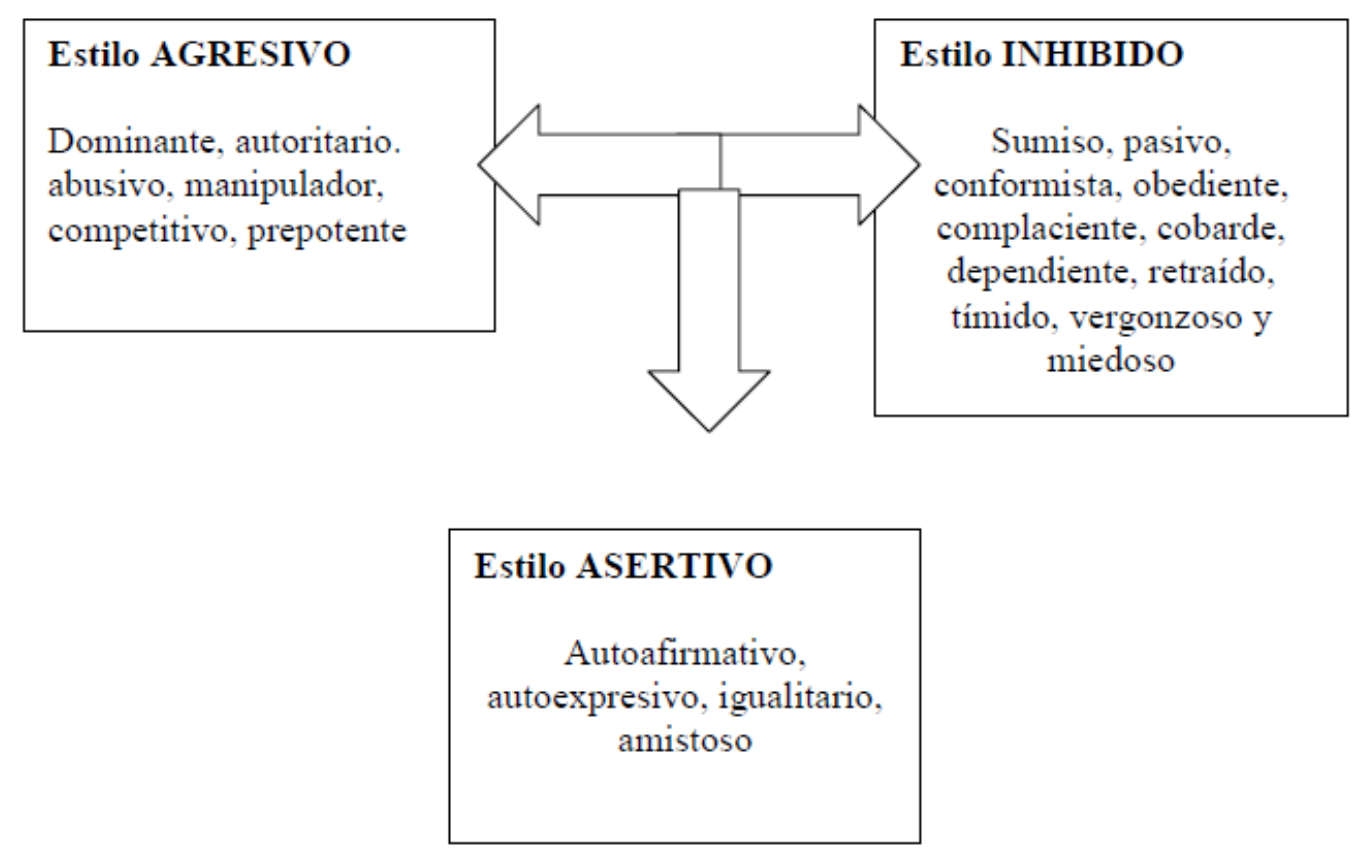

Figura 3. Estilos de relación interpersonal. Tomado de "Aceptación social del alumnado inmigrante en educación primaria: aplicación del programa de asertividad y habilidades sociales (PAHS) para su mejora" por S. Camazón (2012), p. 99. 


\section{Dimensiones de la variable habilidades sociales.}

Habilidades básicas de interacción social.

Se trata de habilidades elementales puestas en práctica cuando alguien interactúa con sus familiares, pareja o amigos. Estos comportamientos básicos son: sonreír, saludar, presentarse ante un nuevo grupo de personas, realizar favores y mostrarse como una persona amable. En un sentido más amplio, estas habilidades son las que permiten iniciar y consolidar relaciones sociales en los contextos donde los niños interactúen. Por ello, para Valdés, Guerra y Camargo (2020) la escuela y los sistemas educativos nacionales deben apuntar a que:

Todos los alumnos se sientan parte del grupo al que pertenecen y puedan interactuar en distintas actividades ya sean de tipo cívica, cultural deportiva, recreativas o académicas, que los prepare para el tránsito a otros niveles educativos, para la familia y para su desenvolvimiento en tareas propias de la comunidad (p. 21).

Habilidades para hacer amigos y amigas.

Consiste en las destrezas necesarias para la interacción positiva y satisfactoria con los pares o iguales. Contribuyen al desarrollo socioafectivo del niño y favorecen una mayor adaptación personal y social. Abarca habilidades tales como compartir (cuando el niño presta sus juguetes a otros), unirse al juego con los demás, ayudar.

Habilidades conversacionales.

Estas habilidades son la base de las interacciones personales y de su eficacia. Se expresan durante una conversación, sea para iniciarla, mantenerla o finalizarla. Habría que recordar que verbalizamos lo que sentimos y también lo que anhelamos alcanzar en una negociación. Por tanto, el niño cuando conversa no solo participa, sino que aprende.

Gambrill y Richey (1985) han recomendado un conjunto de reglas elementales para iniciar una conversación, por ejemplo: transmitir un ánimo positivo y saber anticiparse a una reacción de ese tipo, ser directo, tener un buen sentido del humor, emplear frases iniciales cortas, preguntarse a uno mismo cómo respondería, formular a su interlocutor 
preguntas abiertas lo que demanda no responder únicamente con monosílabos, aprovechar la libre información (al comunicar un punto de vista, opinión o percepción dejar un margen para que los que escuchan tengan algo que decir), acercarse a las personas para iniciar una plática y no esperar a que se nos llame para recién acercarnos, practicar la curiosidad con inteligencia, pero nunca con impertinencia, orientarse hacia objetivos factibles, sacar réditos del estilo personal o de la propia personalidad, sonreír y mirar a la gente, no intimidarse y recompensar los esfuerzos y seguir intentándolo.

Habilidades relacionadas con los sentimientos, emociones y opiniones.

Aquí el concepto clave es asertividad, es decir, ser capaces de expresar nuestros sentimientos y defender nuestros derechos, sin que esto suponga deslegitimar o negar los derechos de los demás. Asimismo, sentirnos bien al comunicar las emociones y valorando y respetando lo que los otros puedan sentir. Esta área de las habilidades sociales comprende las autoafirmaciones positivas y la defensa de los derechos personales y de los demás.

Habilidades de solución de problemas interpersonales.

A través de la experiencia directa los niños deben aprender cómo resolver los conflictos que se presentan con sus amigos, sean del vecindario o de la escuela. Debe solucionarlos él mismo y no buscar que sus padres los resuelvan. Esta área de las habilidades sociales está conformada por la identificación de problemas, la búsqueda de soluciones, la proyección de las consecuencias, la elección de una alternativa y estar dispuesto a aprender de ella si las cosas salen mal.

Habilidades para relacionarse con los adultos.

El niño sabe que el adulto es una persona de estatus superior, debido a su edad, autoridad, experiencia de vida, etc. Por este motivo, la relación entre el niño y un adulto será distinta. Esto no significa que dicha relación esté marcada por la dependencia o la sumisión, pero sí debe ser una relación saludable para ambos. El niño debe ser capaz de defender sus derechos, a través del diálogo y del razonamiento. En esta área se incluyen habilidades tales como dialogar con un adulto, ser amable con él, saber pedir las cosas o expresar las peticiones y solucionar asertivamente los conflictos. 


\section{Objetivos e hipótesis}

\section{Objetivos.}

\section{Objetivo general.}

Comparar las diferencias en el desarrollo de habilidades sociales en los estudiantes de sexto grado de dos instituciones educativas del Callao, 2019.

\section{Objetivos específicos.}

Comparar las diferencias en el en el desarrollo de habilidades básicas de interacción social en los estudiantes de sexto grado de dos instituciones educativas del Callao, 2019.

Comparar las diferencias en el desarrollo de habilidades para hacer amigos y amigas en los estudiantes de sexto grado de dos instituciones educativas del Callao, 2019.

Comparar las diferencias en el desarrollo de habilidades conversacionales en los estudiantes de sexto grado de dos instituciones educativas del Callao, 2019.

Comparar las diferencias en el desarrollo de habilidades relacionadas con las emociones, sentimientos y opiniones en los estudiantes de sexto grado de dos instituciones educativas del Callao, 2019.

Comparar las diferencias en el desarrollo de habilidades para la solución de problemas interpersonales en los estudiantes de sexto grado de dos instituciones educativas del Callao, 2019.

Comparar las diferencias en el desarrollo de habilidades para relacionarse con los adultos en los estudiantes de sexto grado de dos instituciones educativas del Callao, 2019.

Hipótesis.

\section{Hipótesis general.}


Existen diferencias significativas en el desarrollo de habilidades sociales en los estudiantes de sexto grado de dos instituciones educativas del Callao, 2019.

\section{Hipótesis específicas.}

Existen diferencias significativas en el desarrollo de habilidades básicas de interacción social en los estudiantes de sexto grado de dos instituciones educativas del Callao, 2019.

Existen diferencias significativas en el desarrollo de habilidades para hacer amigos y amigas en los estudiantes de sexto grado de dos instituciones educativas del Callao, 2019.

Existen diferencias significativas en el desarrollo de habilidades conversacionales en los estudiantes de sexto grado de dos instituciones educativas del Callao, 2019.

Existen diferencias significativas en el desarrollo de habilidades relacionadas con las emociones, sentimientos y opiniones en los estudiantes de sexto grado de dos instituciones educativas del Callao, 2019.

Existen diferencias significativas en el desarrollo de habilidades para la solución de problemas interpersonales en los estudiantes de sexto grado de dos instituciones educativas del Callao, 2019.

Existen diferencias significativas en el desarrollo de habilidades para relacionarse con los adultos en los estudiantes de sexto grado de dos instituciones educativas del Callao, 2019. 


\section{Marco metodológico}

\section{Tipo y diseño de investigación}

El presente estudio es de tipo básico, de nivel descriptivo comparativo, enmarcado en el enfoque cuantitativo; diseño no experimental transversal. Es básico, porque está orientado a la ampliación y profundización del conocimiento teórico respecto a un ámbito en particular de la realidad (Bernal, 2010), en este caso educativa; a diferencia de la investigación aplicada que sí se interesaría por las posibles aplicaciones prácticas (Guevara, 2016). Es descriptiva y comparativa, ya que enumera exhaustivamente las manifestaciones del fenómeno analizado, además de contrastar las cualidades de la variable Habilidades sociales en dos instituciones educativas (Hernández, Fernández \& Baptista, 2014). Su enfoque es cuantitativo, porque los datos acopiados recibirán un tratamiento estadístico en base a la estadística descriptiva e inferencial (Guevara, 2016). Es no experimental transversal, ya que la variable Habilidades sociales no será objeto de manipulación ni se generará una situación en especial (Hernández et al., 2014).

De acuerdo con Sánchez y Reyes (2015), la investigación descriptiva podría ser representada así:

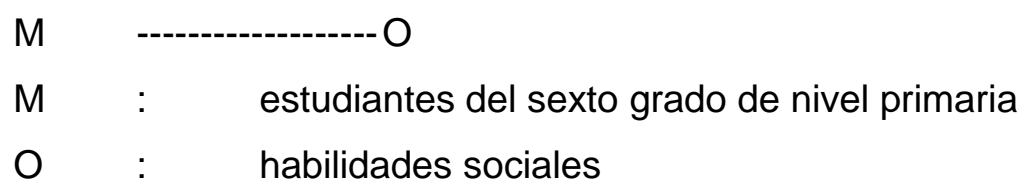

\section{Variables}

Según Arias (2012), una variable es una cualidad o magnitud que puede mostrar cambios, y que es analizable en un proceso de investigación. Para Reguant y Martínez (2014), una variable -al ser producto de la actividad intelectual para poder ser conceptualizada-, debe pasar obligatoriamente por un proceso lógico de desagregación, gracias al cual se formulan dimensiones e indicadores. Para Kerlinger (1988), lo dicho anteriormente no es más que la transformación de conceptos y enunciados teóricos en variables concretas.

Una dimensión es un aspecto de una variable compleja, es uno de sus elementos integrantes, resultado del análisis (Arias, 2012). Un indicador es una señal o indicio cuantificable que permite estudiar una o más dimensiones de la variable. 


\section{Definición conceptual.}

Según Monjas y González (1998), las habilidades sociales son el conjunto de competencias conductuales que hacen posible que el niño entable relaciones sociales positivas con sus pares y que pueda afrontar eficazmente las demandas provenientes de su entorno social. Todo esto contribuirá significativamente a que logre la aceptación de sus compañeros y la necesaria adaptación social. A pesar de que no se les reconozca su importancia, debido a una visión simplista y unilateral de las interacciones sociales, es frecuente observar a individuos que no son capaces de relacionarse constructivamente con los demás, por lo que no tienen las herramientas necesarias para gestionar cierta agresividad, intransigencia 0 falta de empatía (Ortego, López \& Álvarez, 2001). Dicha deficiencia se evidencia en sus relaciones familiares, sociales y laborales.

\section{Definición operacional}

\section{Tabla 1}

Operacionalización de la variable habilidades sociales.

\begin{tabular}{|c|c|c|c|}
\hline Dimensiones & Indicadores & Ítems & $\begin{array}{c}\text { Niveles o } \\
\text { rangos }\end{array}$ \\
\hline $\begin{array}{l}\text { Habilidades básicas de } \\
\text { interacción social }\end{array}$ & $\begin{array}{ll}- & \text { Sonreír y reír } \\
- & \text { Saludar } \\
- & \text { Presentaciones } \\
- & \text { Favores } \\
- & \text { Cortesía y amabilidad }\end{array}$ & $\begin{array}{l}6,13,24,26,36 \\
43,45,57,59\end{array}$ & $\begin{array}{l}\text { Bajo: } \\
60-140\end{array}$ \\
\hline $\begin{array}{l}\text { Habilidades para hacer } \\
\text { amigos y amigas }\end{array}$ & $\begin{array}{ll}- & \text { Reforzar a los otros } \\
- & \text { Iniciadores sociales } \\
- & \text { Unirse al juego con otros } \\
- & \text { Ayuda } \\
- & \text { Cooperar y compartir }\end{array}$ & $\begin{array}{l}11,15,19,21,25 \\
31,32,37,44,55\end{array}$ & \\
\hline $\begin{array}{c}\text { Habilidades } \\
\text { conversacionales }\end{array}$ & $\begin{array}{ll}\text { - } & \text { Iniciar conversaciones } \\
\text { - } & \text { Terminar conversaciones } \\
\text { - } & \text { Unirse a la conversación de otros } \\
\text { - } & \text { Conversaciones de grupo }\end{array}$ & $\begin{array}{l}17,35,39,41,46 \\
50,53,58,60\end{array}$ & $\begin{array}{l}\text { Moderado: } \\
141-220\end{array}$ \\
\hline $\begin{array}{l}\text { Habilidades } \\
\text { relacionadas con las } \\
\text { emociones, } \\
\text { sentimientos y } \\
\text { opiniones }\end{array}$ & $\begin{array}{ll}\text { - } & \text { Autoafirmaciones positivas } \\
\text { - } & \text { Expresar emociones } \\
\text { - } & \text { Recibir emociones } \\
\text { - } & \text { Defender los propios derechos } \\
\text { - } & \text { Defender las propias opiniones }\end{array}$ & $\begin{array}{l}3,5,7,10,20,27 \\
38,47,48,56\end{array}$ & \\
\hline $\begin{array}{l}\text { Habilidades de } \\
\text { solución de problemas } \\
\text { interpersonales }\end{array}$ & $\begin{array}{ll}\text { - } & \text { Identificar problemas } \\
\text { interpersonales } \\
\text { - } & \text { Buscar soluciones } \\
\text { - } & \text { Anticipar las consecuencias } \\
\text { - } & \text { Elegir una solución }\end{array}$ & $\begin{array}{l}2,8,12,28,42 \\
49,51,52,54\end{array}$ & $\begin{array}{c}\text { Alto: } \\
221-300\end{array}$ \\
\hline
\end{tabular}




\begin{tabular}{|c|c|c|c|}
\hline $\begin{array}{l}\text { relacionarse con } \\
\text { adultos }\end{array}$ & $\begin{array}{l}- \\
- \\
- \\
-\end{array}$ & $\begin{array}{l}\text { Cortesía con el adulto } \\
\text { Refuerzo al adulto } \\
\text { Conversar con el adulto } \\
\text { Peticiones al adulto } \\
\text { Solucionar problemas con adultos }\end{array}$ & $\begin{array}{l}1,4,9,14,16,18 \\
22,23,29,33,40\end{array}$ \\
\hline
\end{tabular}

\section{Población y muestra}

\section{Población.}

Por población se entiende el total de elementos que comparten determinadas especificaciones (Hernández et al., 2014). También puede ser definida como la totalidad de casos sobre el cual se planteará un cierto número de inferencias (Bernal, 2010). En la presente investigación, la población fue 96 estudiantes, correspondiente a dos instituciones educativas del Callao.

\section{Muestra.}

Según Bernal (2010) es el segmento de la población del que se acopiarán datos por analizar e interpretar como parte de la investigación. Este término también se utiliza para designar al subgrupo representativo del universo total. Dado que el acceso a la población total era relativamente sencillo, se optó por una muestra censal equivalente a la población total, es decir, 96 estudiantes.

\section{Técnicas e instrumentos de recolección de datos}

Para Hernández et al. (2014) cuando el investigador aplica sus instrumentos de medición y recolecta los datos también está confrontando su planificación y las bases teóricas con la realidad, con los hechos concretos y observables. Para ello, requiere de técnicas e instrumentos.

Según Arias (2012), una técnica de investigación es un procedimiento o una forma específica de obtención de datos e información. La técnica comprende un conjunto de instrumentos y medios por medio de los cuales se efectúa un método. El presente estudio, en lo metodológico, se adscribe al método hipotético deductivo, y tiene como técnica a la encuesta. Para Hechavarría (2012), Fiallo, Cerezal y Huaranga (2016), la encuesta es un método empírico de obtención de información que implica, por lo general, la elaboración de 
un cuestionario para conocer las opiniones y valoraciones de los sujetos seleccionados en la muestra.

Hernández et al. (2014) y Arias (2012) coinciden en definir al instrumento de medición como el recurso, dispositivo o formato físico o digital utilizado por el investigador para el registro de información o datos acerca de las variables en estudio. En el presente estudio, se optó por un cuestionario.

Ficha técnica del instrumento.

Nombre: $\quad$ Cuestionario de Habilidades de Interacción Social (CHIS)

Autora: $\quad$ María Inés Monjas Casares (Universidad de Valladolid)

País, año: $\quad$ España, 1994

Duración: 30 minutos

Aplicación: $\quad$ Estudiantes de primer grado de primaria

Administración: Individual

Significación: Mide el nivel desarrollado por el niño, a partir de seis dimensiones

Estructura: $\quad 60$ ítems

Calificación: $\quad$ (1) significa que el niño (a) no hace la conducta nunca.

(2) significa que el niño (a) no hace la conducta casi nunca.

(3) significa que el niño (a) hace la conducta bastantes veces.

(4) significa que el niño (a) hace la conducta casi siempre.

(5) significa que el niño (a) hace la conducta siempre.

Niveles y rangos: Bajo $\quad 60-140$

Moderado $141-220$

Alto $\quad 221-300$ 
Tabla 2

Baremos de la variable habilidades sociales.

\begin{tabular}{lccc}
\hline \multicolumn{1}{c}{ Variables y dimensiones } & Bajo & Moderado & Alto \\
\hline Habilidades sociales & $60-140$ & $141-220$ & $221-300$ \\
Habilidades básicas de interacción social & $10-23$ & $24-37$ & $38-50$ \\
Habilidades para hacer amigos y amigas & $10-23$ & $24-37$ & $38-50$ \\
Habilidades conversacionales & $10-23$ & $24-37$ & $38-50$ \\
Habilidades relacionadas con las emociones, sentimientos y y & $10-23$ & $24-37$ & $38-50$ \\
opiniones & & $24-37$ & $38-50$ \\
Habilidades de solución de problemas interpersonales & $10-23$ & $24-37$ \\
Habilidades para relacionarse con los adultos & $10-23$ & $38-50$ \\
\hline
\end{tabular}

\section{Procedimientos}

Primero, los datos por acopiar de la muestra censal provendrán de dos instituciones de Educación Básica Regular. Segundo, el instrumento CHIS se aplica en coordinación con los directivos y docentes de dichos centros. Tercero, los datos serán ingresados en una hoja de cálculo Excel para ser procesados por el SPSS 20, para la obtención las tablas y figuras necesarias, además de las tendencias necesarias para el análisis descriptivo e inferencial. 


\section{Resultados}

Análisis descriptivo

Tabla 3

Frecuencia de habilidades sociales.

\begin{tabular}{cccc}
\hline \multirow{2}{*}{ Grupo } & Nivel & Frecuencia (f) & Porcentaje (\%) \\
\hline \multirow{2}{*}{ IE pública } & Alto & 16 & 38,1 \\
& Moderado & 10 & 23,8 \\
& Bajo & 16 & 38,1 \\
& Total & 42 & 100,0 \\
\cline { 2 - 4 } IE privada & Alto & 31 & 57,4 \\
& Moderado & 15 & 27,8 \\
& Bajo & 8 & 14,8 \\
\hline
\end{tabular}

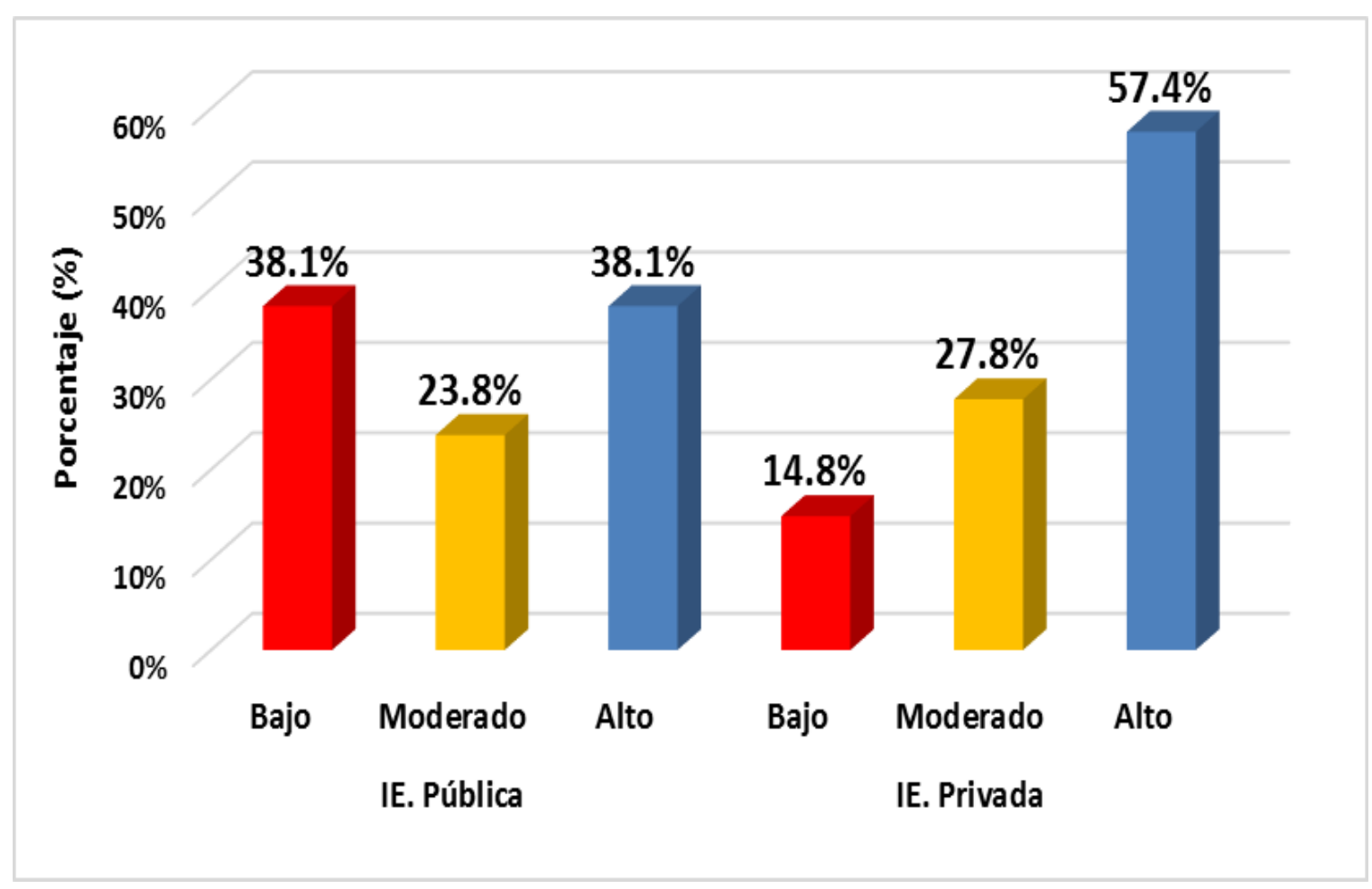

Figura 4. Nivel de habilidades sociales

Según la tabla 3 y la figura 4, se evidenció que la IE privada obtuvo el mayor porcentaje en los niveles alto y moderado (57.4\% y $27.8 \%$, respectivamente) frente a la IE pública. Esta última supera a la IE privada en el mayor porcentaje de nivel bajo: $38.1 \%$ frente a un $14.8 \%$ 
Tabla 4

Frecuencia de habilidades básicas de interacción social.

\begin{tabular}{cccc}
\hline Grupo & Nivel & Frecuencia (f) & Porcentaje (\%) \\
\hline \multirow{3}{*}{ IE pública } & Alto & 16 & 38,1 \\
& Moderado & 14 & 33,3 \\
& Bajo & 12 & 28,6 \\
& Total & 42 & 100,0 \\
\cline { 2 - 4 } IE privada & Alto & 26 & 48,1 \\
& Moderado & 18 & 33,3 \\
& Bajo & 10 & 18,5 \\
& Total & 54 & 100,0 \\
\hline
\end{tabular}

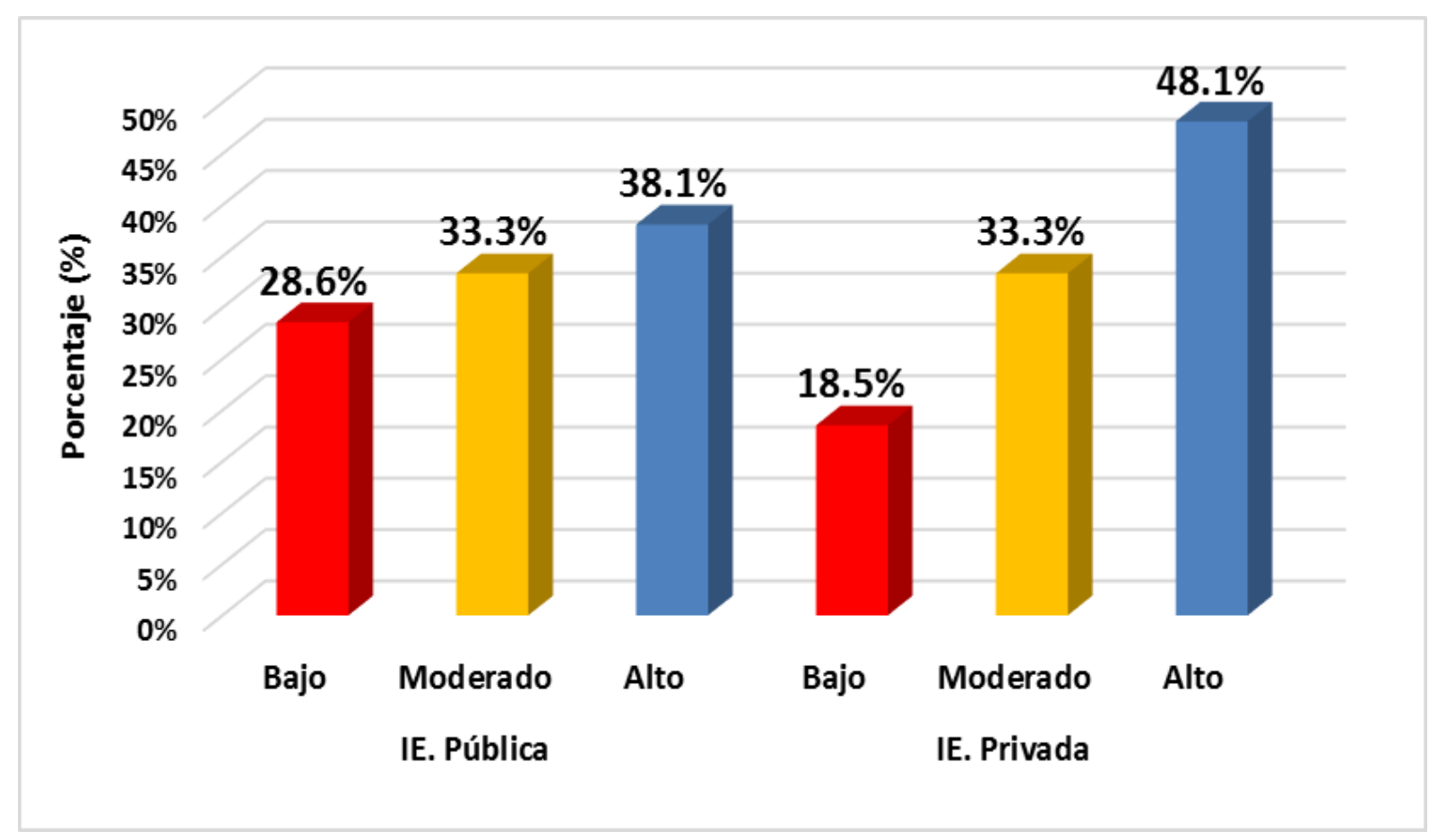

Figura 5. Nivel de habilidades básicas de interacción social.

Según la tabla 4 y la figura 5, se evidenció que la IE privada obtuvo el mayor porcentaje en el nivel alto (48.1\%) frente a la IE pública (38.1\%). Hubo un empate en el nivel moderado (33.3\%). La IE pública supera a la IE privada en el mayor porcentaje de nivel bajo: $28.6 \%$ frente a un $18.5 \%$ 
Tabla 5

Frecuencia de habilidades para hacer amigos y amigas.

\begin{tabular}{cccc}
\hline Grupo & Nivel & Frecuencia (f) & Porcentaje (\%) \\
\hline \multirow{2}{*}{ IE pública } & Alto & 11 & 26,2 \\
& Moderado & 18 & 42,9 \\
& Bajo & 13 & 31,0 \\
& Total & 42 & 100,0 \\
\cline { 2 - 4 } IE privada & Alto & 29 & 53,7 \\
& Moderado & 15 & 27,8 \\
& Bajo & 10 & 18,5 \\
& Total & 54 & 100,0 \\
\hline
\end{tabular}

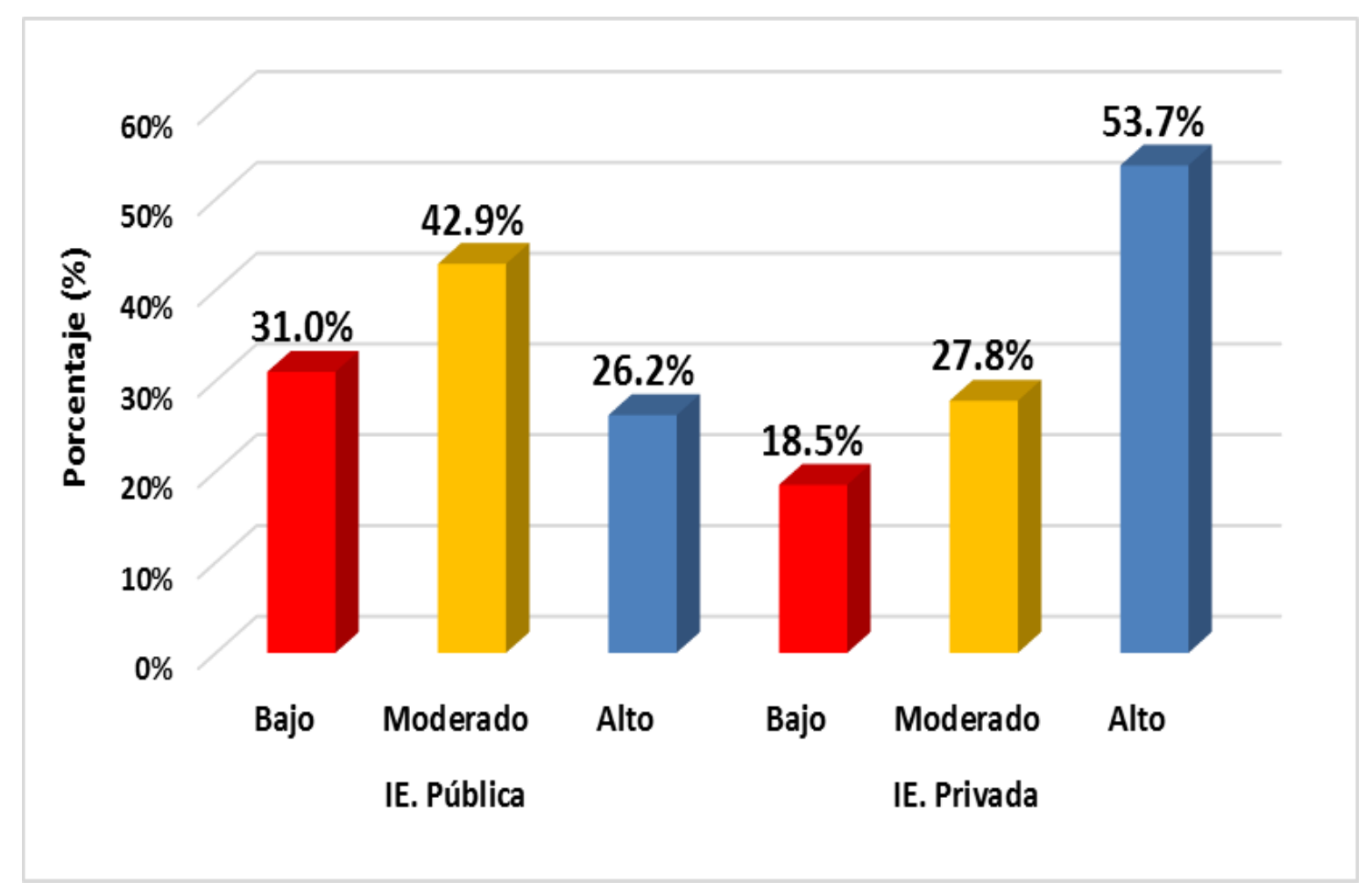

Figura 6. Nivel de habilidades para hacer amigos y amigas.

Según la tabla 5 y la figura 6, se evidenció que la IE privada obtuvo el mayor porcentaje en el nivel alto (53.7\%) frente a la IE pública (26.2\%), pero la IE pública supera a la IE privada en el mayor porcentaje de nivel moderado y bajo ( $42.9 \%$ y $31.0 \%$, respectivamente). 
Tabla 6

Frecuencia de habilidades conversacionales.

\begin{tabular}{cccc}
\hline Grupo & Nivel & Frecuencia (f) & Porcentaje (\%) \\
\hline \multirow{2}{*}{ IE pública } & Alto & 17 & 40,5 \\
& Moderado & 11 & 26,2 \\
& Bajo & 14 & 33,3 \\
& Total & 42 & 100,0 \\
\cline { 2 - 4 } IE privada & Alto & 27 & 50,0 \\
& Moderado & 19 & 35,2 \\
& Bajo & 8 & 14,8 \\
& Total & 54 & 100,0 \\
\hline
\end{tabular}

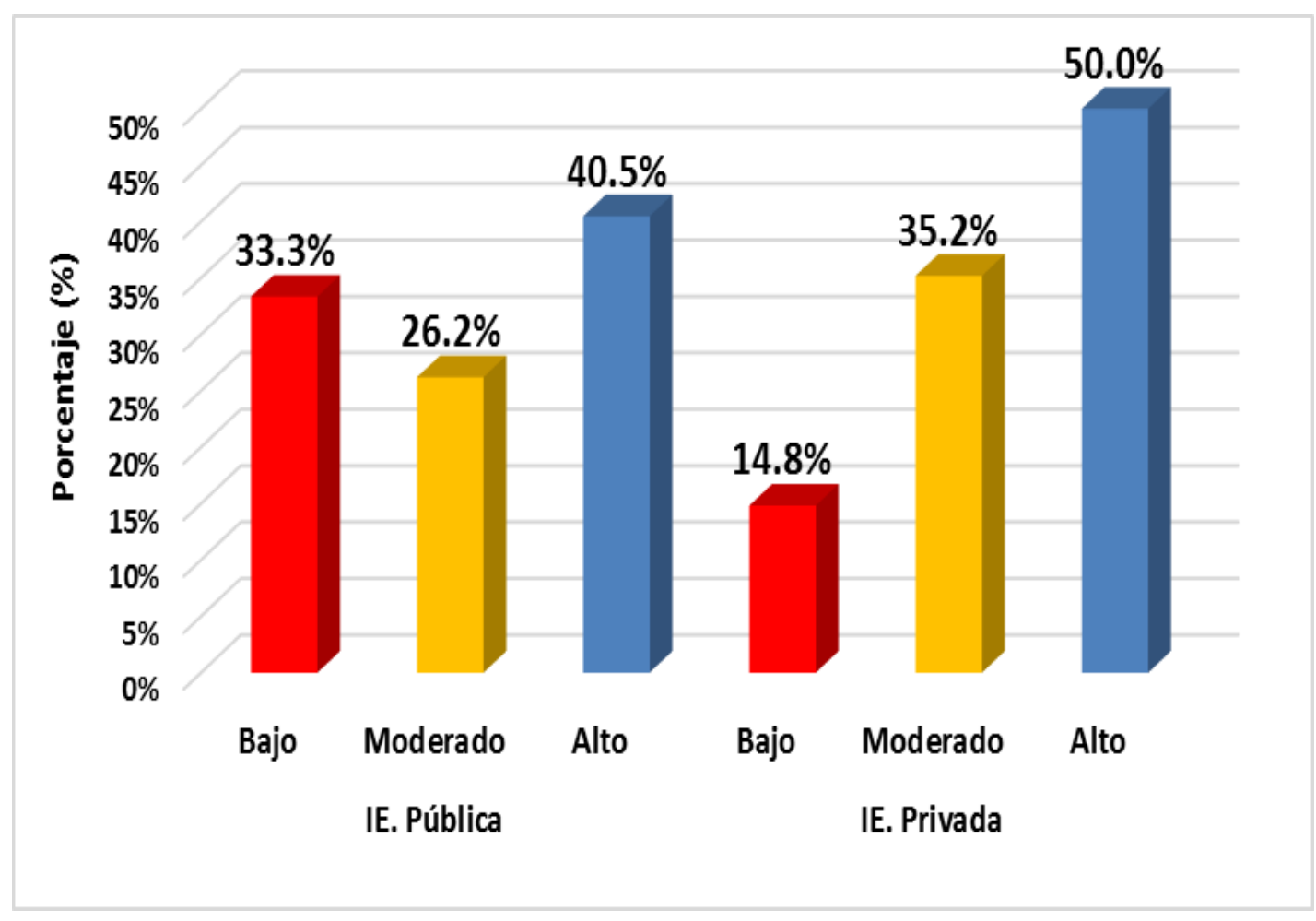

Figura 7. Nivel de habilidades conversacionales.

Según la tabla 6 y la figura 7, se evidenció que la IE privada obtuvo los mayores porcentajes en los niveles moderado y alto (35.2\% y 50.0\%, respectivamente), en comparación con la IE pública. Esta última solo superó a la IE privada en el nivel bajo (33.3\% frente a un 14.8\%). 
Tabla 7

Frecuencia de habilidades relacionadas con las emociones, sentimientos y opiniones.

\begin{tabular}{cccc}
\hline Grupo & Nivel & Frecuencia (f) & Porcentaje (\%) \\
\hline IE pública & Alto & 14 & 33,3 \\
& Moderado & 14 & 33,3 \\
& Bajo & 14 & 33,3 \\
& Total & 42 & 100,0 \\
\cline { 2 - 4 } IE privada & Alto & 32 & 59,3 \\
& Moderado & 17 & 31,5 \\
& Bajo & 5 & 9,3 \\
& Total & 54 & 100,0 \\
\hline
\end{tabular}

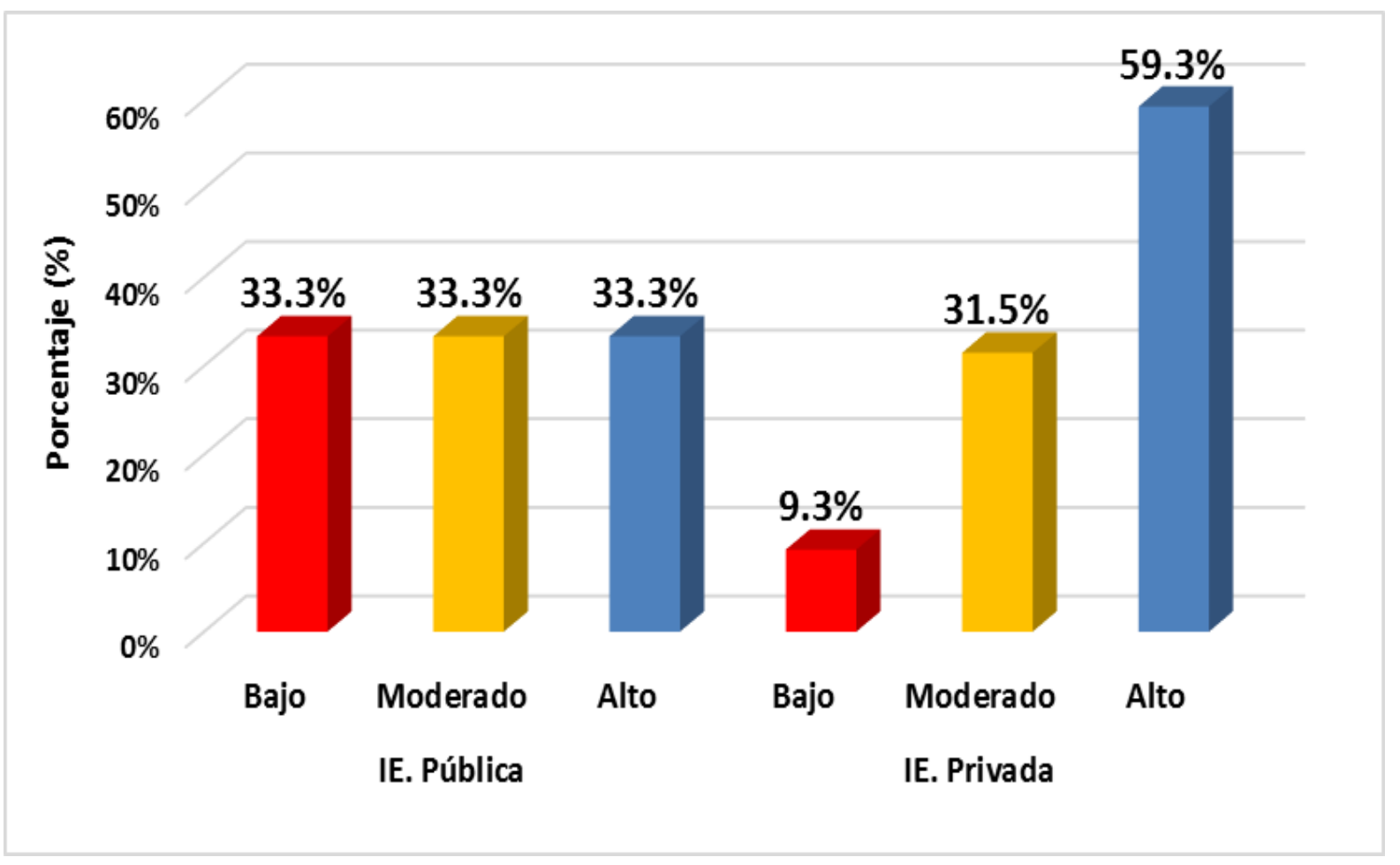

Figura 8. Nivel de habilidades relacionadas con las emociones, sentimientos y opiniones.

Según la tabla 7 y la figura 8, la IE privada obtuvo el mayor porcentaje solo en el nivel alto (59.3\%) frente a la IE pública (33.3\%). Esta última superó a la IE privada en los niveles moderado y bajo (33.3\% y $33.3 \%$, respectivamente). 
Tabla 8

Frecuencia de habilidades de solución de problemas interpersonales.

\begin{tabular}{cccc}
\hline Grupo & Nivel & Frecuencia (f) & Porcentaje (\%) \\
\hline \multirow{2}{*}{ IE pública } & Alto & 19 & 45,2 \\
& Moderado & 9 & 21,4 \\
& Bajo & 14 & 33,3 \\
& Total & 42 & 100,0 \\
\cline { 2 - 4 } IE privada & Alto & 27 & 50,0 \\
& Moderado & 19 & 35,2 \\
& Bajo & 8 & 14,8 \\
& Total & 54 & 100,0 \\
\hline
\end{tabular}

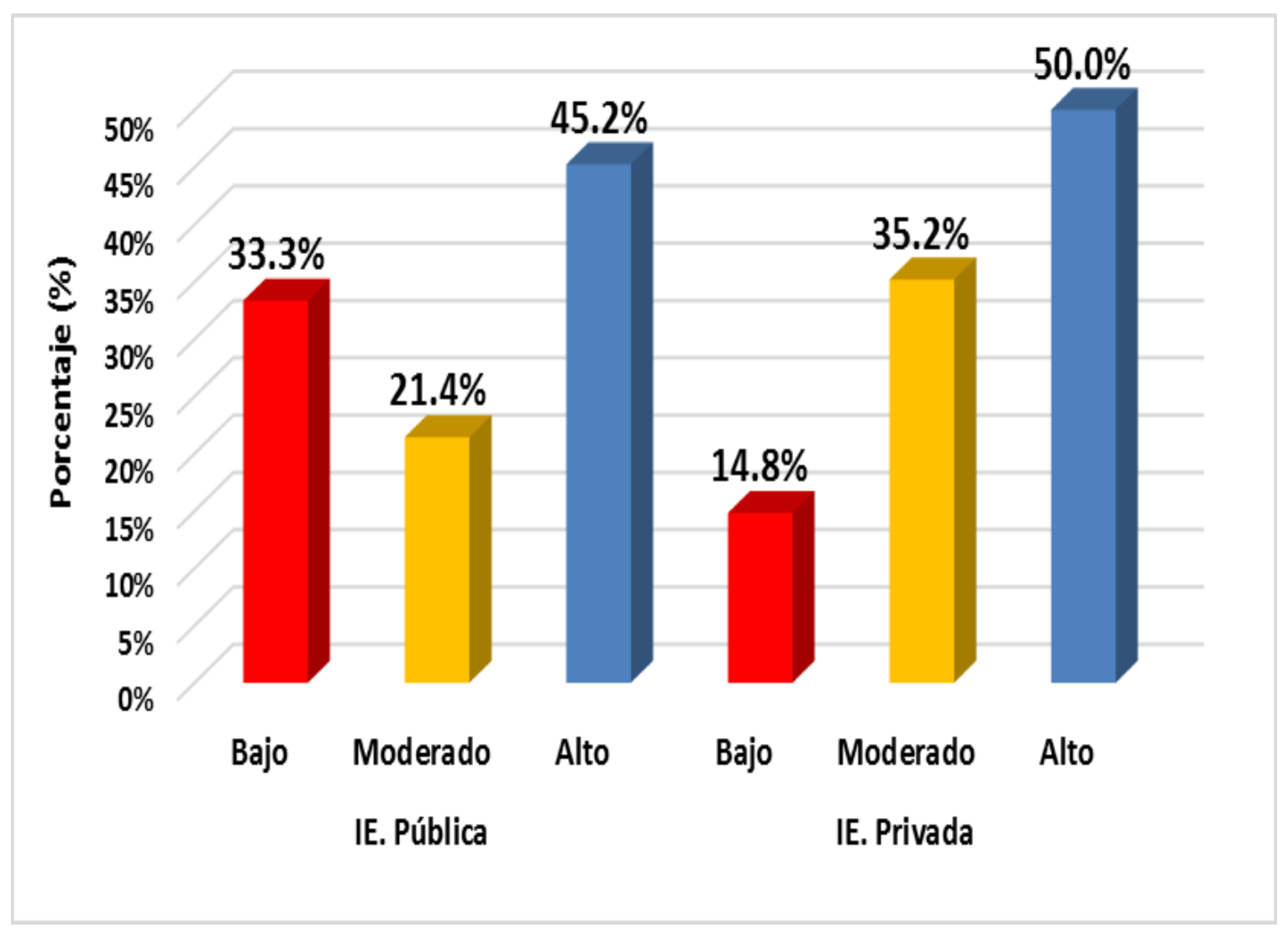

Figura 9. Nivel de habilidades de solución de problemas interpersonales.

Según la tabla 8 y la figura 9, la IE privada obtuvo el mayor porcentaje solo en los niveles alto y moderado (50.0\% y $35.2 \%$ ) frente a la IE pública. Esta última solo superó a la IE privada en el nivel bajo (33.3\%). 
Tabla 9

Frecuencia de habilidades para relacionarse con los adultos.

\begin{tabular}{cccc}
\hline Grupo & Nivel & Frecuencia (f) & Porcentaje (\%) \\
\hline \multirow{2}{*}{ IE pública } & Alto & 15 & 35,7 \\
& Moderado & 12 & 28,6 \\
& Bajo & 15 & 35,7 \\
& Total & 42 & 100,0 \\
\cline { 2 - 4 } IE privada & Alto & 33 & 61,1 \\
& Moderado & 12 & 22,2 \\
& Bajo & 9 & 16,7 \\
& Total & 54 & 100,0 \\
\hline
\end{tabular}

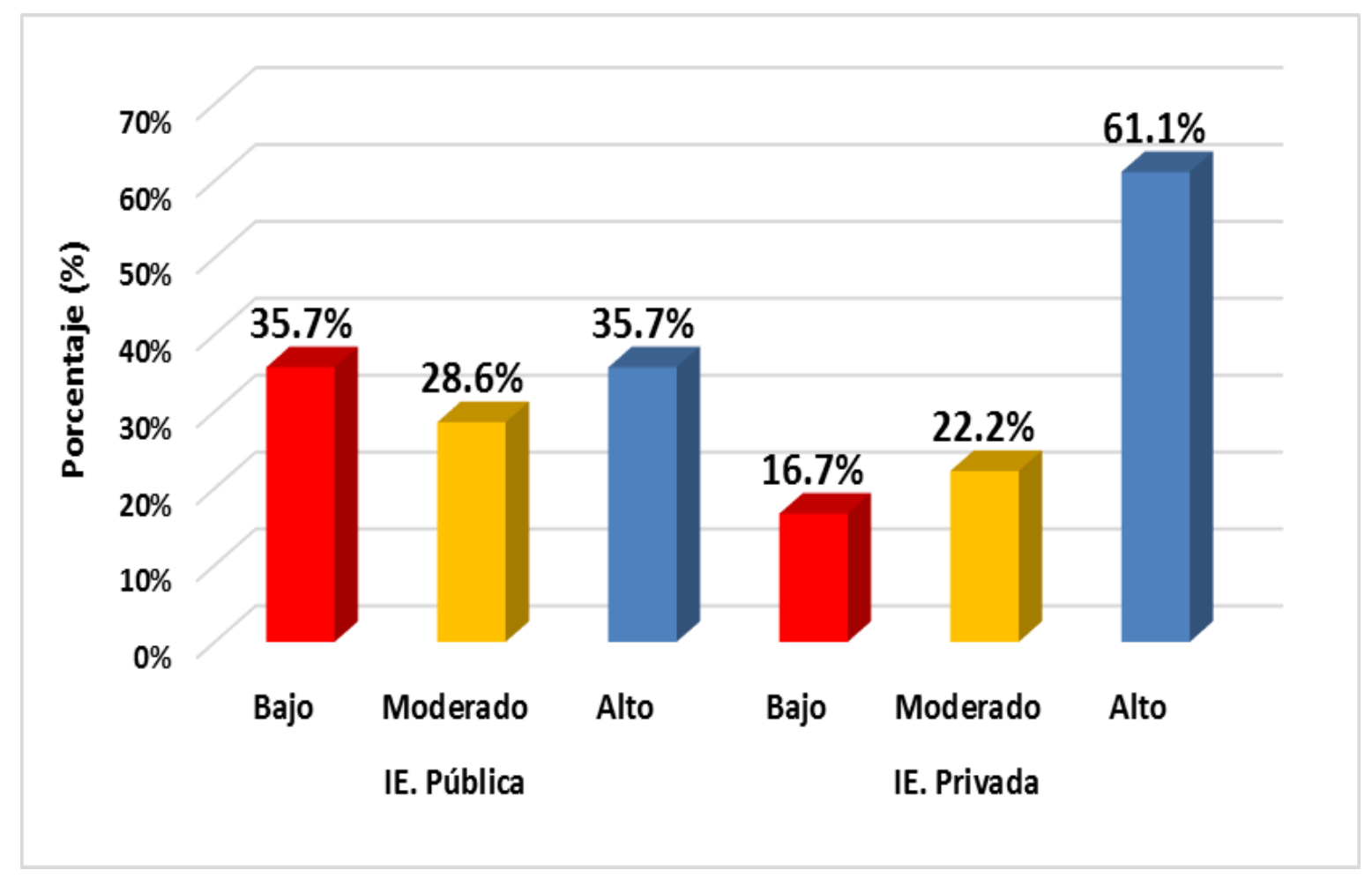

Figura 10. Nivel de habilidades para relacionarse con los adultos.

Según la tabla 9 y la figura 10, la IE privada obtuvo el mayor porcentaje solo en el nivel alto $(61.1 \%)$ frente a la IE pública. Esta última superó a la IE privada en los niveles moderado y bajo ( $28.6 \%$ y $35.7 \%$, respectivamente). 


\section{Análisis inferencial}

\section{Hipótesis de normalidad.}

Ho: La distribución de la variable de estudio no difiere de la distribución normal.

Ha: La distribución de la variable de estudio difiere de la distribución normal.

Regla de decisión:

Si Valor $p>0.05$, se acepta la hipótesis nula $(\mathrm{Ho})$

Si Valor $\mathrm{p}<0.05$, se rechaza la hipótesis nula (Ho). Por tanto, se acepta Ha.

Tabla 10

Prueba de normalidad.

\begin{tabular}{|c|c|c|c|c|c|c|c|}
\hline \multirow[b]{2}{*}{ Grupo } & & \multicolumn{3}{|c|}{$\begin{array}{l}\text { Kolmogorov-Smirnov }{ }^{\mathrm{a}} \\
(\mathrm{n}>=50)\end{array}$} & \multicolumn{3}{|c|}{$\begin{array}{c}\text { Shapiro-Wilk } \\
(\mathrm{n}<50)\end{array}$} \\
\hline & & Estadístico & gl & Sig. & Estadístico & gl & Sig. \\
\hline \multirow{11}{*}{$\begin{array}{c}\mathrm{IE} \\
\text { Pública }\end{array}$} & H. sociales & & & &, 990 & 42 & ,975 \\
\hline & H. básicas de interacción social & & & & 983 & 42 & ,780 \\
\hline & H. para hacer amigos y amigas & & & & ,972 & 42 & 394 \\
\hline & H. conversacionales & & & & ,975 & 42 & ,472 \\
\hline & $\begin{array}{l}\text { H. relacionadas con las emociones, } \\
\text { sentimientos y opiniones }\end{array}$ & & & & ,962 & 42 & 175 \\
\hline & $\begin{array}{l}\text { H. de solución de problemas } \\
\text { interpersonales }\end{array}$ & & & & ,982 & 42 & ,750 \\
\hline & H. para relacionarse con los adultos & & & & ,977 & 42 &, 566 \\
\hline & H. sociales & 068 & 54 & ,200* & & & \\
\hline & H. básicas de interacción social & 083 & 54 & $200^{*}$ & & & \\
\hline & H. para hacer amigos y amigas & 139 & 54 & 011 & & & \\
\hline & H. conversacionales & ,092 & 54 & ,200* & & & \\
\hline \multirow{3}{*}{$\begin{array}{c}\mathrm{IE} \\
\text { Privada }\end{array}$} & $\begin{array}{l}\text { H. relacionadas con las emociones, } \\
\text { sentimientos y opiniones }\end{array}$ & ,101 & 54 & ,200* & & & \\
\hline & $\begin{array}{l}\text { H. de solución de problemas } \\
\text { interpersonales }\end{array}$ & ,086 & 54 & ,200* & & & \\
\hline & H. para relacionarse con los adultos &, 065 & 54 & ,200* & & & \\
\hline
\end{tabular}

*. Esto es un límite inferior de la significación verdadera.

a. Corrección de significación de Lilliefors

Se evidencia que la prueba de normalidad de la variable habilidades sociales y sus dimensiones, no presenta normalidad únicamente en la dimensión Habilidades para hacer amigos y amigas de la IE. Privada ( $<0.05)$, por tanto, no se pueden comparar distribuciones diferentes. Según los resultados presentados, se rechaza la hipótesis nula y se concluye que uno de los datos no procede de una distribución normal, por lo que se justifica el empleo del estadístico no paramétrico, por lo que la prueba para poder comparar dos grupos será la prueba de U Mann Whitney. 


\section{Hipótesis general.}

Ho: No existen diferencias significativas en el desarrollo de habilidades sociales en los estudiantes de sexto grado de dos instituciones educativas del Callao, 2019.

Ha: Existen diferencias significativas en el desarrollo de habilidades sociales en los estudiantes de sexto grado de dos instituciones educativas del Callao, 2019.

Tabla 11

Estadístico prueba U Mann Whitney para el desarrollo de habilidades sociales.

\begin{tabular}{cccccc}
\hline Tipo a & N & $\begin{array}{c}\text { Rango } \\
\text { promedio }\end{array}$ & $\begin{array}{c}\text { Suma de } \\
\text { rangos }\end{array}$ & $\begin{array}{c}\text { U Mann } \\
\text { Whitney }\end{array}$ & p-valor \\
IE. Pública & 42 & 40.82 & 1714.50 & 811.50 & 0,017 \\
IE. Privada & 54 & 54.47 & 2941.50 & & \\
Total & 96 & & & & \\
\hline
\end{tabular}

a. Variable de agrupación: grupo

Según la tabla 11, se observa que el grupo IE pública tuvo un rango promedio de 40.82 mientras que el mayor rango promedio le correspondió al grupo IE privada con 54.47. Como puede apreciarse el estadígrafo de $U$ de Mann-Whitney fue de 811.50 y el valor de $p$ (Sig. asintót. bilateral) es 0,017 (menor que 0,05 ) por lo que se rechaza la hipótesis nula y se concluye que hay evidencias suficientes para afirmar que existe diferencias significativas en el desarrollo de habilidades sociales en los estudiantes de sexto grado de dos instituciones educativas del Callao, 2019, con un nivel de significación del 5\%.

\section{Hipótesis específica 1.}

Ho: No existen diferencias significativas en el desarrollo de habilidades básicas de interacción social en los estudiantes de sexto grado de dos instituciones educativas del Callao, 2019.

Ha: Existen diferencias significativas en el desarrollo de habilidades básicas de interacción social en los estudiantes de sexto grado de dos instituciones educativas del Callao, 2019. 
Tabla 12

Estadístico prueba U Mann Whitney para el desarrollo de habilidades básicas de interacción social.

\begin{tabular}{lccccc}
\hline Tipo a & $\mathrm{N}$ & $\begin{array}{c}\text { Rango } \\
\text { promedio }\end{array}$ & $\begin{array}{c}\text { Suma de } \\
\text { rangos }\end{array}$ & $\begin{array}{c}\text { W Mann } \\
\text { Whitney }\end{array}$ & -valor \\
\hline IE. Pública & 42 & 43.42 & 1823.50 & 920.50 & 0.114 \\
IE. Privada & 54 & 52.45 & 2832.50 & & \\
Total & 96 & & & & \\
\hline
\end{tabular}

a. Variable de agrupación: grupo

Según la tabla 12, se ve que el grupo IE pública tuvo un rango promedio de 43.42 mientras que el mayor rango promedio le correspondió al grupo IE privada con 52.45. Como puede apreciarse el estadígrafo de $U$ de Mann-Whitney fue de 920.50 y el valor de p (Sig. asintót. bilateral) es 0,114 (mayor que 0,05 ) por lo que se acepta la hipótesis nula y se concluye que no hay evidencias suficientes para afirmar que existe diferencias significativas en el desarrollo de habilidades básicas de interacción social en los estudiantes de sexto grado de dos instituciones educativas del Callao, 2019, con un nivel de significación del 5\%.

\section{Hipótesis específica 2.}

Ho: No existen significativas en el desarrollo de habilidades para hacer amigos y amigas en los estudiantes de sexto grado de dos instituciones educativas del Callao, 2019.

Ha: Existen significativas en el desarrollo de habilidades para hacer amigos y amigas en los estudiantes de sexto grado de dos instituciones educativas del Callao, 2019.

Tabla 13

Estadístico prueba U Mann Whitney para el desarrollo de habilidades para hacer amigos y amigas.

\begin{tabular}{lccccc}
\hline Tipo a & N & $\begin{array}{c}\text { Rango } \\
\text { promedio }\end{array}$ & $\begin{array}{c}\text { Suma de } \\
\text { rangos }\end{array}$ & $\begin{array}{c}\text { U Mann } \\
\text { Whitney }\end{array}$ & p-valor \\
\hline IE. Pública & 42 & 38.19 & 1604.00 & 701.00 & 0.010 \\
IE. Privada & 54 & 56.52 & 30.52 .00 & & \\
Total & 96 & & & & \\
\hline
\end{tabular}

a. Variable de agrupación: grupo 
Según la tabla 13, se ve que el grupo IE pública tuvo un rango promedio de 38.19 mientras que el mayor rango promedio le correspondió al grupo IE privada con 56.52. Como puede apreciarse el estadígrafo de $U$ de Mann-Whitney fue de 701.00 y el valor de $p$ (Sig. asintót. bilateral) es 0,010 (menor que 0,05 ) por lo que se rechaza la hipótesis nula y se concluye que sí hay evidencias suficientes para afirmar que existe diferencias significativas en el desarrollo de habilidades para hacer amigos y amigas en los estudiantes de sexto grado de dos instituciones educativas del Callao, 2019, con un nivel de significación del 5\%.

\section{Hipótesis específica 3.}

Ho: No existen diferencias significativas en el desarrollo de habilidades conversacionales en los estudiantes de sexto grado de dos instituciones educativas del Callao, 2019.

Ha: Existen diferencias significativas en el desarrollo de habilidades conversacionales en los estudiantes de sexto grado de dos instituciones educativas del Callao, 2019.

Tabla 14

Estadístico prueba U Mann Whitney para el desarrollo de habilidades conversacionales

\begin{tabular}{lccccc}
\hline Tipo a & N & $\begin{array}{c}\text { Rango } \\
\text { promedio }\end{array}$ & $\begin{array}{c}\text { Suma de } \\
\text { rangos }\end{array}$ & $\begin{array}{c}\text { U Mann } \\
\text { Whitney }\end{array}$ \\
\hline IE. Pública & 42 & 43.94 & 1845.00 & 942.50 & 0.157 \\
IE. Privada & 54 & 52.05 & 2810.50 & & \\
Total & 96 & & & & \\
\hline
\end{tabular}

a. Variable de agrupación: grupo

Según la tabla 14, vemos que el grupo IE. Pública tuvo un rango promedio de 43.94 mientras que el mayor rango promedio le correspondió al grupo IE. Privada con 52.05. Como puede apreciarse el estadígrafo de $U$ de Mann-Whitney fue de 942.50 y el valor de $p$ (Sig. asintót. (bilateral)) es 0,157 (mayor que 0,05 ) por lo que se acepta la hipótesis nula y se concluye que no hay evidencias suficientes para afirmar que existen diferencias significativas en el desarrollo de habilidades conversacionales en los estudiantes de sexto grado de dos instituciones educativas del Callao, 2019, con un nivel de significación del 5\%. 


\section{Hipótesis específica 4.}

Ho: No existen diferencias significativas en el desarrollo de habilidades relacionadas con las emociones, sentimientos y opiniones en los estudiantes de sexto grado de dos instituciones educativas del Callao, 2019.

Ha: Existen diferencias significativas en el desarrollo de habilidades relacionadas con las emociones, sentimientos y opiniones en los estudiantes de sexto grado de dos instituciones educativas del Callao, 2019.

Tabla 15

Estadístico prueba U Mann Whitney para el desarrollo de habilidades relacionadas con las emociones, sentimientos y opiniones.

\begin{tabular}{lccccc}
\hline Tipo a & N & $\begin{array}{c}\text { Rango } \\
\text { promedio }\end{array}$ & $\begin{array}{c}\text { Suma de } \\
\text { rangos }\end{array}$ & $\begin{array}{c}\text { U Mann } \\
\text { Whitney }\end{array}$ & p-valor \\
\hline IE. Pública & 42 & 41.20 & 1730.50 & 827.50 & 0.023 \\
IE. Privada & 54 & 54.18 & 2925.50 & & \\
Total & 96 & & & & \\
\hline
\end{tabular}

a. Variable de agrupación: grupo

Según la tabla 15, se observa que el grupo IE pública tuvo un rango promedio de 41.20 mientras que el mayor rango promedio le correspondió al grupo IE privada con 54.18. Como puede apreciarse el estadígrafo de $U$ de Mann-Whitney fue de 827.50 y el valor de p (Sig. asintót. bilateral) es 0,023 (menor que 0,05) por lo que se rechaza la hipótesis nula. Entonces se concluye que sí hay evidencias suficientes para afirmar que existe diferencias significativas en el desarrollo de habilidades relacionadas con las emociones, sentimientos y opiniones en los estudiantes de sexto grado de dos instituciones educativas del Callao, 2019, con un nivel de significación del 5\%.

\section{Hipótesis específica 5.}

Ho: No existen diferencias significativas en el desarrollo de habilidades para la solución de problemas interpersonales en los estudiantes de sexto grado de dos instituciones educativas del Callao, 2019. 
Ha: Existen diferencias significativas en el desarrollo de habilidades para la solución de problemas interpersonales en los estudiantes de sexto grado de dos instituciones educativas del Callao, 2019.

Tabla 16

Estadístico prueba U Mann Whitney para el desarrollo de habilidades para la solución de problemas interpersonales.

\begin{tabular}{lccccc}
\hline Tipo a & $\mathrm{N}$ & $\begin{array}{c}\text { Rango } \\
\text { promedio }\end{array}$ & $\begin{array}{c}\text { Suma de } \\
\text { rangos }\end{array}$ & $\begin{array}{c}\text { U Mann } \\
\text { Whitney }\end{array}$ & palor \\
\hline IE. Pública & 42 & 44.73 & 1878.50 & 975.50 & 0.241 \\
IE. Privada & 54 & 51.44 & 2777.50 & & \\
Total & 96 & & & \\
\hline
\end{tabular}

a. Variable de agrupación: grupo

Según la tabla 16, vemos que el grupo IE pública tuvo un rango promedio de 44.73 mientras que el mayor rango promedio le correspondió al grupo IE privada con 51.44. Como puede apreciarse el estadígrafo de $U$ de Mann-Whitney fue de 975.50 y el valor de $p$ (Sig. asintót. bilateral) es 0,241 (mayor que 0,05) por lo que se acepta la hipótesis nula y se concluye que no hay evidencias suficientes para afirmar que existe diferencias significativas en el desarrollo de habilidades para la solución de problemas interpersonales en los estudiantes de sexto grado de dos instituciones educativas del Callao, 2019, con un nivel de significación del $5 \%$.

\section{Hipótesis específica 6.}

Ho: No existen diferencias significativas en el desarrollo de habilidades para relacionarse con los adultos en los estudiantes de sexto grado de dos instituciones educativas del Callao, 2019.

Ha: Existen diferencias significativas en el desarrollo de habilidades para relacionarse con los adultos en los estudiantes de sexto grado de dos instituciones educativas del Callao, 2019. 
Tabla 17

Estadístico prueba U Mann Whitney para el desarrollo de habilidades para relacionarse con los adultos.

\begin{tabular}{lccccc}
\hline Tipo a & $\mathrm{N}$ & $\begin{array}{c}\text { Rango } \\
\text { promedio }\end{array}$ & $\begin{array}{c}\text { Suma de } \\
\text { rangos }\end{array}$ & $\begin{array}{c}\text { U Mann } \\
\text { Whitney }\end{array}$ \\
\hline IE. Pública & 42 & 39.92 & 1676.50 & 773.50 & 0.008 \\
IE. Privada & 54 & 55.18 & 2979.50 & & \\
Total & 96 & & & \\
\hline
\end{tabular}

a. Variable de agrupación: grupo

Según la tabla 17, se observa que el grupo IE pública tuvo un rango promedio de 39.92 mientras que el mayor rango promedio le correspondió al grupo IE privada con 55.18. Como puede apreciarse el estadígrafo de U de Mann-Whitney fue de 773.50 y el valor de p (Sig. asintót. bilateral) es 0,008 (menor que 0,05 ) por lo que se rechaza la hipótesis nula y se concluye que sí hay evidencias suficientes para afirmar que existe diferencias significativas en el desarrollo de habilidades para relacionarse con los adultos en los estudiantes de sexto grado de dos instituciones educativas del Callao, 2019, con un nivel de significación del 5\%. 


\section{Discusión, Conclusiones y Sugerencias}

\section{Discusión}

Según la hipótesis general existen diferencias significativas en el desarrollo de habilidades sociales en los estudiantes de sexto grado de primaria de dos instituciones educativas del Callao, 2019. Los resultados del análisis inferencial de la tabla 11 respaldan dicha hipótesis, ya que se obtuvo 811.50 en la prueba de Mann-Whitney y un $p=0.017<p=0.05$. Por ello, se rechaza la hipótesis nula. En el análisis descriptivo de la tabla 3 también se evidenciaron diferencias entre ambos grupos de estudiantes: en los niveles alto y moderado fue la institución privada quien obtuvo mayores porcentajes ( $57.4 \%$ y $38.1 \%$, respectivamente) mientras que en el nivel bajo la institución pública superó a la privada (38.1\% frente a un 14.8\%). El hallazgo concuerda parcialmente con Huertas (2017) quien encontró que los niños de 4 años de edad, de una escuela piurana, habían alcanzado diferentes niveles de logro en sus habilidades sociales. Para Monjas y González (1998), las habilidades sociales son el conjunto de competencias conductuales que posibilitan que el niño entable relaciones sociales positivas con sus pares, además de afrontar eficazmente las demandas provenientes de su entorno social.

Según la hipótesis específica 1 existen diferencias significativas en el desarrollo de habilidades básicas de interacción social en los estudiantes de sexto grado de primaria de dos instituciones educativas del Callao, 2019. Los resultados del análisis inferencial de la tabla 12 no respaldan dicha hipótesis, ya que se obtuvo 920.50 en la prueba de MannWhitney y un $p=0.114>p=0.05$. Por ello, se acepta la hipótesis nula y se afirma que no hay diferencias significativas entre los grupos de estudiantes participantes en la muestra. Sin embargo, en el análisis descriptivo de la tabla 4 sí se evidenciaron diferencias entre ambos grupos de estudiantes: en el nivel alto fue la institución privada quien obtuvo mayores porcentajes ( $48.1 \%$ frente a un $38.1 \%$ ) mientras que en el nivel bajo la institución pública superó a la privada (28.6\% frente a un $18.5 \%$ ). El hallazgo se relaciona indirectamente con Jiménez y Barreto (2017) quienes encontraron en una muestra de niños de educación inicial en Trujillo una paradoja: el 50\% de los encuestados manifestó participar en actividades y tareas grupales. No obstante, había problemas considerables para mostrar las habilidades básicas de interacción social. Estas habilidades, de acuerdo con Monjas y González (1998), son elementales y se ejecutan cuando interactuamos con los familiares, amigos o con la pareja sentimental. Consiste en sonreír, saludar, hacer una breve presentación personal de sí mismo, realizar favores y mostrarse como una persona amable. 
Según la hipótesis específica 2 existen diferencias significativas en el desarrollo de habilidades para hacer amigos y amigas en los estudiantes de sexto grado de primaria de dos instituciones educativas del Callao, 2019. Los resultados del análisis inferencial de la tabla 13 respaldan dicha hipótesis, ya que se obtuvo 701.00 en la prueba de Mann-Whitney y un $p=0.010<p=0.05$. Por ello, se rechaza la hipótesis nula y se afirma que hay diferencias significativas entre los grupos de estudiantes participantes en la muestra. En el análisis descriptivo de la tabla 5 también se evidenciaron diferencias entre ambos grupos de estudiantes: en el nivel alto fue la institución privada quien obtuvo mayor porcentaje (53.7\% frente a un 26.2\%) mientras que en el nivel moderado y bajo la institución pública superó a la privada (42.9\% y $31.0 \%$, respectivamente frente a un $27.8 \%$ y $18.5 \%)$. El hallazgo se relaciona indirectamente con Zelada (2018) quien encontró una relación significativa muy alta (rho de Spearman $=0.903 ; p<0.01$ ) entre Relación como dimensión del Clima social familiar y las Habilidades sociales en un grupo de estudiantes del primer grado de secundaria en una escuela de Miraflores. Las habilidades para hacer amigos y amigas, de acuerdo con Monjas y González (1998), son destrezas que aportan al desarrollo socioafectivo del niño y que lo favorecerán en su adaptación social. Comprende habilidades tales como compartir sus juguetes, unirse al juego con los demás, ayudar a sus pares, etc.

Según la hipótesis específica 3 existen diferencias significativas en el desarrollo de habilidades conversacionales en los estudiantes de sexto grado de primaria de dos instituciones educativas del Callao, 2019. Los resultados del análisis inferencial de la tabla 14 no respaldan dicha hipótesis, ya que se obtuvo 942.50 en la prueba de Mann-Whitney y un $p=0.157>p=0.05$. Por ello, se acepta la hipótesis nula y se afirma que no hay diferencias significativas entre los grupos de estudiantes participantes en la muestra. En el análisis descriptivo de la tabla 6 sí hay diferencias a favor de la institución privada en los niveles alto y moderado (50.0\% y $35.2 \%$, respectivamente) en comparación con la institución pública. Esta última superó a la privada en el nivel bajo (33.3\% frente a un 14.8\%). E hallazgo se relaciona con Huamán (2015) quien encontró que el 38.5\% de estudiantes de quinto grado de secundaria de una escuela de Chiclayo tenía como habilidades todavía no desarrolladas aquellas que eran necesarias para saber escuchar a los demás y entablar una conversación (comunicación asertiva). Las habilidades conversacionales, de acuerdo con Monjas y González (1998), son el sustento de las interacciones personales eficaces. Se muestran durante una conversación, sea para iniciarla, mantenerla o finalizarla.

Según la hipótesis específica 4 existen diferencias significativas en el desarrollo de habilidades relacionadas con las emociones, sentimientos y opiniones en los estudiantes de sexto grado de primaria de dos instituciones educativas del Callao, 2019. Los resultados del 
análisis inferencial de la tabla 15 respaldan dicha hipótesis, ya que se obtuvo 827.50 en la prueba de Mann-Whitney y un $p=0.023<p=0.05$. Por ello, se rechaza la hipótesis nula y se afirma que hay diferencias significativas entre los grupos de estudiantes participantes en la muestra. En el análisis descriptivo de la tabla 7 también hay diferencias a favor de la institución privada en los niveles alto y moderado (59.3\% y $31.5 \%$, respectivamente) en comparación con la institución pública. Esta última superó a la privada en el nivel bajo (33.3\% frente a un 9.3\%). El hallazgo concuerda con Córdova (2018) quien encontró diferencias significativas en la defensa de los propios derechos en niños y niñas de educación inicial de dos escuelas de Oxapampa (Pasco). Las habilidades relacionadas con las emociones, sentimientos y opiniones, de acuerdo con Monjas y González (1998), tienen mucho que ver con la asertividad. Es decir, con el hecho de ser capaces de expresar nuestros sentimientos y defender nuestros derechos, sin que se cuestione o nieguen los derechos de los demás.

Según la hipótesis específica 5 existen diferencias significativas en el desarrollo de habilidades de solución de problemas interpersonales en los estudiantes de sexto grado de primaria de dos instituciones educativas del Callao, 2019. Los resultados del análisis inferencial de la tabla 16 no respaldan dicha hipótesis, ya que se obtuvo 975.50 en la prueba de Mann-Whitney y un $p=0.241>p=0.05$. Por ello, se acepta la hipótesis nula y se afirma que no hay diferencias significativas entre los grupos de estudiantes participantes en la muestra. En el análisis descriptivo de la tabla 8 sí hay diferencias a favor de la institución privada en los niveles alto y moderado (50.0\% y 35.2\%, respectivamente) en comparación con la institución pública. Esta última superó a la privada en el nivel bajo (33.3\% frente a un 14.8\%). El hallazgo se relaciona con Zelada (2018) quien encontró una correlación positiva moderada entre las habilidades instrumentales (en la operacionalización de Zelada, la solución de conflictos es un indicador) y la competencia en proyectos de emprendimiento en una muestra de estudiantes del nivel secundario de La Victoria. Las habilidades de solución de problemas interpersonales, de acuerdo con Monjas y González (1998), le permitirán al niño a aprender a resolver los conflictos con sus amigos. Está constituida por la identificación de problemas, búsqueda de soluciones, proyección de consecuencias, elección de una alternativa y estar dispuesto a aprender de ella si las cosas salen mal.

Según la hipótesis específica 6 existen diferencias significativas en el desarrollo de habilidades para relacionarse con adultos en los estudiantes de sexto grado de primaria de dos instituciones educativas del Callao, 2019. Los resultados del análisis inferencial de la tabla 17 respaldan dicha hipótesis, ya que se obtuvo 773.50 en la prueba de Mann-Whitney y un $p=0.08<p=0.05$. Por ello, se rechaza la hipótesis nula y se afirma que hay diferencias 
significativas entre los grupos de estudiantes participantes en la muestra. En el análisis descriptivo de la tabla 9 también hay diferencias a favor de la institución privada en el nivel alto (61.1\%) en comparación con la institución pública (35.7\%). Esta última superó a la privada en los niveles moderado y bajo (28.6\% y $35.7 \%$, respectivamente). El hallazgo se relaciona con Zelada (2018) quien encontró una correlación positiva moderada entre las habilidades instrumentales (en la operacionalización de Zelada, la solución de conflictos es un indicador) y la competencia en proyectos de emprendimiento en una muestra de estudiantes del nivel secundario de La Victoria. Las habilidades para relacionarse con adultos, de acuerdo con Monjas y González (1998), incluyen dialogar con un adulto, ser amable con él, saber pedir las cosas o expresar las peticiones y solucionar asertivamente los conflictos.

\section{Conclusiones}

Primera. De acuerdo a las evidencias estadísticas sí existen diferencias significativas en el desarrollo de las habilidades sociales en los estudiantes de sexto grado de dos escuelas del Callao-2019. En el análisis inferencial se obtuvo 811.50 en la prueba de Mann-Whitney y un $\mathrm{p}=0.017<\mathrm{p}=0.05$. Por ello, se rechaza la hipótesis nula. En el análisis descriptivo también se evidenciaron diferencias entre ambos grupos de estudiantes: en los niveles alto y moderado fue la institución privada quien obtuvo mayores porcentajes, mientras que en el nivel bajo la institución pública superó a la privada.

Segunda. De acuerdo a las evidencias estadísticas no existen diferencias significativas en el desarrollo de habilidades básicas de interacción social en los estudiantes de sexto grado de dos escuelas del Callao-2019. En el análisis inferencial se obtuvo 920.50 en la prueba de Mann-Whitney y un $p=0.014<p=0.05$. Por ello, se acepta la hipótesis nula. En el análisis descriptivo sí se evidenciaron diferencias entre ambos grupos de estudiantes: en el nivel alto fue la institución privada quien obtuvo mayor porcentaje (48.1\% frente a un $38.1 \%$ ) mientras que en el nivel bajo la institución pública superó a la privada (28.6\% frente a un $18.5 \%$ ).

Tercera. De acuerdo a las evidencias estadísticas sí existen diferencias significativas en el desarrollo de habilidades para hacer amigos y amigas en los estudiantes de sexto grado de dos escuelas del Callao-2019. En el análisis inferencial se obtuvo 701.00 en la prueba de Mann-Whitney y un $p=0.010<p=0.05$. Por ello, se rechaza la hipótesis nula. En el análisis descriptivo también hubo diferencias 
entre ambos grupos de estudiantes: en el nivel alto fue la institución privada quien obtuvo mayor porcentaje (53.7\% frente a un $26.2 \%$ ) mientras que en el nivel moderado y bajo la institución pública superó a la privada (42.9\% y 31.0\%, respectivamente frente a un $27.8 \%$ y $18.5 \%$ ).

Cuarta. De acuerdo a las evidencias estadísticas no existen diferencias significativas en el desarrollo de habilidades conversacionales en los estudiantes de sexto grado de dos escuelas del Callao-2019. En el análisis inferencial se obtuvo 942.50 en la prueba de Mann-Whitney y un $p=0.157>p=0.05$. Por ello, se acepta la hipótesis nula. En el análisis descriptivo sí hay diferencias a favor de la institución privada en los niveles alto y moderado $(50.0 \%$ y $35.2 \%$, respectivamente) en comparación con la institución pública. Esta última superó a la privada en el nivel bajo (33.3\% frente a un $14.8 \%)$.

Quinta. De acuerdo a las evidencias estadísticas sí existen diferencias significativas en el desarrollo de habilidades relacionadas con emociones, sentimientos y opiniones en los estudiantes de sexto grado de dos escuelas del Callao-2019. En el análisis inferencial se obtuvo 827.50 en la prueba de Mann-Whitney y un $p=0.023<p=0.05$. Por ello, se rechaza la hipótesis nula. En el análisis descriptivo también hubo diferencias a favor de la institución privada en los niveles alto y moderado (59.3\% y $31.5 \%$, respectivamente) en comparación con la institución pública. Esta última superó a la privada en el nivel bajo (33.3\% frente a un $9.3 \%)$.

Sexta. De acuerdo a las evidencias estadísticas no existen diferencias significativas en el desarrollo de habilidades de solución de problemas interpersonales en los estudiantes de sexto grado de dos escuelas del Callao-2019. En el análisis inferencial se obtuvo 975.50 en la prueba de Mann-Whitney y un $p=0.241>p=$ 0.05. Por ello, se acepta la hipótesis nula. En el análisis descriptivo sí hay diferencias a favor de la institución privada en los niveles alto y moderado (50.0\% y $35.2 \%$, respectivamente) en comparación con la institución pública. Esta última superó a la privada en el nivel bajo (33.3\% frente a un 14.8\%).

Séptima. De acuerdo a las evidencias estadísticas existen diferencias significativas en el desarrollo de habilidades para relacionarse con adultos en los estudiantes de sexto grado de dos escuelas del Callao-2019. En el análisis inferencial se obtuvo 773.50 en la prueba de Mann-Whitney y un $p=0.008<p=0.05$. Por ello, se 
rechaza la hipótesis nula. En el análisis descriptivo también hay diferencias a favor de la institución privada en el nivel alto (61.1\%) en comparación con la institución pública (35.7\%). Esta última superó a la privada en los niveles moderado y bajo (28.6\% y $35.7 \%$, respectivamente).

\section{Sugerencias}

Primera. En la medida de lo posible los docentes y el Comité de Tutoría y Orientación Educativa deben tener una comunicación fluida. Ambos agentes educativos están encargados de monitorear el progreso de las habilidades sociales de los estudiantes.

Segunda. El desarrollo de una sesión de aprendizaje podría incluir una dinámica de interacción grupal. No solo porque ayuda a la distensión, sino fundamentalmente con el propósito pedagógico de contribuir a las habilidades básicas de interacción social y la de hacer amigos y amigas.

Tercera. Las habilidades conversacionales podrían ser trabajadas a modo de taller o conversatorio. Podrían seleccionarse algunas entrevistas propaladas por la televisión de señal abierta con la finalidad de aprender de sus errores.

Cuarta. Los padres deben recordar que, al igual que los maestros, son los adultos más cercanos a los niños. Por ese motivo, están obligados a ser un ejemplo positivo para sus hijos y contribuir al desarrollo de las habilidades sociales en especial de aquella relacionada con las emociones, sentimientos y opiniones, además de la habilidad para la solución de problemas interpersonales.

Quinta. Algunas sesiones de tutoría podrían abocarse a la educación emocional durante la programación bimestral. Las maestras podrían ser apoyadas por los psicólogos de la institución educativa. En ese sentido, habría que evaluar la posibilidad de que estos profesionales puedan realizar algunas visitas a los hogares de aquellos estudiantes cuyo desarrollo de habilidades sociales positivas sea una necesidad perentoria. 


\section{Referencias}

Alfageme, B. (2002). Modelo colaborativo de enseñanza-aprendizaje en situaciones no presenciales: un estudio de caso. Tesis doctoral inédita. España: Universidad de Murcia. Recuperado de https://www.tesisenred.net/handle/10803/10768\#page=1

Arias, F. (2012). El proyecto de investigación. Introducción a la metodología científica (6á ed.). Caracas: Editorial Episteme.

Aspegren, K. (1999). BEME guide no.2: Teaching and learning communication skills in medicine--a review. Medical Teacher, 21(6), 563-570.

Bandura, A. (1977). Social learning theory. Englewood Cliffs, N.J: Prentice-Hall.

Barrera, M., Berkel, C., \& Castro, F. G. (2017). Directions for the advancement of culturally adapted preventive interventions: Local adaptations, engagement, and sustainability. Prevention Science, 18(6), 640-648. http://dx.doi.org/10.1007/s11121016-0705-9

Barrientos, A. (2016). Habilidades sociales y emocionales del profesorado de educación infantil relacionadas con la gestión del clima de aula (tesis doctoral). Universidad Complutense de Madrid, España. Recuperado de https://bit.ly/2Gojryk

Bernal, G., \& Scharró-del-Río, M. R. (2001). Are empirically supported treatments valid for ethnic minorities? Toward an alternative approach for treatment research. Cultural Diversity and Ethnic Minority Psychology, 7, 328-342. http://dx.doi.org/10.1037/1099-9809.7.4.328.

Bernal, C. (2010). Metodología de la investigación. Administración, economía, humanidades y ciencias sociales. ( $3^{\underline{a}}$ ed.). Colombia: Pearson Educación.

Blacher, J., Cohen, S. R., \& Azad, G. (2014). In the eye of the beholder: Reports of autism symptoms by Anglo and Latino mothers. Research in Autism Spectrum Disorders, 8, 1648-1656. http://dx.doi.org/10.1016/j.rasd.2014.08.017

Brophy, H. E., Lee, R. E., Nievar, M. A., \& Stollak, G. (2007). Preschoolers' social competence: Relations to family characteristics, teacher behaviors and classroom climate. Journal of Applied Developmental Psychology, 28(2), 134-148. doi: 10.1016/j.appdev.2006.12.004

Butler, A. M., \& Titus, C. (2015). Systematic review of engagement in culturally adapted parent training for disruptive behavior. Journal of Early Intervention. http://dx. doi.org/10.1177/1053815115620210. 
Caballo, V. (1993). Manual de evaluación y entrenamiento de las habilidades sociales. Madrid: Siglo XXI Editores. Recuperado de https://cideps.com/wpcontent/uploads/2015/04/Caballo-V.-Manual-de-evaluaci\%C3\%B3n-y-entrenamientode-las-habilidades-sociales-ebook.pdf

Caballo, V. \& Verdugo, M. (2005). Habilidades sociales: Programa para mejorar las relaciones sociales entre niños y jóvenes con deficiencia visual y sus iguales sin discapacidad. Madrid: ONCE. Recuperado de https://portal.once.es/bibliotecas/fondo-bibliografico-discapacidadvisual/14372/habilidades-sociales-doc-271/at download/file.

Caballo, V., Salazar, I., Irurtia, M., Olivares, P. \& Olivares, J. (2014). Relación de las habilidades sociales con la ansiedad social y los estilos/trastornos de la personalidad. Psicología Conductual, 22(3), 401-422. Recuperado de https://go.aws/2NU1Naf

Carrillo, G. (2015). Validación de un programa lúdico para la mejora de las habilidades sociales en niños de 9 a 12 años (tesis doctoral). Universidad de Granada, España. Recuperado de https://bit.ly/2vglxOa

Carter, J. A., Lees, J. A., Murira, G. M., Gona, J., Neville, B. G. R., \& Newton, C. R. J. C. (2005). Issues in the development of cross-cultural assessments of speech and language for children. International Journal of Language and Communication Disorders. http://dx.doi.org/10.1080/13682820500057301

Castelló, P. (2013) Habilidades sociales en el aula (tesis de maestría). Universitat Jaume. Castellón, España. Recuperado de http://hdl.handle.net/10234/81426

Córdova, M. (2018). Habilidades sociales en niños y niñas de nivel inicial de dos instituciones educativas, Oxapampa-2018 (tesis de maestría). Universidad César Vallejo, Lima, Perú.

Díaz, M. \& Aguado, J. (1995). Niños con dificultades socioemocionales. Instrumentos de evaluación. Madrid: Ministerio de Asuntos Sociales. Recuperado de https://www.researchgate.net/publication/301771634 La evaluacion de la adaptaci on socioemocional a traves del autoinforme El autoconcepto y la empatia/link/5 $\underline{72724 f 108 a e 586 b 21 e 2527 e / d o w n l o a d}$

Durlak, J., Weissberg, R., Dymnicki, B., Taylor, D., \& Schellinger, B. (2011). The impact of enhancing students' social and emotional learning: A Meta-Analysis of School-based universal interventions. Child Development, 82(1), 405-432. doi: 10.1111/j.14678624.2010.01564.x

Eisenberg, N. (1999). Infancia y conductas de ayuda. Madrid: Morata Recuperado de http://www.movilizacioneducativa.net/imprimir.asp?idLibro=131 
Fernández, R. (1994). Evaluación conductual hoy. Un enfoque para el cambio en psicología clínica y de la salud. Madrid: Pirámide. Recuperado de https://es.scribd.com/document/377052745/Evaluacion-Conductual-Hoy-Un-EnfoquePara-El-Cambio-en-Psicologia-Clinica-y-de-La-Salud

Fiallo, J., Cerezal, J. \& Huaranga, O. (2016). Métodos científicos de la investigación pedagógica. Lima: Colectivo Pedagógico Escuela Abierta.

Gambrill, E. \& Richey, L. (1985). Taking Charge of Your Social Life. Belmont, CA: Wadsworth.

García, B. (2018). Las habilidades socioemocionales, no cognitivas o "blandas": aproximaciones a su evaluación. Revista Digital Universitaria, 19(6). doi: 10.22201/codeic.16076079e.2018.v19n6.a5

Gil, F., León, J. \& Jarana, L. (Eds.) (1995). Habilidades sociales y salud. Madrid: Pirámide.

Gismero, E. (2000). EHS Escala de Habilidades Sociales. Manual. Madrid: TEA Publicaciones de Psicología Aplicada.

Goleman, D. (1996). La inteligencia emocional. Barcelona: Kairós.

González, A. (2009). Habilidades sociales en educación. Temas para la educación. 3, 1-7. Recuperado de http://www2.fe.ccoo.es/andalucia/docu/p5sd4974.pdf

Gresham, F. (1988). Social skills: Conceptual and applied aspects of assessment, training and social validation. En J.C. Witt, S.N. Elliot \& F. Gresham (Eds.), Handbook of Behavior Therapy in Education (pp. 523-546). New York: Plenum Press.

Guevara, R. (2016). Metodología de la Investigación. Lima: Centrum PUCP.

Gutiérrez, F. \& Prieto, D. (2002). Mediación pedagógica. Apuntes para una educación a distancia alternativa ( $3^{\underline{a}}$ ed.). Guatemala: Universidad de San Carlos de Guatemala.

Hamre, B., Hatfield, B., Pianta, R. \& Jamil, F. (2014). Evidence for general and domainspecific elements of teacher? Child interactions: Associations with preschool children's development. Child Development, 85(3), 1257-1274. doi:

10.1111/cdev.12184

Hechavarría, S. (2012, 30 de mayo). Diferencias entre cuestionario y encuesta. Universidad Virtual de Salud Manuel Fajardo, Cuba. Recuperado de https://bit.ly/2Qaol29 
Hernández, S., Pozo, C. \& Alonso, E. (2004). La aproximación multimétodo en la evaluación de necesidades. Apuntes de Psicología, 22(3), 293-308.

Hernández, R., Fernández, C. \& Baptista, P. (2014). Metodología de la investigación. (6ª ed.). México: McGraw-Hill/ Interamericana Editores S.A.

Holst, I., Galicia, Y., Gómez, G. \& Degante, A. (2017). Las habilidades sociales y sus diferencias en estudiantes universitarios. Vertientes. Revista Especializada en Ciencias de la Salud, 20(2), 22-29.

Hurd, N., Zimmerman, M. \& Xue, Y. (2009). Negative adult influences and the protective effects of role models: A study with urban adolescents. Journal of Youth and Adolescence, 38(6), 777-789.

Huamán, A. (2015). Habilidades sociales en estudiantes de quinto año de nivel secundarias de una institución educativa de Chiclayo, 2015 (tesis de titulación). Universidad Juan Mejía Baca, Chiclayo, Perú.

Huertas, R. (2017). Habilidades sociales de los estudiantes de 4 años de la I.E.I. Nº01 María Concepción Ramos Campos - Piura, 2016 (tesis de maestría). Universidad de Piura, Perú. Recuperado de https://bit.ly/2tPWVeU

Ibarra, E. (2018). Habilidades sociales y clima social escolar en estudiantes de 1 ro y 2 do de secundaria de la institución particular Guadalupe (tesis de maestría). Universidad César Vallejo, Lima, Perú.

Instituto Nacional de Estadística e Informática, INEI (2015). Perú-Encuesta Nacional sobre Relaciones Sociales, 2015. Lima: Dirección Nacional de Censos y Encuestas.

Instituto de Estadística de la Unesco (2016). Habilidades para el progreso social. El poder de las habilidades sociales y emocionales. Montreal: UIS.

Iruarrizaga, I., Gómez, J., Criado, T., Zuazo, M. \& Sastre, E. (1999). Reducción de la ansiedad a través del entrenamiento en habilidades sociales. Revista Electrónica de Motivación y Emoción, 2(1). Recuperado de www.reme.uji.es/articulos/airvai462031195/texto.html

Jara, K. (2018). Habilidades sociales, habilidades comunicativas y manejo de conflictos en estudiantes de secundaria, Huacho-2017 (tesis doctoral). Universidad César Vallejo, Lima, Perú.

Jennings, P. \& Greenberg, M. (2009). The prosocial classroom: teacher social and emotional competence in relation to student and classroom outcomes. Review of Educational Research, 79(1), 491-525. 
Jiménez, L. \& Barreto, J. (2017). Las habilidades de interacción social en niños de educación inicial (tesis de bachillerato). Universidad Pedro Ruiz Gallo, Trujillo, Perú.

Kelly, J. (1992). Entrenamiento de las habilidades sociales. (3를 ed.). Bilbao: Biblioteca de Psicología Desclée de Brouwer.

Kerlinger, F. (1988). Investigación del comportamiento. México: Interamericana.

Lacunza, A. \& Contini, N. (2011). Las habilidades sociales en niños y adolescentes. Su importancia en la prevención de trastornos psicopatológicos. Fundamentos en Humanidades, 12(1), 159-182.

Lazarus, A. (1973). Behavior therapy and Beyond. McGraw-Hill. Recuperado de http://garfield.library.upenn.edu/classics1979/A1979HH36300001.pdf

López, F., Etxebarria, I., Fuentes, M. \& Ortiz, M. (1999). Desarrollo afectivo y social. Madrid: Pirámide.

López, T. (2016). Clima social familiar y Habilidades sociales en estudiantes de primer año de secundaria de una institución educativa del distrito de Miraflores (tesis de maestría). Universidad César Vallejo, Lima, Perú.

Losada, L. (2015). Adaptación del "Social Skills Improvement System-rating Scales" al contexto español en la etapa de educación primaria (tesis doctoral). Universidad Nacional de Educación a Distancia, España. Recuperado de https://bit.ly/2uvNLEI

Meichenbaum, D., Butler, L. \& Gruson, L. (1981). Toward a conceptual model of social competence. En: J. Wine y M. Smye (Eds.), Social competence (36-60). New York: The Guilford Press.

Miller, P.W. (1998). Nonverbal communication: what a researcher says to the teacher. Estados Unidos: Nea. Recuperado de https://files.eric.ed.gov/fulltext/ED293190.pdf

Ministerio de Educación del Perú (2004). Desarrollando nuestras habilidades sociales. Cartillas autoinstructivas para padres de familia. Programa de prevención del uso indebido de drogas. Lima: Devida, Naciones Unidas.

Monjas, I. (1993). Programa de entrenamiento en habilidades de interacción social. PEHIS. Salamanca: Trilce. 
Monjas, I. (1994). Evaluación de la competencia y las habilidades sociales en la edad escolar. Evaluación curricular: Una guía para la intervención psicopedagógica ( $\mathrm{p}$. 423-497). Madrid: Siglo XXI Editores.

Monjas, I., Verdugo, M., \& Arias, B. (1995). Eficacia de un Programa para enseñar habilidades de interacción social a alumnado con necesidades educativas especiales en Educación Infantil y Primaria. Madrid: CEPE.

Monjas, I. \& González, B. (1998). Las habilidades sociales en el currículo. Madrid España: Ministerio de Educación, Cultura y Deporte, Secretaria técnica.

Monjas, I. (2004). ¿Mi hijo es tímido? Madrid: Pirámide.

Monjas, I. (2009). Programa de Enseñanza de Habilidades de Interacción Social para niños y niñas en edad escolar (PEHIS). Madrid: CEPE.

Monjas, I. (2011). Como promover la convivencia: Programa de Asertividad y Habilidades Sociales (PAHS). Madrid: CEPE.

Monjas, I. (2012). Programa de enseñanza de habilidades de interacción social (PEHIS) para niños y niñas en edad escolar (10ª ed.). Madrid: CEPE.

Morales, F. \& Olsa, M. (2001). Psicología Social y Trabajo Social. España: McGraw Hill.

Unesco (2016). Habilidades para un mundo cambiante. Recuperado de https://bit.ly/2txgi09

Ortego, M., López, S. \& Álvarez, L. (2001). Las habilidades sociales (Ciencias Psicosociales I). Universidad de Cantabria, España. Recuperado desde: https://bit.ly/2Grc74E

Pelenchano, V. (1996). Habilidades interpersonales. Teoría mínima y programas de intervención. Programas para niños y adolescentes. Valencia: Promolibro.

Pérez, M. (2012). Habilidades sociales en el aula. Revista Digital Innovación y experiencias educativas, 52, 1-8. Recuperado de https://bit.ly/2U95a0n

Ramírez, M. (2012). Modelos y estrategias de enseñanza para ambientes innovadores. Monterrey, México: Editorial Digital del Tecnológico de Monterrey.

Ratto, A. B., Reznick, J. S., \& Turner-Brown, L. (2016). Cultural effects on the diagnosis of autism spectrum disorder among Latinos. Focus on Autism and Other Developmental Disabilities, 31(4), 275-283. http://dx.doi.org/10.1177/1088357615587501 
Reguant, M. \& Martínez, F. (2014). Operacionalización de conceptos/variables. Barcelona: Depósito Digital de la Universidad de Barcelona. Recuperado de https://bit.ly/34M80tK

Roca, E. (2007). Cómo mejorar tus habilidades sociales. Valencia: ACDE.

Salvat Editores (2004). La Enciclopedia (vol. 16). Colombia: Mediasat Group.

Sanz, J., Gil, F. \& García, M. (1998). Evaluación de las habilidades sociales. En F. Gil \& J. León (Eds.), Entrenamiento en habilidades sociales: Teoría, evaluación y aplicaciones (pp. 25-62). Madrid: Síntesis.

Sánchez, H. \& Reyes, C. (2015). Metodología y diseño de la investigación científica (5ª ed.). Lima: Business Support Aneth.

Sendín, M. (2000). Diagnóstico psicológico. Bases conceptuales y guía práctica en los contextos clínico y educativo. Madrid: Psimática.

Sierra, R. (2001). Técnicas de Investigación Social. Teoría y ejercicios. (14ª ed.). Madrid: Paraninfo, Thomson Learning.

Thayer, R.E. (1986). Activation-Deactivation Adjective Check List: Current Overview and Structural Analysis. Psychological Reports. Recuperado de https://www.scirp.org/(S(i43dyn45teexjx455qlt3d2q))/reference/ReferencesPapers.as px?ReferencelD=1449927

Trianes, M., Rivas, T., \& Muñoz, A. (1990). Una intervención psicoeducativa sobre las habilidades de solución de problemas interpersonales en preescolar. Análisis y Modificación de la Conducta, 16(50), 587-625.

Trianes, T., Muñoz, A.M., \& Jiménez, M. (2007). Las relaciones sociales en la infancia y en La adolescencia y sus problemas. Madrid: Pirámide. Recuperado de https://online.ucv.es/resolucion/competencia-social/

Valles, A. \& Valles, C. (1996). Las habilidades sociales en la escuela. España: EOS. Recuperado de https://online.ucv.es/resolucion/habilidades-sociales-en-la-escuela/

Verde, L. (2019). Programa de tutoría en las habilidades sociales de los estudiantes del segundo grado de secundaria de una institución educativa (tesis de maestría). Universidad César Vallejo, Lima, Perú. Recuperado de https://bit.ly/2OswBic 
Wang, M., \& Lam, Y. (2017). Evidence-based practice in special education and cultural adaptations. Research and Practice for Persons with Severe Disabilities, 42(1), 53-61. http://dx.doi.org/10.1177/1540796916685872

Zelada, N. (2018). Habilidades sociales y competencia en proyectos de emprendimiento en estudiantes de secundaria (tesis de maestría). Universidad César Vallejo, Lima, Perú. 
Anexos 


\section{Anexo 1 : Matriz de consistencia}

TITULO: Habilidades sociales en los estudiantes de sexto grado de primaria de dos instituciones educativas del Callao, 2019 AUTOR: Liliana Celedonia Huamán Pretell

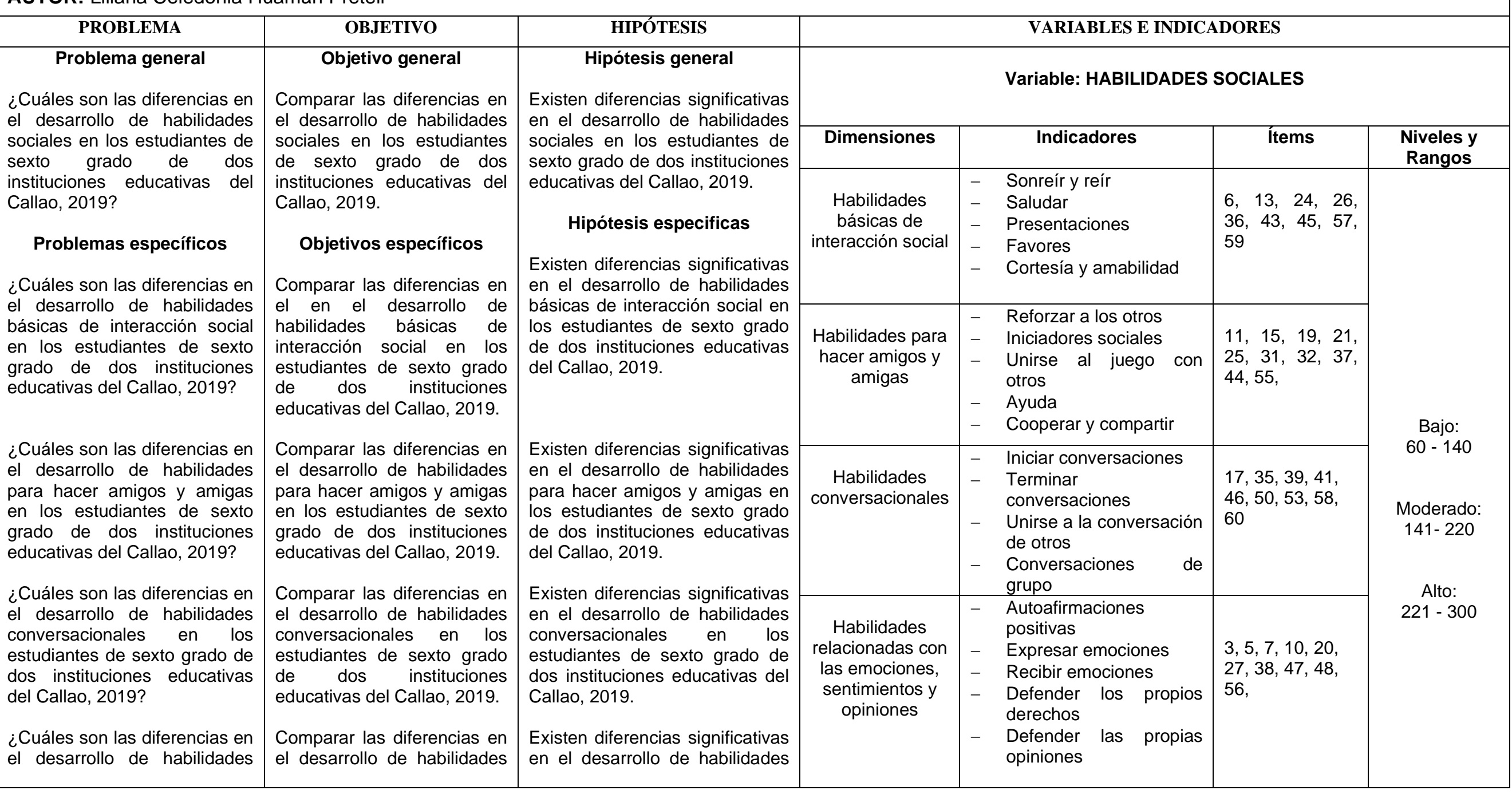




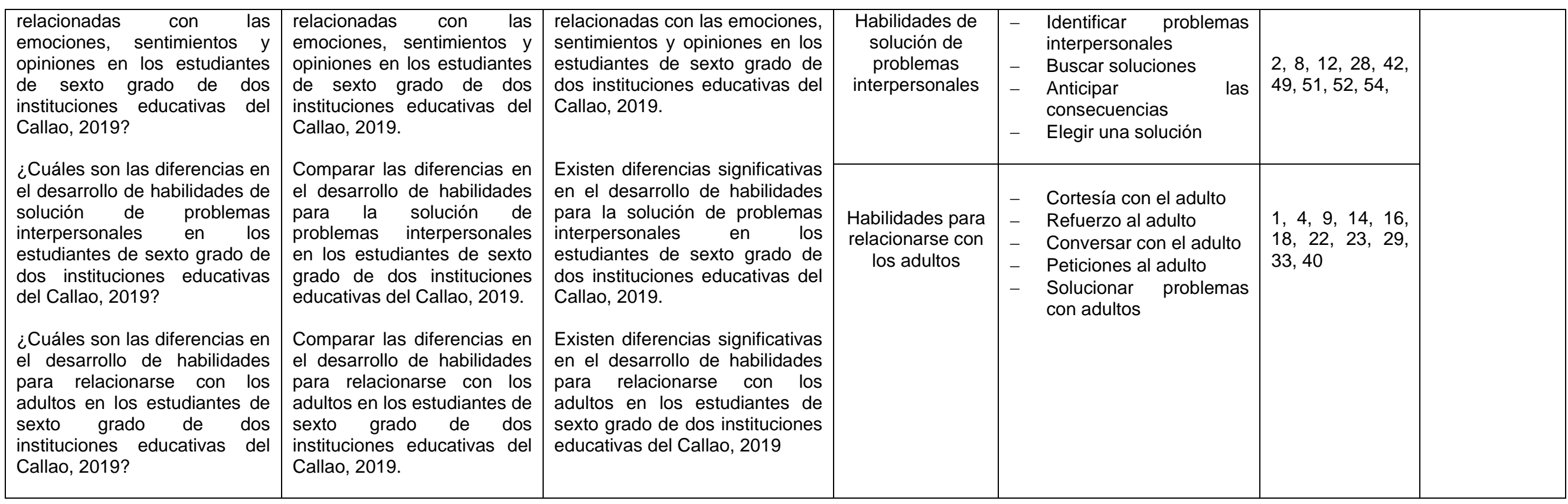

\begin{tabular}{|c|c|c|c|}
\hline $\begin{array}{l}\text { Tipo y diseño de } \\
\text { investigación }\end{array}$ & Población y muestra & Técnicas e instrumentos & Estadística a utilizar \\
\hline $\begin{array}{l}\text { Tipo: } \\
\text { Investigación básica } \\
\text { Nivel: } \\
\text { Descriptivo comparativa } \\
\text { Diseño: } \\
\text { No experimental } \\
\text { transversal }\end{array}$ & $\begin{array}{l}\text { Población: } \\
96 \text { estudiantes } \\
\text { Tipo de muestreo: } \\
\text { Censal } \\
\text { Tamaño de la muestra: } \\
96 \text { estudiantes del sexto } \\
\text { grado de primaria }\end{array}$ & $\begin{array}{l}\text { Variable: Habilidades sociales } \\
\text { Técnica: encuesta } \\
\text { Instrumento: Cuestionario de Habilidades de Interacción } \\
\text { Social } \\
\text { - Autora: Monjas (España, 1994) } \\
\text { - } \text { Estructura: } 60 \text { ítems } \\
\text { - } \\
\quad \text { Palificación: Nunca ( } 1 \text { punto), Casi nunca ( } 2 \\
\quad \text { (4 puntos), bastantes veces ( } 3 \text { puntos (siempre) }\end{array}$ & $\begin{array}{l}\text { Estadística descriptiva } \\
\text { Según Monje (2011), el concepto } \\
\text { central en estadística descriptiva es la } \\
\text { distribución de frecuencias, por lo que } \\
\text { los datos son tratados, y se les } \\
\text { presenta por medio de tablas y figuras. } \\
\text { Estadística inferencial } \\
\text { De acuerdo con Fiallo et al (2016), la } \\
\text { prueba de hipótesis es uno de los } \\
\text { principales procedimientos de la } \\
\text { estadística inferencial. }\end{array}$ \\
\hline
\end{tabular}




\section{CUESTIONARIO DE HABILIADES DE INTERACCIÓN SOCIAL (Versión autoinforme) \\ (Monjas, 1994)}

Nombre

Apellidos

I.E.:

Sexo:

Fecha:

\section{INSTRUCCIONES:}

Por favor, lee cuidadosamente cada enunciado y rodea con un circulo el número que mejor describa el funcionamiento interpersonal del niño, niña o adolescente, teniendo en cuenta las siguientes calificaciones:

1. Significa que el niño, niña o adolescente no hace la conducta nunca.

2. Significa que el niño, niña o adolescente no hace la conducta casi nunca.

3. Significa que el niño, niña o adolescente hace la conducta bastantes veces.

4. Significa que el niño, niña o adolescente hace la conducta casi siempre.

5. Significa que el niño, niña o adolescente hace la conducta siempre.

\begin{tabular}{|c|c|c|c|c|c|c|}
\hline $\begin{array}{l}\text { Sub- } \\
\text { escala }\end{array}$ & ítems & Nunca & $\begin{array}{c}\text { Casi } \\
\text { nunca }\end{array}$ & $\begin{array}{l}\text { Bastantes } \\
\text { veces }\end{array}$ & $\begin{array}{l}\text { Casi } \\
\text { siempre }\end{array}$ & Siempre \\
\hline (6) & $\begin{array}{l}\text { 1. Soluciono por mí mismo/a los conflictos } \\
\text { que se me plantean con las personas adultas. }\end{array}$ & 1 & 2 & 3 & 4 & 5 \\
\hline (5) & $\begin{array}{l}\text { 2. Cuando tengo un problema con otros } \\
\text { niños y niñas, después de poner en práctica } \\
\text { la solución elegida, evalúo los resultados } \\
\text { obtenidos. }\end{array}$ & 1 & 2 & 3 & 4 & 5 \\
\hline (4) & 3. Me digo a mí mismo/a cosas positivas. & 1 & 2 & 3 & 4 & 5 \\
\hline (6) & $\begin{array}{l}\text { 4. Alabo y digo cosas positivas y agradables } \\
\text { a las personas adultas. }\end{array}$ & 1 & 2 & 3 & 4 & 5 \\
\hline$(4)$ & $\begin{array}{l}\text { 5. Defiendo y reclamo mis derechos ante las } \\
\text { y los demás. }\end{array}$ & 1 & 2 & 3 & 4 & 5 \\
\hline (1) & $\begin{array}{l}\text { 6. Saludo de modo adecuado a otras } \\
\text { personas. }\end{array}$ & 1 & 2 & 3 & 4 & 5 \\
\hline (4) & $\begin{array}{l}\text { 7. Expreso y defiendo adecuadamente mis } \\
\text { opiniones. }\end{array}$ & 1 & 2 & 3 & 4 & 5 \\
\hline (5) & $\begin{array}{l}\text { 8. Ante un problema con otros niños y niñas, } \\
\text { elijo una solución efectiva y justa para las } \\
\text { personas implicadas. }\end{array}$ & 1 & 2 & 3 & 4 & 5 \\
\hline (6) & $\begin{array}{l}\text { 9. Respondo correctamente a las peticiones y } \\
\text { sugerencias de las personas adultas. }\end{array}$ & 1 & 2 & 3 & 4 & 5 \\
\hline (4) & $\begin{array}{l}\text { 10. Respondo adecuadamente a las } \\
\text { emociones y sentimientos agradables y } \\
\text { positivos de los y las demás (felicitaciones, }\end{array}$ & 1 & 2 & 3 & 4 & 5 \\
\hline
\end{tabular}




\begin{tabular}{|c|c|c|c|c|c|c|}
\hline & alegría, ...) & & & & & \\
\hline (2) & $\begin{array}{l}\text { 11. Ayudo a otros niños y niñas en distintas } \\
\text { ocasiones. }\end{array}$ & 1 & 2 & 3 & 4 & 5 \\
\hline (5) & $\begin{array}{l}\text { 12. Cuando tengo un problema con otros } \\
\text { niños y niñas, me pongo en su lugar y busco } \\
\text { soluciones. }\end{array}$ & 1 & 2 & 3 & 4 & 5 \\
\hline (1) & $\begin{array}{l}\text { 13. Me río con otras personas cuando es } \\
\text { oportuno. }\end{array}$ & 1 & 2 & 3 & 4 & 5 \\
\hline (6) & $\begin{array}{l}\text { 14. Cuando tengo un problema con una } \\
\text { persona adulta, me pongo en su lugar y trato } \\
\text { de solucionarlo. }\end{array}$ & 1 & 2 & 3 & 4 & 5 \\
\hline (2) & $\begin{array}{l}\text { 15. Pido favores a otras personas cuando } \\
\text { necesito algo. }\end{array}$ & 1 & 2 & 3 & 4 & 5 \\
\hline (6) & $\begin{array}{l}\text { 16. Inicio y termino conversaciones con } \\
\text { personas adultas. }\end{array}$ & 1 & 2 & 3 & 4 & 5 \\
\hline (3) & $\begin{array}{l}\text { 17. Respondo adecuadamente cuando las } \\
\text { personas con las que estoy hablando quieren } \\
\text { terminar la conversación. }\end{array}$ & 1 & 2 & 3 & 4 & 5 \\
\hline (6) & $\begin{array}{l}\text { 18. Respondo correctamente cuando las } \\
\text { personas adultas se dirigen a mí de modo } \\
\text { amable y educado. }\end{array}$ & 1 & 2 & 3 & 4 & 5 \\
\hline (2) & $\begin{array}{l}\text { 19. Hago alabanzas y digo cosas positivas a } \\
\text { otros niños y niñas. }\end{array}$ & 1 & 2 & 3 & 4 & 5 \\
\hline (4) & $\begin{array}{l}\text { 20. Respondo adecuadamente a las } \\
\text { emociones y sentimientos desagradables y } \\
\text { negativos de los y las demás (críticas, } \\
\text { enfado, tristeza, ...) }\end{array}$ & 1 & 2 & 3 & 4 & 5 \\
\hline (2) & $\begin{array}{l}\text { 21. Respondo de modo apropiado cuando } \\
\text { otros niños y niñas quieren unirse conmigo a } \\
\text { jugar o a realizar una actividad. }\end{array}$ & 1 & 2 & 3 & 4 & 5 \\
\hline (6) & $\begin{array}{l}\text { 22. Respondo adecuadamente cuando otras } \\
\text { personas me saludan. }\end{array}$ & 1 & 2 & 3 & 4 & 5 \\
\hline (6) & $\begin{array}{l}\text { 23. Cuando me relaciono con las personas } \\
\text { adultas, soy cortés y educado/a. }\end{array}$ & 1 & 2 & 3 & 4 & 5 \\
\hline (1) & $\begin{array}{l}\text { 24. Pido favores a otras personas cuando } \\
\text { necesito algo. }\end{array}$ & 1 & 2 & 3 & 4 & 5 \\
\hline (2) & $\begin{array}{l}\text { 25. Coopero con otros niños y niñas en } \\
\text { diversas actividades y juegos (participo, } \\
\text { animo, doy sugerencias, etc.) }\end{array}$ & 1 & 2 & 3 & 4 & 5 \\
\hline (1) & $\begin{array}{l}\text { 26. Sonrío a las demás personas en } \\
\text { situaciones adecuadas. }\end{array}$ & 1 & 2 & 3 & 4 & 5 \\
\hline
\end{tabular}




\begin{tabular}{|c|c|c|c|c|c|c|}
\hline (4) & $\begin{array}{l}\text { 27. Expreso adecuadamente a las demás } \\
\text { personas mis emociones y sentimientos } \\
\text { agradables y positivos (felicidad, placer, } \\
\text { alegría ...) }\end{array}$ & 1 & 2 & 3 & 4 & 5 \\
\hline (5) & $\begin{array}{l}\text { 28. Cuando tengo un conflicto con otros } \\
\text { niños y niñas, preparo cómo voy a poner en } \\
\text { práctica la solución elegida. }\end{array}$ & 1 & 2 & 3 & 4 & 5 \\
\hline (6) & $\begin{array}{l}\text { 29. Hago peticiones, sugerencias y quejas a } \\
\text { las personas adultas. }\end{array}$ & 1 & 2 & 3 & 4 & 5 \\
\hline (5) & $\begin{array}{l}\text { 30. Cuando tengo un problema con otros } \\
\text { niños y niñas, pienso en las consecuencias } \\
\text { de lo hagan los demás para solucionarlo. }\end{array}$ & 1 & 2 & 3 & 4 & 5 \\
\hline (2) & $\begin{array}{l}\text { 31. Respondo adecuadamente cuando otras } \\
\text { personas me hacen alabanzas, elogios y } \\
\text { cumplidos. }\end{array}$ & 1 & 2 & 3 & 4 & 5 \\
\hline (2) & $\begin{array}{l}\text { 32. Comparto mis cosas con los otros niños } \\
\text { y niñas. }\end{array}$ & 1 & 2 & 3 & 4 & 5 \\
\hline (6) & $\begin{array}{l}\text { 33. Tengo conversaciones con las personas } \\
\text { adultas. }\end{array}$ & 1 & 2 & 3 & 4 & 5 \\
\hline (3) & $\begin{array}{l}\text { 34. Cuando hablo con otra persona, escucho } \\
\text { lo que me dice, respondo a lo que me } \\
\text { pregunta y digo lo que yo pienso y siento. }\end{array}$ & 1 & 2 & 3 & 4 & 5 \\
\hline (3) & $\begin{array}{l}\text { 35. Cuando charlo con otros niños y niñas, } \\
\text { termino la conversación de modo adecuado. }\end{array}$ & 1 & 2 & 3 & 4 & 5 \\
\hline (1) & $\begin{array}{l}\text { 36. Respondo adecuadamente cuando otros } \\
\text { niños y niñas se dirigen a mí de modo } \\
\text { amable y educado. }\end{array}$ & 1 & 2 & 3 & 4 & 5 \\
\hline (2) & $\begin{array}{l}\text { 37. Me junto con otros niños y niñas que } \\
\text { están jugando o realizando una actividad. }\end{array}$ & 1 & 2 & 3 & 4 & 5 \\
\hline (4) & $\begin{array}{l}\text { 38. Expreso adecuadamente a las demás } \\
\text { personas mis emociones y sentimientos } \\
\text { desagradables y negativos (tristeza, enfado, } \\
\text { fracaso ...) }\end{array}$ & 1 & 2 & 3 & 4 & 5 \\
\hline (3) & $\begin{array}{l}\text { 39. Respondo adecuadamente cuando otros } \\
\text { niños y niñas quieren entrar en nuestra } \\
\text { conversación. }\end{array}$ & 1 & 2 & 3 & 4 & 5 \\
\hline (6) & $\begin{array}{l}\text { 40. Soy sincero/a cuando alabo y elogio a las } \\
\text { personas adultas. }\end{array}$ & 1 & 2 & 3 & 4 & 5 \\
\hline (3) & $\begin{array}{l}\text { 41. Respondo adecuadamente cuando otros } \\
\text { niños y niñas quieren entrar en nuestra } \\
\text { conversación }\end{array}$ & 1 & 2 & 3 & 4 & 5 \\
\hline (5) & $\begin{array}{l}\text { 42. Cuando quiero solucionar un problema } \\
\text { que tengo con otros niños y niñas, trato de }\end{array}$ & 1 & 2 & 3 & 4 & 5 \\
\hline
\end{tabular}




\begin{tabular}{|c|c|c|c|c|c|c|}
\hline & elegir la mejor solución. & & & & & \\
\hline (1) & $\begin{array}{l}\text { 43. Me presento ante otras personas cuando } \\
\text { es necesario. }\end{array}$ & 1 & 2 & 3 & 4 & 5 \\
\hline (2) & $\begin{array}{l}\text { 44. Respondo de modo apropiado cuando } \\
\text { otros niños y niñas quieren unirse conmigo a } \\
\text { jugar o a realizar una actividad. }\end{array}$ & 1 & 2 & 3 & 4 & 5 \\
\hline (1) & $\begin{array}{l}\text { 45. Hago favores a otras personas en } \\
\text { distintas ocasiones. }\end{array}$ & 1 & 2 & 3 & 4 & 5 \\
\hline (3) & $\begin{array}{l}\text { 46. Me uno a la conversación que tienen } \\
\text { otros niños y niñas. }\end{array}$ & 1 & 2 & 3 & 4 & 5 \\
\hline (4) & $\begin{array}{l}\text { 47. Respondo adecuadamente cuando otras } \\
\text { personas defienden sus derechos. }\end{array}$ & 1 & 2 & 3 & 4 & 5 \\
\hline (4) & $\begin{array}{l}\text { 48. Expreso desacuerdo con otras personas } \\
\text { cuando es oportuno. }\end{array}$ & 1 & 2 & 3 & 4 & 5 \\
\hline (5) & $\begin{array}{l}\text { 49. Cuando tengo un problema con otros } \\
\text { niños y niñas, trato de buscar las causas que } \\
\text { lo motivaron. }\end{array}$ & 1 & 2 & 3 & 4 & 5 \\
\hline (3) & $\begin{array}{l}\text { 50. Cuando tengo una conversación con } \\
\text { otras personas participo activamente } \\
\text { (cambio de tema, intervengo en la } \\
\text { conversación, etc.) }\end{array}$ & 1 & 2 & 3 & 4 & 5 \\
\hline (5) & $\begin{array}{l}\text { 51. Identifico los problemas que me surgen } \\
\text { cuando me relaciono con otros niños y niñas. }\end{array}$ & 1 & 2 & 3 & 4 & 5 \\
\hline (5) & $\begin{array}{l}\text { 52. Ante un problema con otros niños y } \\
\text { niñas, busco muchas soluciones. }\end{array}$ & 1 & 2 & 3 & 4 & 5 \\
\hline (3) & $\begin{array}{l}\text { 53. Inicio conversaciones con otros niños y } \\
\text { niñas. }\end{array}$ & 1 & 2 & 3 & 4 & 5 \\
\hline (5) & $\begin{array}{l}\text { 54. Cuando tengo un problema con otros } \\
\text { niños y niñas, pienso en las consecuencias } \\
\text { de lo que puedo hacer para solucionarlo. }\end{array}$ & 1 & 2 & 3 & 4 & 5 \\
\hline (2) & $\begin{array}{l}\text { 55. Inicio juegos y otras actividades con } \\
\text { otros niños y niñas }\end{array}$ & 1 & 2 & 3 & 4 & 5 \\
\hline (4) & $\begin{array}{l}56 \text {. Expreso cosas positivas de mí mismo/a } \\
\text { ante otras personas. }\end{array}$ & 1 & 2 & 3 & 4 & 5 \\
\hline (1) & $\begin{array}{l}\text { 57. Presento a otras personas que no se } \\
\text { conocen entre sí. }\end{array}$ & 1 & 2 & 3 & 4 & 5 \\
\hline (3) & $\begin{array}{l}\text { 58. Cuando hablo con un grupo de niños y } \\
\text { niñas, participo de acuerdo a las normas } \\
\text { establecidas. }\end{array}$ & 1 & 2 & 3 & 4 & 5 \\
\hline (1) & $\begin{array}{l}\text { 59. Cuando me relaciono con otros niños y } \\
\text { niñas, pido las cosas por favor, digo gracias, }\end{array}$ & 1 & 2 & 3 & 4 & 5 \\
\hline
\end{tabular}




\begin{tabular}{|l|l|c|c|c|c|c|}
\hline & me disculpo, etc. & & & & & \\
\hline$(3)$ & $\begin{array}{l}\text { 60. Cuando tengo una conversación en } \\
\text { grupo, intervengo cuando es necesario y lo } \\
\text { hago de modo correcto. }\end{array}$ & 1 & 2 & 3 & 4 & 5 \\
\hline
\end{tabular}

\begin{tabular}{|r|l|l|l|l|l|l|l|}
\cline { 2 - 6 } & Subesc. 1 & Subesc. 2 & Subesc. 3 & Subesc. 4 & Subesc. 5 & Subesc. 6 & $\begin{array}{c}\text { Puntuación } \\
\text { Final }\end{array}$ \\
\hline Puntuación directa & & & & & & & \\
\hline Puntuación típica & & & & & & & \\
\hline Percentil & & & & & & & \\
\hline
\end{tabular}

COMENTARIOS Y OBSERVACIONES 


\section{Anexo $3 \quad$ : $\quad$ Certificados de validez}

\section{Juicio de expertos 1.}

ANEXO 04

CERTIFICADO DE VALIDEZ DE CONTENIDO DEL INSTRUMENTO QUE MIDE LAS HABILIDADES SOCIALES.

\begin{tabular}{|c|c|c|c|c|c|c|c|c|}
\hline \multirow[t]{2}{*}{$\mathrm{N}^{\circ}$} & \multirow[t]{2}{*}{ DIMENSIONES / items } & \multicolumn{2}{|c|}{ Pertinencia' } & \multicolumn{2}{|c|}{ Relevancia ${ }^{2}$} & \multicolumn{2}{|c|}{ Claridad $^{3}$} & \multirow{2}{*}{ Sugerencias } \\
\hline & & Si & No & $\mathrm{Si}$ & No & Si & No & \\
\hline & DIMENSIÓN 1: HABILIDADES BÁSICAS DE INTERACCIÓN SOCIAL & & & & & & & \\
\hline 1 & Saludo de modo adecuado a otras personas. & $\checkmark$ & & 5 & & 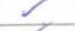 & & \\
\hline 2 & Me río con otras personas cuando es oportuno. & 5 & & 2 & & $\Omega$ & & \\
\hline 3 & Pido favores a otras personas cuando necesito algo. & 5 & & 2 & & $\checkmark$ & & \\
\hline 4 & Sonrío a las demás personas en situaciones adecuadas. & 1 & & 2 & & & & \\
\hline 5 & $\begin{array}{l}\text { Respondo adecuadamente cuando otros niños y niñas se dirigen a mí } \\
\text { de modo amable y educado. }\end{array}$ & $\checkmark$ & & $\checkmark$ & & & & \\
\hline 6 & Me presento ante otras personas cuando es necesario. & 2 & & 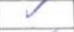 & & 4 & & \\
\hline 7 & Hago favores a otras personas en distintas ocasiones. & 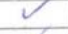 & & $\checkmark$ & & $\checkmark$ & & \\
\hline 8 & Presento a otras personas que no se conocen entre sí. & $\checkmark$ & & $\checkmark$ & & 2 & & \\
\hline \multirow[t]{2}{*}{9} & $\begin{array}{l}\text { Cuando me relaciono con otros nif̃os y niñas, pido las cosas por favor, } \\
\text { digo gracias, me disculpo, etc. }\end{array}$ & $\checkmark$ & & $\checkmark$ & & & & \\
\hline & DIMENSIOON 2: HABILIDADES PARA HACER AMIGOS Y AMIGAS & & & & & & & \\
\hline 10 & Ayudo a otros niños y niñas en distintas ocasiones. & $\checkmark$ & & 8 & & I & & \\
\hline 11 & Pido ayuda a otras personas cuando lo necesito. & $J$ & & $\checkmark$ & & & & \\
\hline 12 & Hago alabanzas y digo cosas positivas a otros niños y niñas. & $\checkmark$ & & $c$ & & & & \\
\hline 13 & $\begin{array}{l}\text { Coopero con otros niños y niñas en diversas actividades y juegos } \\
\text { (participo, animo, doy sugerencias, etc.) }\end{array}$ & $\checkmark$ & & & & & & \\
\hline 14 & $\begin{array}{l}\text { Respondo adecuadamente cuando otras personas me hacen } \\
\text { alabanzas, elogios y cumplidos. }\end{array}$ & $\checkmark$ & & $\checkmark$ & & & & \\
\hline 15 & Comparto mis cosas con los otros niños y niñas. & $\checkmark$ & & $\checkmark$ & & $\checkmark$ & & \\
\hline 16 & $\begin{array}{l}\text { Me junto con otros niños y niñas que están jugando o realizando una } \\
\text { actividad. }\end{array}$ & 2 & & $\checkmark$ & & & & \\
\hline 17 & $\begin{array}{l}\text { Respondo de modo aproplado cuando otros niños y niñas quieren } \\
\text { unirse conmigo a jugar o a realizar una actividad. }\end{array}$ & $\checkmark$ & & $\checkmark$ & & & & \\
\hline 18 & Inicio juegos y otras actividades con otros niños y niñas & $\checkmark$ & & $\checkmark$ & & $\gamma$ & & \\
\hline
\end{tabular}

DIMENSIÓN 3: HABILIDADES CONVERSACIONALES

19 Respondo adecuadamente cuando las personas con las que estoy

hablando quieren terminar la conversación.

20 Cuando hablo con otra persona, escucho lo que me dice, respondo lo que me pregunta y digo lo que yo pienso y siento.

21 Cuando charlo con otros niños y niñas, termino la conversación de modo adecuado.

22 Respondo adecuadamente cuando otros niños y niñas quieren entrar en nuestra conversación.

23 Respondo adecuadamente cuando otros niños y niñas quieren iniciar una conversación conmigo.

24 Me uno a la conversación que tienen otros niños y niñas.

25 Me uno a la conversación que tienen otros niños y niñas.

26 Cuando tengo una conversación con otras personas participo activamente (cambio de tema, intervengo en la conversación, etc.)

27 Inicio conversaciones con otros niños y niñas.

28 Cuando hablo con un grupo de niños y niñas, participo de acuerdo a las normas establecidas.

29 Cuando tengo una conversación en grupo, intervengo cuando es necesario y lo hago de modo correcto. DIMENSIÓN 4: HABILIDADES RELACIONADAS CON LOS SENTIMIENTOS, EMOCIONES Y OPINIONES.

30 Me digo a mi mismo/a cosas positivas.

31 Defiendo y reclamo mis derechos ante las y los demás.

32 Expreso y defiendo adecuadamente mis opiniones.

33 Respondo adecuadamente a las emociones y sentimientos agradables y positivos de los y las demás (felicitaciones, alegría, ...)

34 Respondo adecuadamente a las emociones y sentimientos desagradables y negativos de los y las demás (críticas, enfado, tristeza, ...)

35 Expreso adecuadamente a las demás personas mis emociones y sentimientos agradables y positivos (felicidad, placer, alegría ....

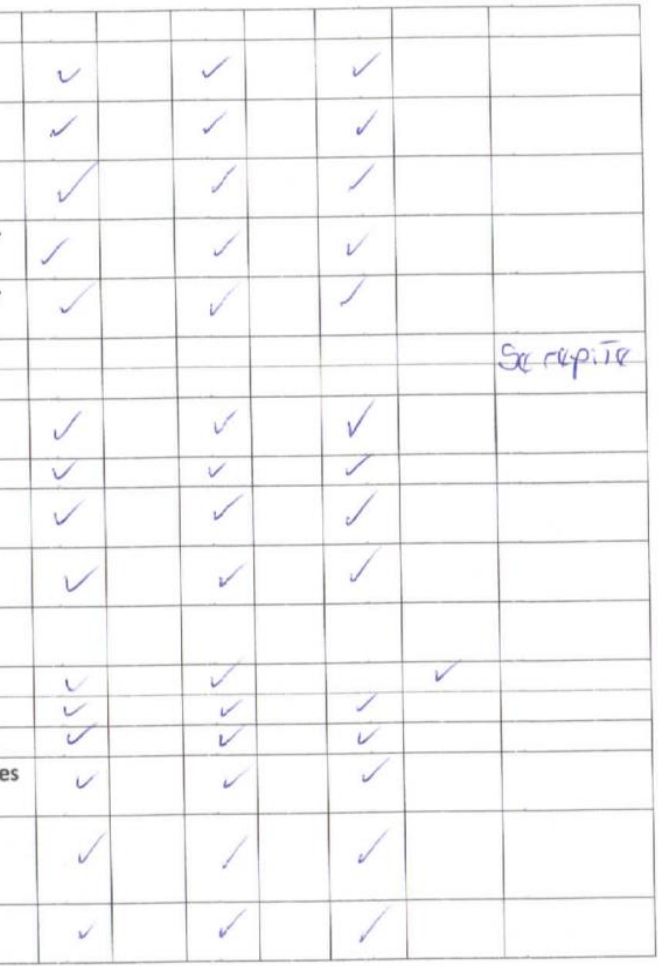


36 Expreso adecuadamente a las demás personas mis emociones y sentimientos desagradables y negativos (tristeza, enfado, fracaso ...)

37 Respondo adecuadamente cuando otras personas defienden sus derechos.

38 Expreso desacuerdo con otras personas cuando es oportuno.

39 Expreso cosas positivas de mí mismo/a ante otras personas. DIMENSIÓN 5: HABILIDADES DE SOLUCIÓN DE PROBLEMAS INTERPERSONALES.

40 Cuando tengo un problema con otros nifíos y niñas, después de poner en práctica la solución elegida, evalúo los resultados obtenidos.

41 Ante un problema con otros niños y niñas, elijo una solución efectiva y justa para las personas implicadas.

42 Cuando tengo un problema con otros niños y niñas, me pongo en su lugar $y$ busco soluciones.

43 Cuando tengo un conflicto con otros niños y niñas, preparo cómo voy a poner en práctica la solución elegida.

44 Cuando tengo un problema con otros niños y niñas, pienso en las consecuencias de lo que puedo hacer para solucionarlo.

45 Cuando quiero solucionar un problema que tengo con otros niños y niñas, trato de elegir la mejor solución

46 Cuando tengo un problema con otros niños y niñas, trato de buscar las causas que lo motivaron.

47 Identifico los problemas que me surgen cuando me relaciono con otros niños y niñas.

48 Ante un problema con otros niños y niñas, busco muchas soluciones.

49 Cuando tengo un problema con otros niños $y$ niñas, pienso en las consecuencias de lo hagan los demás para solucionarlo. DIMENSIÓN 6: HABILIDADES DE RELACIÓN CON LOS ADULTOS

50 Soluciono por mí mismo/a los conflictos que se me plantean con las personas adultas.

51 Alabo y digo cosas positivas y agradables a las personas adultas.

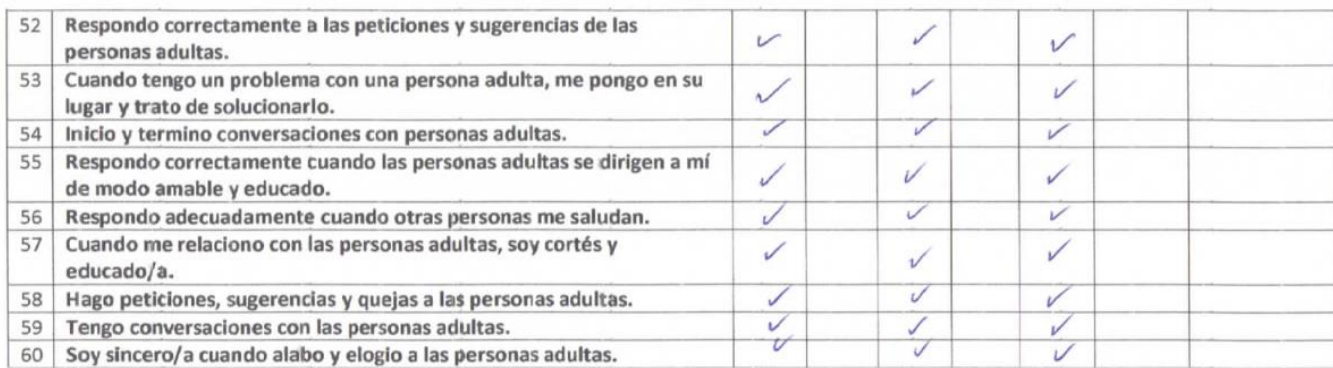

Observaciones (precisar si hay suficiencia): SUFiEIENGIA

Opinión de aplicabilidad : Aplicable $(X)$

Apellidos y nombres del juez evaluador BELLID G GAR EIA ROBERTO ... DN1.0888 3139

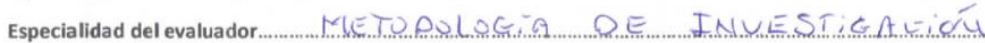

Pertinencia: El ítem corresponde al concepto teórico formulado.

Relevancia: El item es apropiado para representar al componente o dimensión específica del constructo.

Claridad: Se entiende sin dificultad alguna el enunciado cel item, es conciso, es exacto y directo.

Nota: Suficiencia, se dice suficiencia cuando los items planteados son suficientes para medir. 
Juicio de expertos 2.

ANEXO 04

CERTIFICADO DE VALIDEZ DE CONTENIDO DEL INSTRUMENTO QUE MIDE LAS HABILIDADES SOCIALES.

\begin{tabular}{|c|c|c|c|c|c|c|c|c|}
\hline \multirow[t]{3}{*}{$\mathbf{N}^{\bullet}$} & \multirow[t]{2}{*}{ DIMENSIONES / items } & \multicolumn{2}{|c|}{ Pertinencia' } & \multicolumn{2}{|c|}{ Relevancia ${ }^{2}$} & \multicolumn{2}{|c|}{ Claridad $^{3}$} & \multirow{2}{*}{ Sugerencias } \\
\hline & & Si & No & $\mathrm{Si}$ & No & $\mathrm{Si}$ & No & \\
\hline & DIMENSIÓN 1: HABILIDADES BÁSICAS DE INTERACCIÓN SOCIAL & & & & & & & \\
\hline 1 & Saludo de modo adecuado a otras personas. & $\sqrt{ }$ & & $\sqrt{ }$ & & $\sqrt{ }$ & & \\
\hline 2 & Me río con otras personas cuando es oportuno. & $\sqrt{ }$ & & $\sqrt{ }$ & & $\sqrt{ }$ & & \\
\hline 3 & Respondo adecuadamente cuando otros me saludan. & $\sqrt{ }$ & & $\sqrt{ }$ & & $\sqrt{ }$ & & \\
\hline 4 & Pido favores a otras personas cuando necesito algo. & $\sqrt{ }$ & & $\sqrt{ }$ & & $\sqrt{ }$ & & \\
\hline 5 & Sonrío a las demás personas en situaciones adecuadas. & $\sqrt{ }$ & & $\sqrt{ }$ & & $\sqrt{ }$ & & \\
\hline 6 & $\begin{array}{l}\text { Respondo adecuadamente cuando otros niños y niñas se dirigen a mí } \\
\text { de modo amable y educado. }\end{array}$ & $\sqrt{ }$ & & $\sqrt{ }$ & & $\sqrt{ }$ & & \\
\hline 7 & Me presento ante otras personas cuando es necesario. & $\checkmark$ & & $\sqrt{ }$ & & $\sqrt{ }$ & & \\
\hline 8 & Hago favores a otras personas en distintas ocasiones. & $\sqrt{ }$ & & $\sqrt{ }$ & & $\sqrt{ }$ & & \\
\hline 9 & Presento a otras personas que no se conocen entre si. & $\sqrt{ }$ & & $\sqrt{ }$ & & $\sqrt{ }$ & & \\
\hline \multirow[t]{2}{*}{10} & $\begin{array}{l}\text { Cuando me relaciono con otros niños y niñas, pido las cosas por favor, } \\
\text { digo gracias, me disculpo, etc. }\end{array}$ & $\sqrt{ }$ & & $\sqrt{ }$ & & $\sqrt{ }$ & & \\
\hline & DIMENSIÓN 2: HABILIDADES PARA HACER AMIGOS Y AMIGAS & $\sqrt{ }$ & & $\sqrt{ }$ & & $\checkmark$ & & \\
\hline 11 & Ayudo a otros niños y niñas en distintas ocasiones. & $\sqrt{ }$ & & $\sqrt{ }$ & & $\sqrt{ }$ & & \\
\hline 12 & Pido ayuda a otras personas cuando lo necesito. & $\sqrt{ }$ & & $\sqrt{ }$ & & $\sqrt{ }$ & & \\
\hline 13 & Hago alabanzas y digo cosas positivas a otros niños y niñas. & $\sqrt{ }$ & & $\sqrt{ }$ & & $\sqrt{ }$ & & \\
\hline 14 & $\begin{array}{l}\text { Respondo correctamente cuando otro niño o nifia me pide que juegue } \\
\text { o realice alguna actividad con él o ella. }\end{array}$ & $\sqrt{ }$ & & $\sqrt{ }$ & & $\sqrt{ }$ & & \\
\hline 15 & $\begin{array}{l}\text { Coopero con otros niños y niñas en diversas actividades y juegos } \\
\text { (participo, animo, doy sugerencias, etc.) }\end{array}$ & $\sqrt{ }$ & & $\sqrt{ }$ & & $\sqrt{ }$ & & \\
\hline 16 & $\begin{array}{l}\text { Respondo adecuadamente cuando otras personas me hacen } \\
\text { alabanzas, elogios y cumplidos. }\end{array}$ & $\sqrt{ }$ & & $\sqrt{ }$ & & $\sqrt{ }$ & & \\
\hline 17 & Comparto mis cosas con los otros niños y niñas. & $\sqrt{ }$ & & $\sqrt{ }$ & & $\sqrt{ }$ & & \\
\hline 18 & $\begin{array}{l}\text { Me junto con otros niños y niñas que están jugando o realizando una } \\
\text { actividad. }\end{array}$ & $\sqrt{ }$ & & $\sqrt{ }$ & & $\sqrt{ }$ & & \\
\hline
\end{tabular}

19 Respondo de modo apropiado cuando otros niños y niñas quieren unirse conmigo a jugar 0 a realizar una actividad.

20 Inicio juegos y otras actividades con otros niños y niñas DIMENSIÓN 3: HABILIDADES CONVERSACIONALES

21 Me doy cuenta y respondo adecuadamente cuando la persona con quien hablo quiere terminar la conversación

22 Cuando hablo con otra persona, escucho lo que me dice, respondo a su pregunta y digo lo que yo pienso y siento.

23 Cuando charlo con otros niños y niñas, termino la conversación de manera adecuada.

24 Respondo adecuadamente cuando otros niños y niñas quieren participar en mi conversación con otras personas.

25 Respondo adecuadamente cuando otros niños y niñas quieren inicia una conversación conmigo.

26 Me uno adecuadamente a la conversación que tienen otros niños y niñas

27 Cuando converso con otras personas participo activamente (cambio de tema, intervengo en la conversación, etc.)

28 Inicio conversaciones con diferentes niños y niñas.

29 Cuando hablo con un grupo de niños y niñas, participo de acuerdo las normas establecidas.

30 Cuando tengo una conversación en grupo, intervengo cuando es necesario y lo hago de modo correcto. DIMENSIÓN 4: HABILIDADES RELACIONADAS CON LOS SENTIMIENTOS, EMOCIONES Y OPINIONES.

31 Me digo a mi mismo(a) cosas positivas.

32 Defiendo y reclamo mis derechos ante las y los demás.

33 Expreso y defiendo adecuadamente mis opiniones.

34 Respondo adecuadamente a las emociones y sentimientos positivos de las demás personas (felicitaciones, alegría, ...)

35 Respondo adecuadamente a las emociones y sentimientos negativos de las demás personas (críticas, enfado, tristeza, ...)

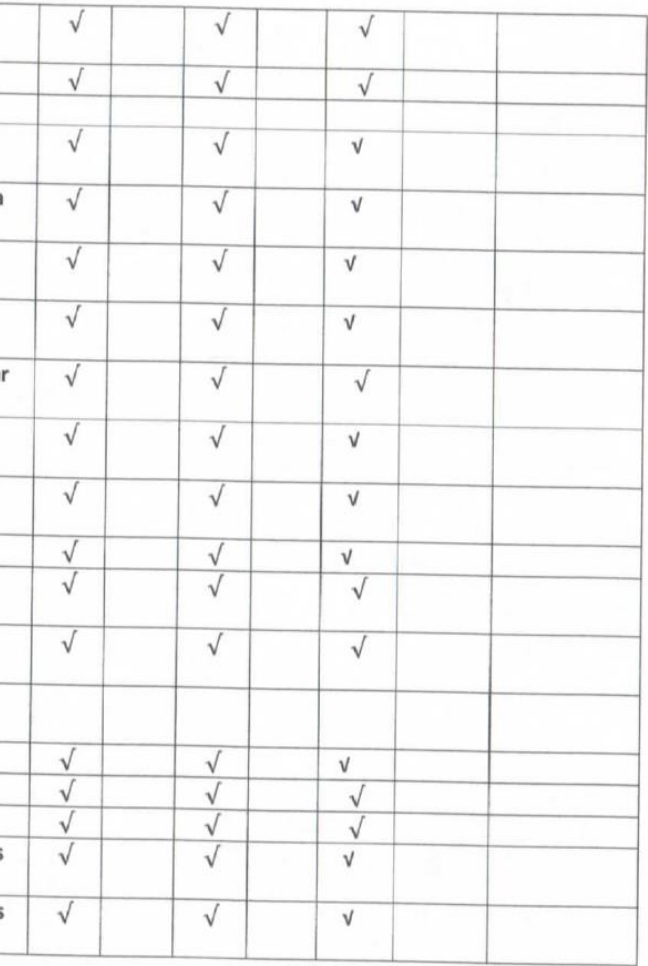


36 Expreso adecuadamente a las demás personas mis emociones y sentimientos positivos (felicidad, placer, alegria ...)

Expreso adecuadamente a las demás personas mis emociones y

sentimientos negativos (tristeza, enfado, fracaso ....

38 Respondo adecuadamente cuando otras personas defienden sus

39 Expreso mi desacuerdo con otras personas cuando es oportuno.

40 Expreso cosas positivas de mí mismo(a) ante otras personas. DIMENSIÓN 5: HABILIDADES DE SOLUCIÓN DE PROBLEMAS INTERPERSONALES.

41 Cuando tengo un problema con otros niños y niñas, después de poner en práctica la solución elegida, evalúo los resultados obtenidos.

22 Ante un problema con otros niños y niñas, elijo una solución efectiva y justa para las personas implicadas.

Cuando tengo un problema con otros niños y niñas, me pongo en si lugar y busco soluciones.

44 Cuando tengo un conflicto con otros niños y niñas, preparo çmo voy a poner en práctica la solución elegida.

45 Cuando tengo un pr. pueden hacer los demblema con otros niños y nifas, pienso en lo que

46 Cuando quiro solucios para solucionario y evaluo las consecuencias. niñas, trato Cuas, trato de elegir la mejor solución

47 Cuando tengo un problema con otros niños y niñas, trato de buscar las causas que lo motivaron.

48 Identifico que problemas tengo cuando me relaciono con otros nif̄os $y$ niñas.

49 Ante un problema con otros niగ̄os y niñas, busco muchas soluciones.

50 Cuando tengo un problema con otros niños y niñas, pienso en los que puedo hacer para solucionarlo y evalúo las consecuencias.

51 SOLENSION 6: HABILIDADES DE RELACIÓN CON LOS ADULTOS

51 Soluciono por mí mismo(a) los conflictos que se me presentan con las personas adultas.

52 Alabo y digo cosas positivas y agradables a las personas adultas.

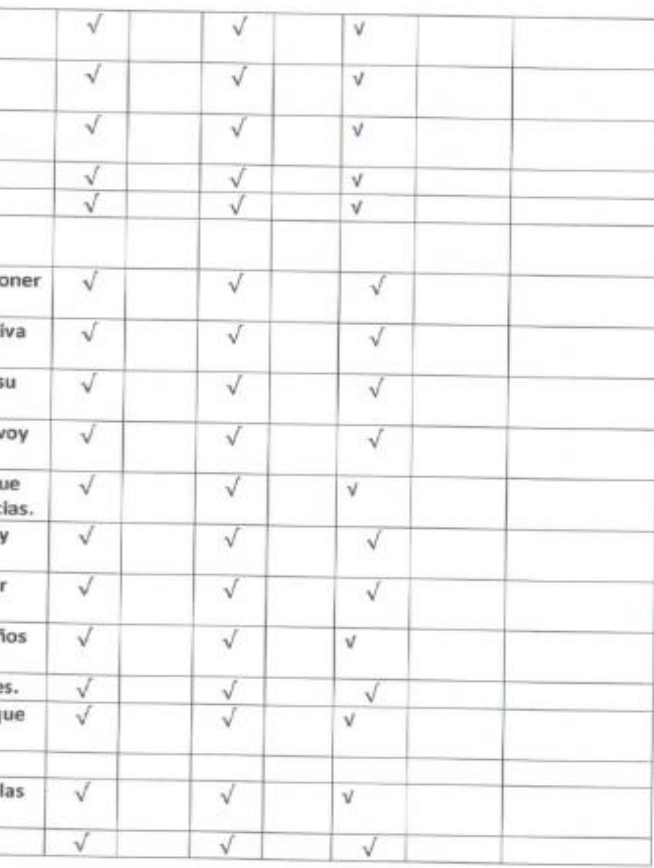

53 Respondo correctamente a las peticiones y sugerencias de las

54 Personas aduitas.

54 Cuando tengo un problema con una persona adulta, me pongo en su lugar y trato de solucionario.

55 Inicio y termino conversaciones con personas adultas.

56 Respondo correctamente cuando las personas ad

de modo amable y educado(a)

educado me relaciono con las personas aduitas, soy cortés y

58 Hago peticiones, sugerencias $y$ quejas a las personas adultas.

59 Tengo conversaciones con las personas adultas.

60 Soy sincero cuando alabo y elogio a las personas adultas.

Observaciones (precisar si hay suficiencia):

Si hay suficiencia

Opinión de aplicabilidad: Aplicable (X)

No aplicable ()

Apellidos y nombres del juez evaluador Quispe Fuentes Isabel

DNI 10281288

Lima, 28 de Naviambredel 2019

Especialldad del evaluador Psicopedagogía de la Infancia.

Pertinencia: El item corresponde al concepto teórico formulado.

Relevancla: El item es apropiado para representar al componente o dimensión especifica del constructo.

Claridad: Se entiende sin dificultad alguna el enunciado del item, es conciso, es exacto y directo.

Nota: Suficiencia, se dice suficiencia cuando los items planteados son suficientes para medir. 


\section{Juicio de expertos 3.}

ANEXO 04

CERTIFICADO DE VALIDEZ DE CONTENIDO DEL INSTRUMENTO QUE MIDE LAS HABILIDADES SOCIALES.

\begin{tabular}{|c|c|c|c|c|c|c|c|c|}
\hline \multirow[t]{2}{*}{$\mathrm{N}^{0}$} & \multirow[t]{2}{*}{ DIMENSIONES / items } & \multicolumn{2}{|c|}{ Pertinencia' } & \multicolumn{2}{|c|}{ Relevancia $^{2}$} & \multicolumn{2}{|c|}{ Claridad $^{3}$} & \multirow[t]{2}{*}{ Sugerencias } \\
\hline & & Si & No & $\mathrm{Si}$ & No & Si & No & \\
\hline & DIMENSIÓN 1: HABILIDADES BÁSICAS DE INTERACCIÓN SOCIAL. & & & & & & & \\
\hline 1 & Saludo de modo adecuado a otras personas. & $\checkmark$ & & 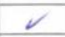 & & $\gamma$ & & \\
\hline 2 & Me río con otras personas cuando es oportuno. & $r$ & & $\checkmark$ & & r & & \\
\hline 3 & Respondo adecuadamente cuando otros me saludan. & z & & $\checkmark$ & & $\checkmark$ & & \\
\hline 4 & Pido favores a otras personas cuando necesito algo. & r & & $\checkmark$ & & $\gamma$ & & \\
\hline 5 & Sonrío a las demás personas en situaciones adecuadas. & 7 & & $\gamma$ & & $\gamma$ & & \\
\hline 6 & $\begin{array}{l}\text { Respondo adecuadamente cuando otros niños y niñas se dirigen a mí } \\
\text { de modo amable y educado. }\end{array}$ & $r$ & & $r$ & & $\checkmark$ & & \\
\hline 7 & Me presento ante otras personas cuando es necesario. & 2 & & $\checkmark$ & & 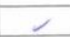 & & \\
\hline 8 & Hago favores a otras personas en distintas ocasiones. & 1 & & $\gamma$ & & $\checkmark$ & & \\
\hline 9 & Presento a otras personas que no se conocen entre sí. & / & & $\checkmark$ & & $\gamma$ & & \\
\hline 10 & $\begin{array}{l}\text { Cuando me relaciono con otros niños y niñas, pido las cosas por favor, } \\
\text { digo gracias, me disculpo, etc. }\end{array}$ & 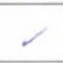 & & $\gamma$ & & $\checkmark$ & & \\
\hline & DIMENSIÓN 2: HABILIDADES PARA HACER AMIGOS Y AMIGAS & $\sigma$ & & & & & & \\
\hline 11 & Ayudo a otros niños y niñas en distintas ocasiones. & $\gamma$ & & $\gamma$ & & r & & \\
\hline 12 & Pido ayuda a otras personas cuando lo necesito. & r & & 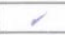 & & $\checkmark$ & & \\
\hline 13 & Hago alabanzas y digo cosas positivas a otros niños y niñas. & / & & / & & r & & \\
\hline 14 & $\begin{array}{l}\text { Respondo correctamente cuando otro niño o niña me pide que juegue } \\
\text { o realice alguna actividad con él o ella. }\end{array}$ & $\checkmark$ & & , & & $d$ & & \\
\hline 15 & $\begin{array}{l}\text { Coopero con otros niños y niñas en diversas actividades y juegos } \\
\text { (participo, animo, doy sugerencias, etc.) }\end{array}$ & $r$ & & $\checkmark$ & & $\gamma$ & & \\
\hline 16 & $\begin{array}{l}\text { Respondo adecuadamente cuando otras personas me hacen } \\
\text { alabanzas, elogios y cumplidos. }\end{array}$ & $\mathscr{\gamma}$ & & Y & & Y & & \\
\hline 17 & Comparto mis cosas con los otros niños y niñas. & $\checkmark$ & & $d$ & & I & & \\
\hline 18 & $\begin{array}{l}\text { Me junto con otros niños y niñas que están jugando o realizando una } \\
\text { actividad. }\end{array}$ & / & & / & & $\gamma$ & & \\
\hline
\end{tabular}

19 Respondo de modo apropiado cuando otros niños y niñas quieren unirse conmigo a jugar 0 a realizar una actividad.

20 Inicio juegos y otras actividades con otros niños y niñas DIMENSIÓN 3: HABILIDADES CONVERSACIONALES

21 Respondo adecuadamente cuando las personas con las que estoy hablando quieren terminar la conversación.

22 Cuando hablo con otra persona, escucho lo que me dice, respondo a lo que me pregunta y digo lo que yo pienso y siento.

23 Cuando hablo con otros niños y niñas, termino la conversación de modo adecuado.

24 Respondo adecuadamente cuando otros niños y niñas quieren entrar en nuestra conversación.

25 Respondo adecuadamente cuando otros niños y niñas quieren iniciar una conversación conmigo.

26 Me uno a la conversación que tienen otros niños y niñas.

27 Cuando tengo una conversación con otras personas participo activamente (cambio de tema, intervengo en la conversación, etc.)

28 Inicio conversaciones con otros niños y niñas.

29 Cuando hablo con un grupo de niños y niñas, participo de acuerdo a las normas establecidas.

30 Cuando tengo una conversación en grupo, intervengo cuando es necesario y lo hago de modo correcto. DIMENSIÓN 4: HABILIDADES RELACIONADAS CON LOS SENTIMIENTOS, EMOCIONES Y OPINIONES.

31 Me digo a mi mismo/a cosas positivas.

32 Defiendo y reclamo mis derechos ante las y los demás.

33 Expreso y defiendo adecuadamente mis opiniones.

34 Respondo adecuadamente a las emociones $y$ sentimientos agradables y positivos de los y las demás (felicitaciones, alegría,...)

35 Respondo adecuadamente a las emociones y sentimientos desagradables y negativos de los y las demás (críticas, enfado, tristeza, ...)

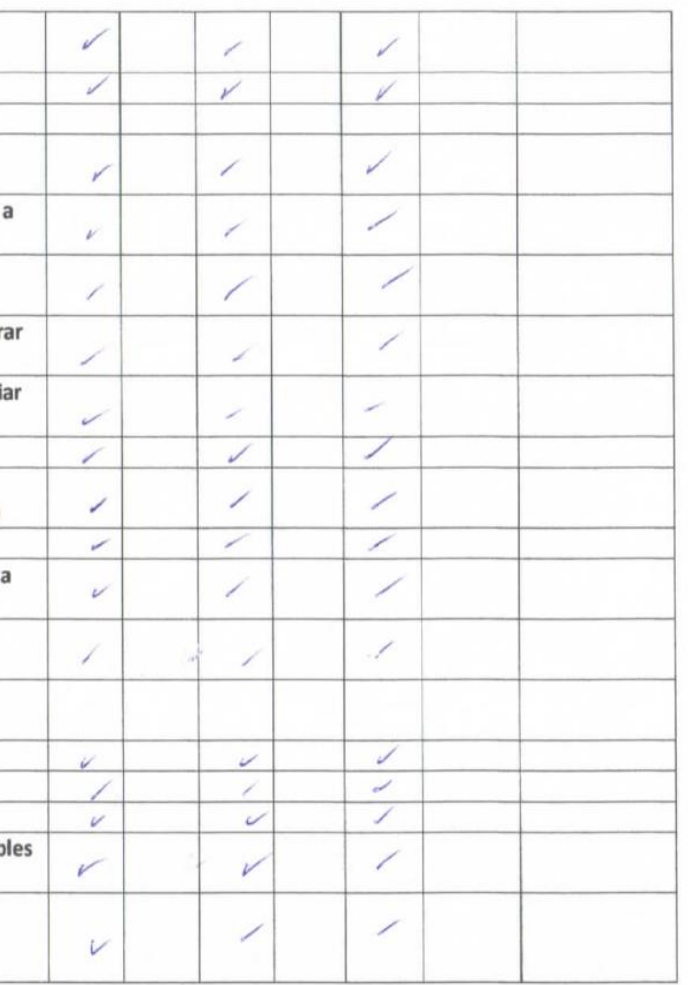




\begin{tabular}{|c|c|c|c|c|c|c|}
\hline 36 & $\begin{array}{l}\text { Expreso adecuadamente a las demás personas mis emociones y } \\
\text { sentimientos agradables y positivos (felicidad, placer, alegría ....) }\end{array}$ & $r$ & r & r & & \\
\hline 37 & $\begin{array}{l}\text { Expreso adecuadamente a las demás personas mis emociones y } \\
\text { sentimientos desagradables y negativos (tristeza, enfado, fracaso ...) }\end{array}$ & > & r & $\gamma$ & & \\
\hline 38 & $\begin{array}{l}\text { Respondo adecuadamente cuando otras personas defienden sus } \\
\text { derechos. }\end{array}$ & $\checkmark$ & r & r & & \\
\hline 39 & Expreso desacuerdo con otras personas cuando es oportuno. & $\checkmark$ & 2 & 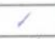 & & \\
\hline \multirow[t]{2}{*}{40} & Expreso cosas positivas de mi mismo/a ante otras personas. & 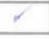 & $\gamma$ & I & & \\
\hline & $\begin{array}{l}\text { DIMENSIÓN 5: HABILIDADES DE SOLUCIÓN DE PROBLEMAS } \\
\text { INTERPERSONALES. }\end{array}$ & & & & & \\
\hline 41 & $\begin{array}{l}\text { Cuando tengo un problema con otros niños y niñas, después de poner } \\
\text { en práctica la solución elegida, evalúo los resultados obtenidos. }\end{array}$ & $\checkmark$ & I & $\gamma$ & & \\
\hline 42 & $\begin{array}{l}\text { Ante un problema con otros niños y niñas, elijo una solución efectiva } \\
\text { y justa para las personas implicadas. }\end{array}$ & $\gamma$ & $\gamma$ & Y & & \\
\hline 43 & $\begin{array}{l}\text { Cuando tengo un problema con otros niños y niñas, me pongo en su } \\
\text { lugar y busco soluciones. }\end{array}$ & $\checkmark$ & $\gamma$ & Y & & \\
\hline 44 & $\begin{array}{l}\text { Cuando tengo un conflicto con otros niños y niñas, preparo cómo voy } \\
\text { a poner en práctica la solución elegida. }\end{array}$ & 1 & $\mathcal{L}$ & / & & \\
\hline 45 & $\begin{array}{l}\text { Cuando tengo un problema con otros niños y niñas, pienso en las } \\
\text { consecuencias de lo que puedo hacer para solucionarlo. }\end{array}$ & $\sim$ & $d$ & $\gamma$ & & \\
\hline 46 & $\begin{array}{l}\text { Cuando quiero solucionar un problema que tengo con otros niños y } \\
\text { niñas, trato de elegir la mejor solución }\end{array}$ & 2 & & ব & & \\
\hline 47 & $\begin{array}{l}\text { Cuando tengo un problema con otros niños y niñas, trato de buscar } \\
\text { las causas que lo motivaron. }\end{array}$ & $\mathcal{J}$ & & $\gamma$ & & \\
\hline 48 & $\begin{array}{l}\text { Identifico los problemas que me surgen cuando me relaciono con } \\
\text { otros niños y niñas. }\end{array}$ & $\checkmark$ & $\checkmark$ & 1 & & \\
\hline 49 & Ante un problema con otros niños y niñas, busco muchas soluciones. & $\checkmark$ & $v$ & - & & \\
\hline \multirow[t]{2}{*}{50} & $\begin{array}{l}\text { Cuando tengo un problema con otros niños y niñas, pienso en las } \\
\text { consecuencias de lo hagan los demás para solucionarlo. }\end{array}$ & $\checkmark$ & $\checkmark$ & - & & \\
\hline & DIMENSIÓN 6: HABILIDADES DE RELACIÓN CON LOS ADULTOS & & & & & \\
\hline 51 & $\begin{array}{l}\text { Soluciono por mi mismo/a los conflictos que se me plantean con las } \\
\text { personas adultas. }\end{array}$ & J & s & I & & \\
\hline
\end{tabular}

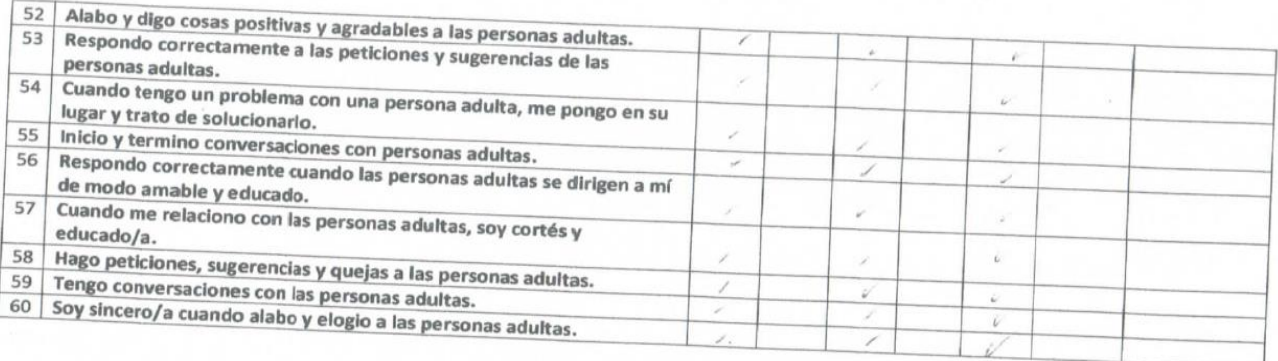

Observaciones (precisar si hay suficiencia): Opinión de aplicabilidad : Aplicable $P$ SUFICIENCIA

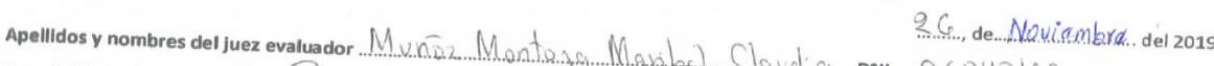

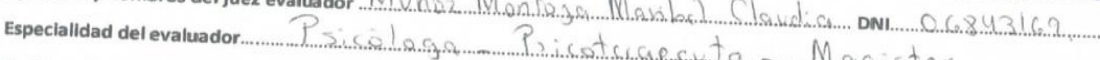
Pertinencia: El item corresponde al concepto teórico formulado

Relevancia: El item es apropiado para repres

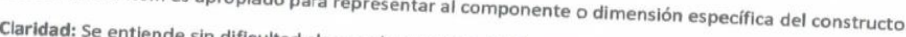

Claridad: Se entiende sin dificultad alguna el enunciado del item, es conciso, es exacto y directo.

Nota: Suficiencia, se dice suficiencia cuando los ítems planteados son suficientes para medir. 


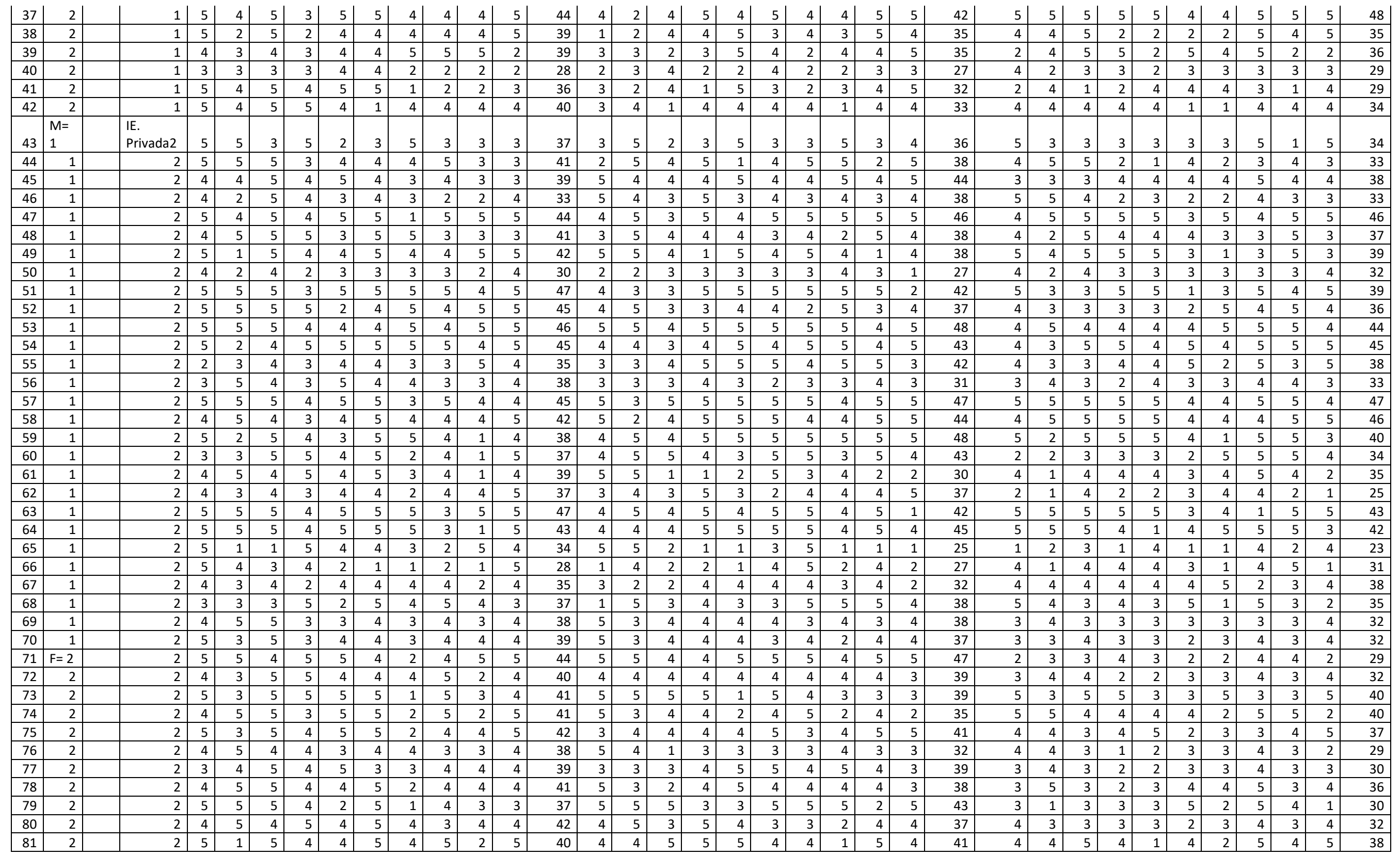




\begin{tabular}{|c|c|c|c|c|c|c|c|c|c|c|c|c|c|c|c|c|c|c|c|c|c|c|c|c|c|c|c|c|c|c|c|c|c|c|c|}
\hline 82 & 2 & 2 & 1 & 4 & 5 & 5 & 4 & 3 & 1 & 3 & 2 & 5 & 33 & 5 & 3 & 2 & 5 & 5 & 3 & 5 & 3 & 5 & 5 & 41 & 3 & 5 & 5 & 5 & 4 & 4 & 1 & 5 & 5 & 1 & 38 \\
\hline 83 & 2 & 2 & 3 & 2 & 3 & 5 & 3 & 4 & 4 & 3 & 2 & 4 & 33 & 4 & 5 & 4 & 5 & 4 & 3 & 4 & 3 & 4 & 3 & 39 & 4 & 3 & 3 & 3 & 4 & 3 & 5 & 1 & 3 & 4 & 33 \\
\hline 84 & 2 & 2 & 5 & 2 & 5 & 4 & 5 & 4 & 4 & 3 & 4 & 3 & 39 & 4 & 4 & 2 & 4 & 5 & 5 & 3 & 4 & 4 & 5 & 40 & 4 & 4 & 2 & 4 & 4 & 4 & 3 & 4 & 3 & 2 & 34 \\
\hline 85 & 2 & 2 & 4 & 2 & 5 & 2 & 3 & 4 & 3 & 3 & 4 & 4 & 34 & 3 & 2 & 4 & 4 & 4 & 4 & 3 & 4 & 3 & 4 & 35 & 4 & 3 & 3 & 4 & 4 & 3 & 4 & 3 & 3 & 4 & 35 \\
\hline 86 & 2 & 2 & 5 & 2 & 5 & 1 & 2 & 5 & 3 & 2 & 3 & 5 & 33 & 2 & 2 & 3 & 4 & 3 & 1 & 1 & 3 & 4 & 4 & 27 & 3 & 2 & 5 & 5 & 5 & 1 & 1 & 3 & 4 & 4 & 33 \\
\hline 88 & 2 & 2 & 3 & 4 & 3 & 5 & 4 & 4 & 1 & 4 & 2 & 3 & 33 & 3 & 5 & 4 & 5 & 4 & 4 & 3 & 3 & 3 & 4 & 38 & 5 & 4 & 3 & 4 & 4 & 3 & 2 & 5 & 4 & 3 & 37 \\
\hline 89 & 2 & 2 & 4 & 5 & 5 & 3 & 5 & 4 & 5 & 4 & 4 & 3 & 42 & 5 & 4 & 4 & 5 & 5 & 4 & 3 & 3 & 4 & 5 & 42 & 4 & 4 & 4 & 4 & 4 & 4 & 5 & 5 & 4 & 4 & 42 \\
\hline 90 & 2 & 2 & 4 & 2 & 5 & 2 & 5 & 5 & 3 & 3 & 2 & 3 & 34 & 5 & 2 & 4 & 5 & 3 & 5 & 3 & 4 & 5 & 4 & 40 & 5 & 4 & 5 & 3 & 3 & 2 & 1 & 4 & 3 & 4 & 34 \\
\hline 91 & 2 & 2 & 5 & 5 & 5 & 1 & 5 & 5 & 5 & 5 & 5 & 5 & 46 & 4 & 4 & 5 & 5 & 5 & 5 & 5 & 5 & 5 & 5 & 48 & 5 & 5 & 5 & 5 & 5 & 5 & 5 & 5 & 5 & 5 & 50 \\
\hline 92 & 2 & 2 & 5 & 2 & 4 & 3 & 4 & 4 & 3 & 3 & 3 & 4 & 35 & 3 & 3 & 3 & 3 & 2 & 3 & 3 & 2 & 4 & 2 & 28 & 3 & 4 & 3 & 3 & 3 & 2 & 3 & 3 & 3 & 4 & 31 \\
\hline 93 & 2 & 2 & 5 & 5 & 5 & 4 & 5 & 5 & 5 & 4 & 5 & 5 & 48 & 4 & 4 & 5 & 5 & 5 & 5 & 5 & 5 & 5 & 5 & 48 & 5 & 5 & 5 & 5 & 5 & 2 & 2 & 5 & 5 & 5 & 44 \\
\hline 94 & 2 & 2 & 5 & 3 & 5 & 2 & 3 & 5 & 5 & 5 & 3 & 5 & 41 & 4 & 2 & 4 & 3 & 2 & 4 & 2 & 3 & 5 & 3 & 32 & 3 & 4 & 4 & 5 & 5 & 4 & 3 & 3 & 4 & 4 & 39 \\
\hline 95 & 2 & 2 & 5 & 5 & 5 & 5 & 5 & 5 & 4 & 5 & 4 & 5 & 48 & 4 & 4 & 4 & 5 & 4 & 5 & 4 & 4 & 5 & 4 & 43 & 5 & 5 & 5 & 5 & 5 & 4 & 4 & 5 & 5 & 4 & 47 \\
\hline 96 & 2 & 2 & 5 & 4 & 5 & 4 & 5 & 5 & 3 & 4 & 3 & 4 & 42 & 4 & 3 & 4 & 4 & 4 & 4 & 4 & 3 & 4 & 5 & 39 & 4 & 4 & 4 & 5 & 5 & 4 & 4 & 5 & 4 & 4 & 43 \\
\hline
\end{tabular}

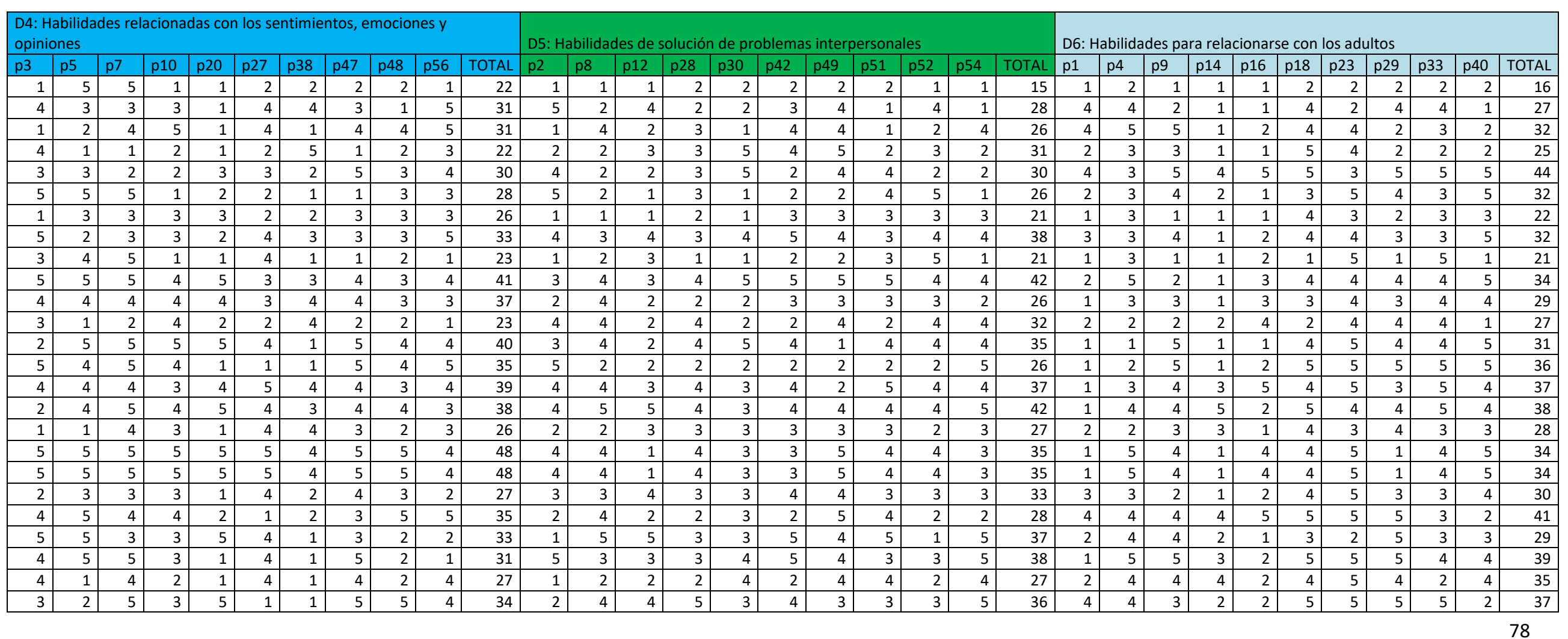




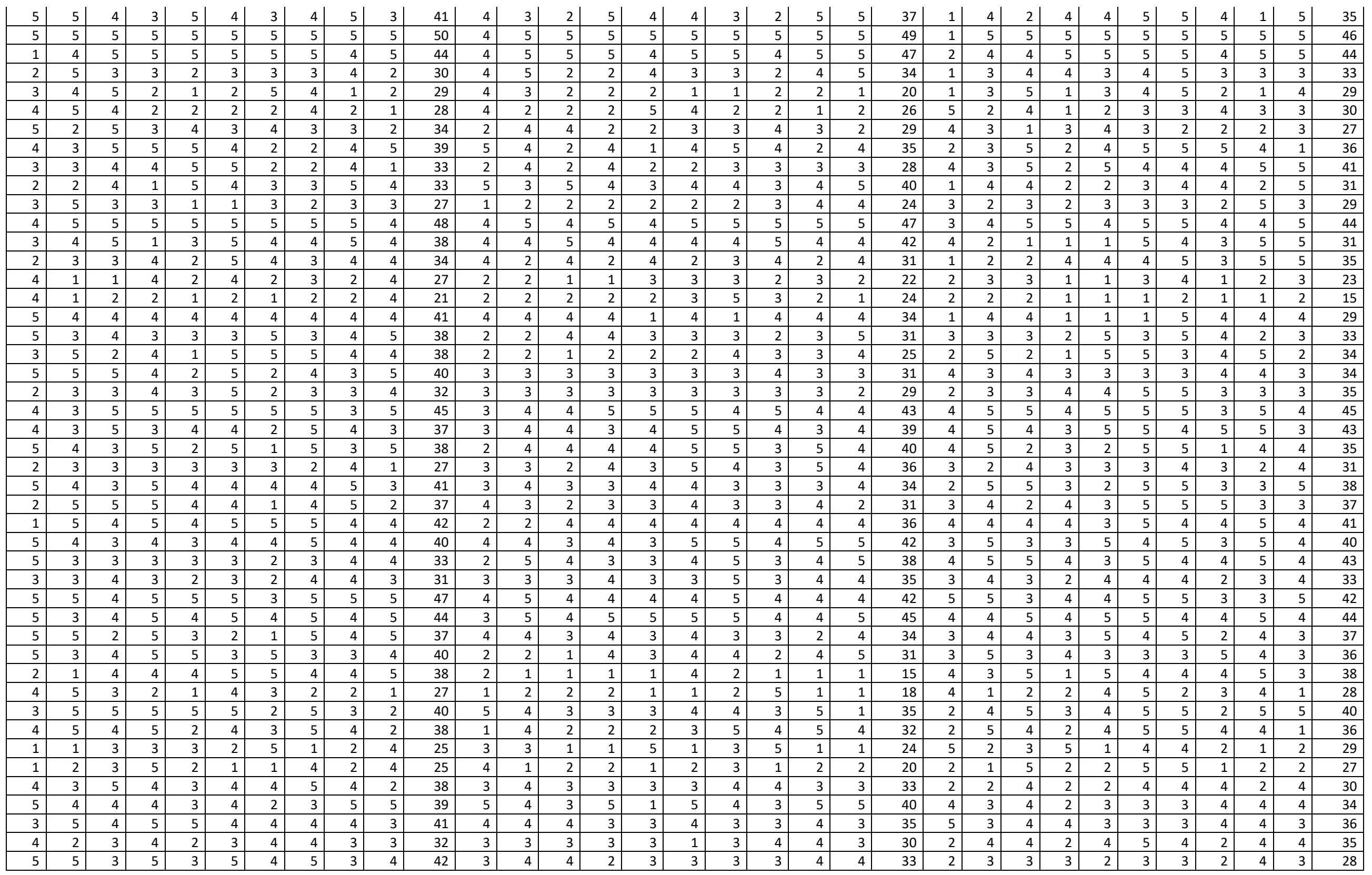




\begin{tabular}{|c|c|c|c|c|c|c|c|c|c|c|c|c|c|c|c|c|c|c|c|c|c|c|c|c|c|c|c|c|c|c|c|c|}
\hline 5 & 5 & 4 & 5 & 2 & 5 & 4 & 5 & 3 & 5 & 43 & 1 & 3 & 3 & 4 & 2 & 4 & 5 & 4 & 4 & 3 & 33 & 1 & 4 & 3 & 4 & 3 & 5 & 5 & 4 & 4 & 3 & 36 \\
\hline 4 & 4 & 3 & 5 & 5 & 5 & 2 & 5 & 2 & 5 & 40 & 2 & 4 & 5 & 5 & 1 & 5 & 5 & 2 & 5 & 2 & 36 & 2 & 2 & 5 & 5 & 1 & 5 & 5 & 3 & 5 & 5 & 38 \\
\hline 5 & 4 & 5 & 5 & 4 & 4 & 2 & 4 & 2 & 4 & 39 & 2 & 4 & 2 & 3 & 2 & 5 & 5 & 4 & 3 & 5 & 35 & 2 & 3 & 4 & 1 & 4 & 5 & 5 & 4 & 5 & 5 & 38 \\
\hline 5 & 5 & 3 & 3 & 2 & 3 & 2 & 5 & 2 & 3 & 33 & 2 & 3 & 4 & 4 & 3 & 3 & 4 & 2 & 5 & 4 & 34 & 4 & 5 & 4 & 4 & 3 & 5 & 5 & 1 & 4 & 3 & 38 \\
\hline 1 & 2 & 2 & 2 & 1 & 3 & 2 & 3 & 3 & 1 & 20 & 3 & 1 & 2 & 3 & 2 & 4 & 4 & 3 & 3 & 3 & 28 & 3 & 3 & 1 & 2 & 4 & 4 & 4 & 4 & 3 & 3 & 31 \\
\hline 3 & 2 & 3 & 3 & 2 & 4 & 4 & 3 & 4 & 2 & 30 & 2 & 3 & 3 & 3 & 4 & 3 & 5 & 2 & 3 & 3 & 31 & 3 & 4 & 3 & 2 & 4 & 5 & 5 & 4 & 5 & 3 & 38 \\
\hline 3 & 3 & 2 & 4 & 2 & 1 & 4 & 3 & 3 & 5 & 30 & 1 & 4 & 5 & 2 & 3 & 4 & 4 & 3 & 4 & 3 & 33 & 2 & 3 & 3 & 4 & 2 & 4 & 4 & 4 & 3 & 3 & 32 \\
\hline 4 & 5 & 5 & 1 & 3 & 2 & 4 & 1 & 3 & 3 & 31 & 1 & 2 & 1 & 1 & 3 & 2 & 4 & 4 & 1 & 3 & 22 & 2 & 1 & 4 & 1 & 1 & 4 & 5 & 3 & 2 & 1 & 24 \\
\hline 3 & 3 & 5 & 4 & 3 & 3 & 3 & 4 & 3 & 3 & 34 & 1 & 2 & 1 & 4 & 4 & 4 & 4 & 3 & 3 & 4 & 30 & 2 & 2 & 2 & 2 & 2 & 4 & 4 & 1 & 2 & 3 & 24 \\
\hline 4 & 4 & 5 & 5 & 2 & 5 & 2 & 5 & 2 & 4 & 38 & 3 & 5 & 4 & 4 & 5 & 4 & 2 & 4 & 5 & 4 & 40 & 4 & 5 & 4 & 3 & 4 & 5 & 5 & 5 & 4 & 4 & 43 \\
\hline 5 & 4 & 2 & 3 & 4 & 5 & 4 & 1 & 5 & 3 & 36 & 1 & 1 & 3 & 5 & 2 & 4 & 4 & 2 & 4 & 3 & 29 & 1 & 4 & 5 & 2 & 3 & 5 & 3 & 4 & 5 & 3 & 35 \\
\hline 3 & 3 & 4 & 5 & 3 & 2 & 2 & 3 & 4 & 3 & 32 & 4 & 3 & 3 & 3 & 2 & 5 & 3 & 4 & 3 & 3 & 33 & 3 & 4 & 3 & 3 & 2 & 3 & 4 & 3 & 2 & 4 & 31 \\
\hline 2 & 5 & 3 & 4 & 3 & 5 & 3 & 3 & 2 & 3 & 33 & 3 & 3 & 3 & 4 & 3 & 2 & 5 & 4 & 5 & 4 & 36 & 2 & 3 & 2 & 3 & 2 & 3 & 3 & 2 & 5 & 3 & 28 \\
\hline 4 & 3 & 3 & 4 & 3 & 4 & 4 & 3 & 3 & 3 & 34 & 4 & 3 & 3 & 3 & 3 & 3 & 1 & 3 & 4 & 3 & 30 & 3 & 4 & 3 & 3 & 3 & 4 & 4 & 3 & 3 & 3 & 33 \\
\hline 4 & 3 & 5 & 3 & 3 & 5 & 2 & 5 & 2 & 3 & 35 & 3 & 3 & 3 & 1 & 3 & 4 & 3 & 1 & 4 & 3 & 28 & 2 & 4 & 3 & 3 & 1 & 5 & 1 & 2 & 1 & 1 & 23 \\
\hline 5 & 3 & 4 & 5 & 4 & 4 & 4 & 5 & 4 & 5 & 43 & 4 & 5 & 5 & 3 & 4 & 4 & 4 & 4 & 5 & 4 & 42 & 4 & 5 & 4 & 4 & 2 & 5 & 5 & 2 & 4 & 4 & 39 \\
\hline 4 & 4 & 4 & 5 & 2 & 5 & 3 & 4 & 3 & 3 & 37 & 3 & 3 & 3 & 3 & 2 & 3 & 3 & 3 & 2 & 3 & 28 & 3 & 4 & 4 & 3 & 5 & 3 & 5 & 2 & 2 & 3 & 34 \\
\hline 3 & 5 & 1 & 5 & 4 & 4 & 2 & 4 & 3 & 2 & 33 & 2 & 4 & 5 & 4 & 3 & 4 & 3 & 4 & 5 & 3 & 37 & 4 & 4 & 5 & 5 & 3 & 5 & 5 & 3 & 4 & 3 & 41 \\
\hline 1 & 5 & 3 & 5 & 3 & 2 & 2 & 5 & 3 & 1 & 30 & 3 & 5 & 3 & 1 & 2 & 2 & 2 & 2 & 5 & 1 & 26 & 1 & 4 & 5 & 3 & 3 & 3 & 4 & 4 & 5 & 5 & 37 \\
\hline 5 & 5 & 4 & 5 & 5 & 5 & 5 & 5 & 5 & 5 & 49 & 5 & 4 & 5 & 5 & 5 & 5 & 5 & 5 & 5 & 5 & 49 & 5 & 5 & 5 & 5 & 5 & 5 & 5 & 1 & 5 & 5 & 46 \\
\hline 3 & 5 & 3 & 3 & 2 & 2 & 2 & 3 & 3 & 4 & 30 & 3 & 4 & 3 & 2 & 2 & 3 & 2 & 2 & 4 & 2 & 27 & 2 & 4 & 2 & 2 & 2 & 5 & 5 & 2 & 2 & 3 & 29 \\
\hline 5 & 5 & 5 & 5 & 5 & 5 & 5 & 5 & 5 & 5 & 50 & 3 & 5 & 5 & 5 & 5 & 5 & 5 & 5 & 5 & 5 & 48 & 4 & 4 & 5 & 5 & 4 & 5 & 5 & 2 & 5 & 5 & 44 \\
\hline 3 & 5 & 4 & 5 & 2 & 2 & 3 & 4 & 4 & 3 & 35 & 5 & 3 & 3 & 3 & 3 & 4 & 3 & 4 & 3 & 3 & 34 & 1 & 4 & 5 & 4 & 4 & 4 & 5 & 3 & 4 & 5 & 39 \\
\hline 3 & 5 & 5 & 5 & 4 & 5 & 5 & 5 & 4 & 4 & 45 & 4 & 4 & 5 & 4 & 4 & 5 & 4 & 4 & 5 & 4 & 43 & 4 & 4 & 5 & 4 & 4 & 5 & 5 & 4 & 4 & 5 & 44 \\
\hline 3 & 4 & 5 & 4 & 5 & 4 & 5 & 5 & 4 & 4 & 43 & 4 & 4 & 4 & 4 & 4 & 4 & 5 & 5 & 4 & 4 & 42 & 4 & 4 & 4 & 5 & 5 & 5 & 4 & 4 & 5 & 4 & 44 \\
\hline
\end{tabular}


Prueba piloto

\begin{tabular}{|c|c|c|c|c|c|c|c|c|c|c|c|c|c|c|}
\hline \multicolumn{4}{|c|}{ Variable: Habilidades Sociales } & \multicolumn{11}{|c|}{ Dimensión 1} \\
\hline Inf. & Sexo & Edad & Escuela de procedencia & P6 & p13 & p22 & p24 & p26 & p36 & $\mathrm{p} 43$ & p45 & p57 & p59 & Total \\
\hline 1 & 1 & & Piloto & 3 & 3 & 5 & 5 & 3 & 4 & 5 & 3 & 2 & 4 & 37 \\
\hline 2 & 1 & & & 2 & 5 & 4 & 4 & 1 & 2 & 4 & 3 & 1 & 4 & 30 \\
\hline 3 & 1 & & & 5 & 3 & 5 & 1 & 5 & 5 & 4 & 1 & 5 & 4 & 38 \\
\hline 4 & 1 & & & 4 & 3 & 5 & 4 & 5 & 4 & 4 & 3 & 4 & 3 & 39 \\
\hline 5 & 1 & & & 3 & 4 & 4 & 3 & 4 & 3 & 3 & 4 & 4 & 4 & 36 \\
\hline 6 & 1 & & & 5 & 4 & 5 & 4 & 2 & 2 & 2 & 3 & 2 & 4 & 33 \\
\hline 7 & 1 & & & 5 & 5 & 3 & 3 & 5 & 4 & 3 & 2 & 5 & 5 & 40 \\
\hline 8 & 1 & & & 5 & 5 & 5 & 4 & 3 & 4 & 5 & 2 & 4 & 5 & 42 \\
\hline 9 & 1 & & & 4 & 4 & 4 & 4 & 4 & 5 & 4 & 5 & 5 & 5 & 44 \\
\hline 10 & 1 & & & 4 & 5 & 4 & 3 & 4 & 3 & 4 & 2 & 4 & 4 & 37 \\
\hline 11 & 1 & & & 4 & 2 & 3 & 4 & 2 & 3 & 2 & 2 & 5 & 5 & 32 \\
\hline 12 & 2 & & & 3 & 5 & 3 & 5 & 3 & 3 & 4 & 3 & 4 & 3 & 36 \\
\hline 13 & 2 & & & 5 & 2 & 5 & 4 & 5 & 4 & 3 & 4 & 4 & 5 & 41 \\
\hline 14 & 2 & & & 4 & 2 & 3 & 1 & 5 & 5 & 5 & 2 & 5 & 5 & 37 \\
\hline 15 & 2 & & & 4 & 3 & 5 & 4 & 4 & 4 & 2 & 5 & 5 & 5 & 41 \\
\hline 16 & 2 & & & 5 & 4 & 5 & 4 & 5 & 5 & 1 & 2 & 2 & 3 & 36 \\
\hline 17 & 2 & & & 2 & 1 & 4 & 5 & 3 & 4 & 3 & 5 & 4 & 4 & 35 \\
\hline 18 & 2 & & & 3 & 5 & 3 & 5 & 3 & 3 & 4 & 3 & 4 & 3 & 36 \\
\hline
\end{tabular}

\begin{tabular}{|c|c|c|c|c|c|c|c|c|c|c|}
\hline \multicolumn{11}{|l|}{ Dimensión 2} \\
\hline $\mathrm{p} 11$ & p15 & p19 & p21 & p25 & p31 & p32 & p36 & p44 & p55 & Total \\
\hline 3 & 5 & 3 & 4 & 4 & 4 & 4 & 4 & 4 & 2 & 37 \\
\hline 2 & 5 & 1 & 4 & 2 & 1 & 5 & 2 & 5 & 1 & 28 \\
\hline 1 & 1 & 1 & 5 & 5 & 4 & 5 & 5 & 5 & 4 & 36 \\
\hline 3 & 4 & 3 & 4 & 3 & 5 & 4 & 4 & 4 & 5 & 39 \\
\hline 4 & 4 & 2 & 4 & 4 & 4 & 4 & 3 & 4 & 3 & 36 \\
\hline 3 & 3 & 1 & 3 & 2 & 5 & 3 & 2 & 4 & 3 & 29 \\
\hline
\end{tabular}




\begin{tabular}{|c|c|c|c|c|c|c|c|c|c|c|}
\hline 4 & 4 & 3 & 3 & 2 & 4 & 4 & 4 & 3 & 5 & 36 \\
\hline 5 & 2 & 4 & 5 & 5 & 2 & 3 & 4 & 3 & 3 & 36 \\
\hline 4 & 4 & 4 & 4 & 4 & 5 & 4 & 5 & 5 & 4 & 43 \\
\hline 3 & 3 & 4 & 5 & 5 & 4 & 4 & 3 & 2 & 5 & 38 \\
\hline 4 & 4 & 4 & 3 & 4 & 3 & 3 & 3 & 4 & 3 & 35 \\
\hline 5 & 4 & 2 & 5 & 3 & 2 & 3 & 3 & 4 & 5 & 36 \\
\hline 4 & 3 & 4 & 4 & 4 & 4 & 4 & 4 & 4 & 2 & 37 \\
\hline 5 & 1 & 5 & 3 & 1 & 5 & 5 & 5 & 5 & 4 & 39 \\
\hline 3 & 3 & 5 & 5 & 5 & 4 & 5 & 4 & 5 & 5 & 44 \\
\hline 3 & 2 & 4 & 1 & 5 & 4 & 2 & 5 & 4 & 5 & 35 \\
\hline 1 & 5 & 4 & 4 & 5 & 5 & 2 & 4 & 4 & 3 & 37 \\
\hline 5 & 4 & 2 & 5 & 3 & 2 & 3 & 3 & 4 & 5 & 36 \\
\hline
\end{tabular}

Dimensión 3

\begin{tabular}{|c|c|c|c|c|c|c|c|c|c|c|}
\hline p17 & p34 & p35 & p39 & p41 & $\mathrm{p} 46$ & p50 & p53 & p58 & $\mathrm{p} 60$ & Total \\
\hline 4 & 2 & 2 & 4 & 4 & 1 & 5 & 2 & 3 & 5 & 32 \\
\hline 4 & 1 & 4 & 4 & 4 & 1 & 1 & 1 & 3 & 1 & 24 \\
\hline 5 & 4 & 5 & 5 & 5 & 4 & 2 & 5 & 5 & 2 & 42 \\
\hline 4 & 5 & 4 & 3 & 3 & 3 & 3 & 4 & 4 & 4 & 37 \\
\hline 4 & 2 & 4 & 4 & 2 & 4 & 4 & 3 & 2 & 4 & 33 \\
\hline 5 & 4 & 5 & 4 & 4 & 3 & 3 & 2 & 3 & 5 & 38 \\
\hline 5 & 3 & 4 & 3 & 4 & 2 & 2 & 4 & 5 & 4 & 36 \\
\hline 4 & 4 & 5 & 5 & 5 & 4 & 4 & 5 & 3 & 3 & 42 \\
\hline 5 & 4 & 5 & 5 & 4 & 3 & 3 & 5 & 4 & 4 & 42 \\
\hline 4 & 3 & 5 & 3 & 5 & 1 & 1 & 5 & 3 & 2 & 32 \\
\hline 3 & 3 & 3 & 2 & 4 & 1 & 3 & 4 & 4 & 4 & 31 \\
\hline 4 & 3 & 3 & 2 & 2 & 3 & 2 & 4 & 3 & 3 & 29 \\
\hline 4 & 4 & 5 & 4 & 4 & 2 & 4 & 2 & 2 & 4 & 35 \\
\hline 4 & 1 & 5 & 3 & 5 & 2 & 5 & 2 & 5 & 4 & 36 \\
\hline 2 & 5 & 5 & 5 & 5 & 1 & 5 & 5 & 4 & 4 & 41 \\
\hline 2 & 4 & 1 & 2 & 4 & 4 & 4 & 3 & 1 & 4 & 29 \\
\hline
\end{tabular}




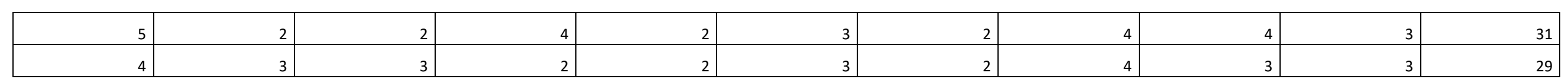

\begin{tabular}{|c|c|c|c|c|c|c|c|c|c|c|}
\hline Dimensión 4 & & & & & & & & & & \\
\hline p3 & $\mathrm{p} 5$ & p7 & $\mathrm{p} 10$ & $\mathrm{p} 20$ & p27 & p38 & $\mathrm{p} 47$ & p48 & p56 & Total \\
\hline 5 & 1 & 4 & 4 & 2 & 4 & 2 & 3 & 2 & 1 & 28 \\
\hline 2 & 1 & 1 & 4 & 4 & 3 & 1 & 5 & 3 & 3 & 27 \\
\hline 1 & 4 & 5 & 5 & 5 & 5 & 4 & 4 & 2 & 5 & 40 \\
\hline 4 & 5 & 3 & 5 & 3 & 4 & 4 & 4 & 4 & 4 & 40 \\
\hline 3 & 2 & 2 & 5 & 2 & 4 & 2 & 4 & 4 & 3 & 31 \\
\hline 2 & 2 & 3 & 4 & 4 & 3 & 1 & 3 & 4 & 2 & 28 \\
\hline 5 & 4 & 4 & 5 & 4 & 4 & 4 & 3 & 3 & 5 & 41 \\
\hline 5 & 5 & 5 & 5 & 5 & 3 & 5 & 5 & 4 & 4 & 46 \\
\hline 4 & 5 & 4 & 5 & 4 & 4 & 4 & 4 & 3 & 4 & 41 \\
\hline 4 & 2 & 3 & 3 & 4 & 2 & 5 & 4 & 2 & 2 & 31 \\
\hline 4 & 4 & 3 & 5 & 2 & 3 & 2 & 2 & 3 & 4 & 32 \\
\hline 3 & 3 & 2 & 2 & 2 & 3 & 2 & 3 & 2 & 2 & 24 \\
\hline 3 & 3 & 4 & 5 & 2 & 4 & 4 & 2 & 2 & 4 & 33 \\
\hline 5 & 5 & 4 & 5 & 1 & 3 & 1 & 4 & 1 & 4 & 33 \\
\hline 3 & 4 & 3 & 4 & 5 & 4 & 5 & 4 & 5 & 5 & 42 \\
\hline 4 & 1 & 2 & 2 & 1 & 2 & 1 & 2 & 2 & 4 & 21 \\
\hline 5 & 2 & 2 & 5 & 4 & 3 & 2 & 5 & 3 & 3 & 34 \\
\hline 3 & 3 & 2 & 2 & 2 & 3 & 2 & 3 & 2 & 2 & 24 \\
\hline
\end{tabular}




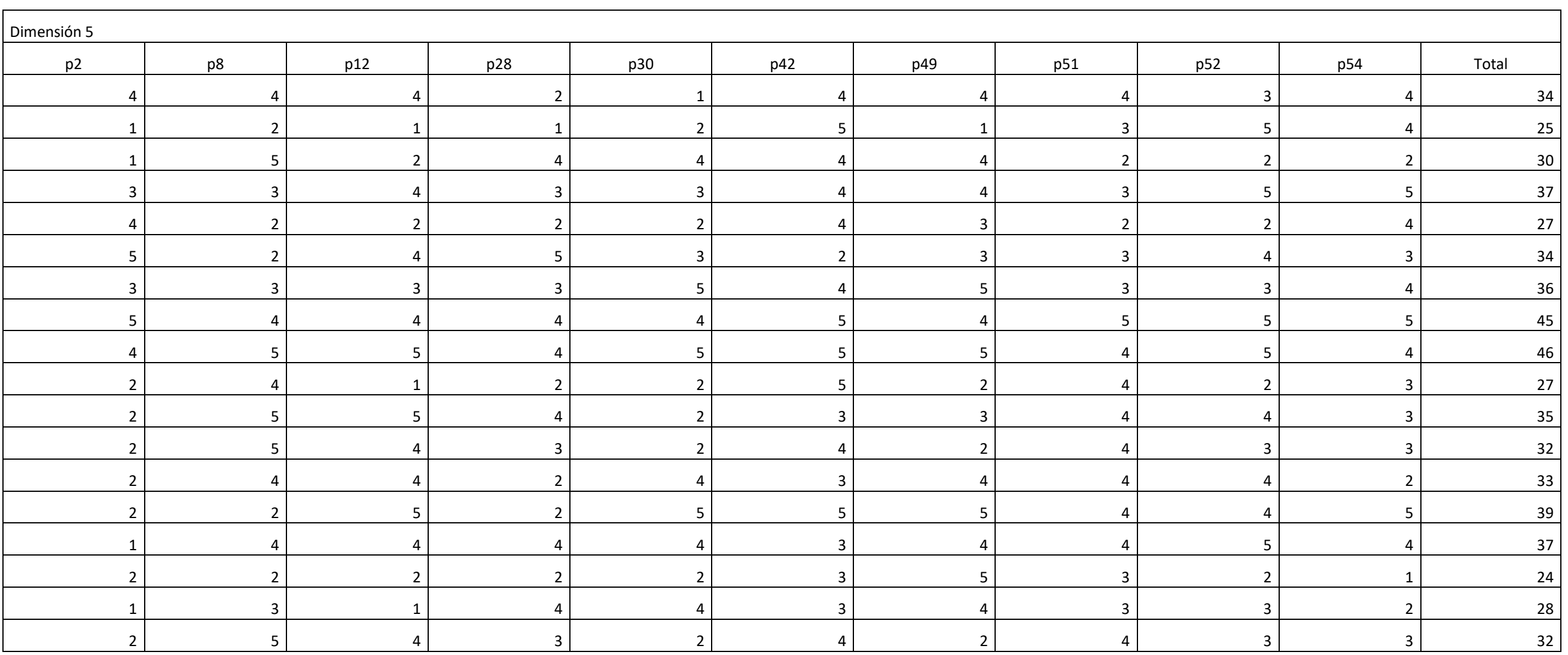

\begin{tabular}{|c|c|c|c|c|c|c|c|c|c|c|}
\hline \multicolumn{11}{|l|}{ Dimensión 6} \\
\hline p1 & $\mathrm{p} 4$ & p9 & p14 & p16 & p18 & p23 & p29 & p33 & $\mathrm{p} 40$ & Total \\
\hline 3 & 2 & 5 & 2 & 2 & 5 & 3 & 1 & 3 & 3 & 29 \\
\hline 2 & 1 & 2 & 1 & 1 & 4 & 4 & 1 & 1 & 1 & 18 \\
\hline 1 & 1 & 4 & 1 & 1 & 5 & 5 & 4 & 5 & 4 & 31 \\
\hline 3 & 4 & 4 & 2 & 3 & 5 & 4 & 2 & 4 & 4 & 35 \\
\hline 2 & 4 & 4 & 2 & 2 & 4 & 2 & 2 & 4 & 3 & 29 \\
\hline 3 & 1 & 5 & 4 & 4 & 5 & 4 & 4 & 4 & 5 & 39 \\
\hline 2 & 4 & 5 & 2 & 3 & 3 & 3 & 2 & 5 & 3 & 32 \\
\hline
\end{tabular}




\begin{tabular}{|c|c|c|c|c|c|c|c|c|c|c|}
\hline 5 & 4 & 4 & 4 & 5 & 4 & 4 & 2 & 4 & 4 & 40 \\
\hline 4 & 4 & 5 & 5 & 5 & 4 & 4 & 4 & 5 & 5 & 45 \\
\hline 1 & 2 & 5 & 1 & 4 & 3 & 2 & 2 & 4 & 4 & 28 \\
\hline 2 & 5 & 4 & 1 & 4 & 5 & 4 & 2 & 4 & 2 & 33 \\
\hline 2 & 2 & 3 & 4 & 2 & 4 & 2 & 2 & 2 & 2 & 25 \\
\hline 4 & 4 & 4 & 3 & 4 & 3 & 5 & 2 & 4 & 2 & 35 \\
\hline 1 & 5 & 3 & 4 & 2 & 5 & 5 & 1 & 3 & 5 & 34 \\
\hline 2 & 5 & 2 & 4 & 4 & 3 & 5 & 2 & 5 & 4 & 36 \\
\hline 2 & 2 & 2 & 1 & 1 & 1 & 2 & 1 & 1 & 2 & 15 \\
\hline 1 & 1 & 2 & 1 & 1 & 5 & 2 & 2 & 4 & 4 & 23 \\
\hline 2 & 2 & 3 & 4 & 2 & 4 & 2 & 2 & 2 & 2 & 25 \\
\hline
\end{tabular}




\section{Anexo $5 \quad$ : Otras evidencias}

\subsection{Confiabilidad del instrumento de medición.}

Para determinar el grado de confiabilidad del instrumento de medición se aplicará el coeficiente alfa de Cronbach, que es utilizada para escala politómica, cuya fórmula utilizada es:

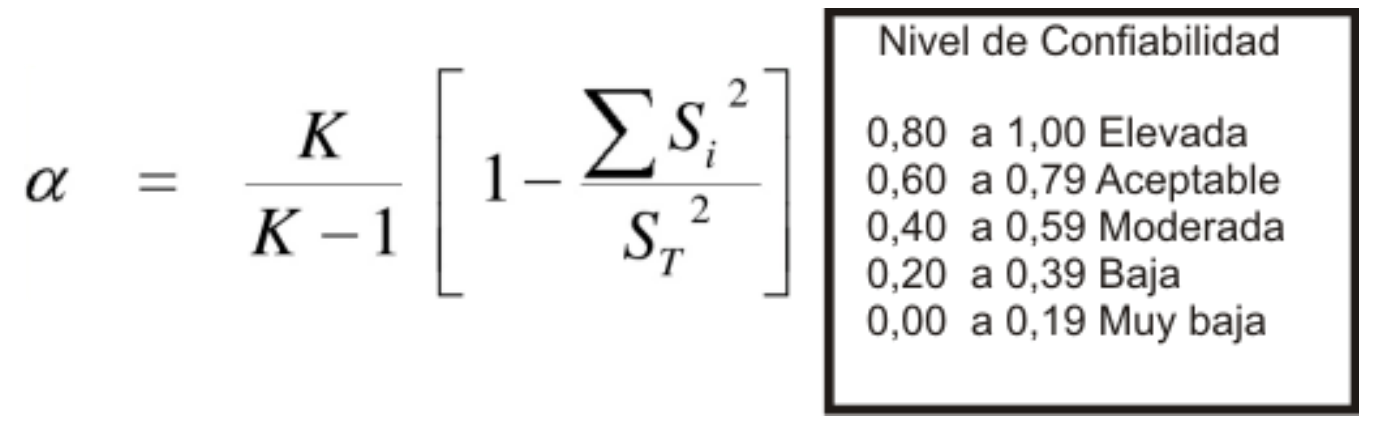

Donde:

K: Número de ítems

$\mathrm{Si}^{2}$ : Sumatoria de varianzas de los ítems

$\mathrm{St}^{2}$ : Varianza de la suma de los ítems

$\alpha$ : Coeficiente alfa de Cronbach.

\begin{tabular}{lccc}
\hline Variable & $\mathrm{N}^{\mathrm{o}}$ de Ítems & Alfa de Cronbach. & Confiabilidad \\
\hline Habilidades sociales & 60 & 0.918 & Elevada \\
\hline
\end{tabular}

En la prueba piloto, el coeficiente alfa de Cronbach para la variable habilidades sociales fue 0.918, significa que el instrumento tiene elevada confiabilidad. Se recomienda el uso de dicho instrumento para recoger información con respecto a la variable de estudio. 


\subsection{Documentos de autorización}

INSTIUCION EDUCATIVA N" 5039 "DIVINA PASTORA" CREADA POR R.M. No 16846 - 1954- ED. NTVEL. PRIMARIA CODIGO MODUI.AR N* 0215921

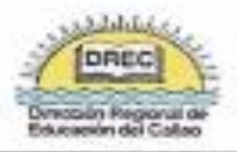

\section{CONSENTIMIENTO INFORMADO}

Por el presente documento, aprobamos el uso de la información de la institución Educativa $\mathrm{N}^{*}$ 5039'Divina Pastora" para que la alumna Liliana Celedonia Huamán Pretell pueda desarrollar el trabajo de grado titulado "HABILDADES SOCIALES EN LOS ESTUDLANTES DE SEXTO GRADO DE PRIMARIA DE DOS INSTITUCIONES EDUCATIVAS DEL CALLAO, 2019", Por tal motivo, nos comprometemos a brindar las facilidades necesarias en términos de acceso a la información relacionada para el desarrolio de su trabajo de grado, asi como aceptamos su utilización con fines académicos y colocación en diwersas bases de datos $y / 0$ concursos nacionáles e internacionales, en formato digital y/o impreso.

Se firma el presente documento en señal de conformidad:

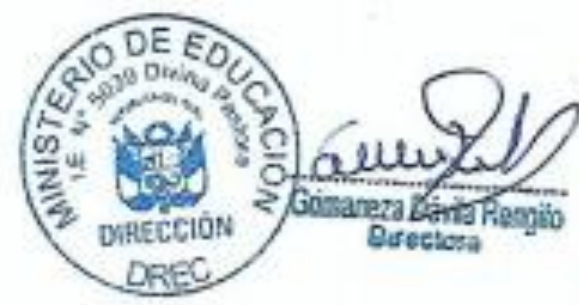

Nombres y apellidos: Grimaneza Dávila Rengifo

DNE: 18980032

Correo electrónico: cgdr_25_0511e@hotmail.com

Teléfono: 955818590 - 992437996

Fecha: Lima, 03 de diciembre del 2019. 


\section{CONSENTIMIENTO INFORMADO}

Por el presente documento, aprobamos el uso de la información de la Institución Educativa Particular "Jesús es mi Luz" para que la alumna Liliana Celedonia Huamán Pretell pueda desarrollar el trabajo de grado titulado "HABILIDADES SOCIALES EN LOS ESTUDIANTES DE SEXTO GRADO DE PRIMARIA DE DOS INSTITUCIONES EDUCATIVAS DEL CALLAO, 2019". Por tal motivo, nos comprometemos a brindar las facilidades necesarias en términos de acceso a la información relacionada para el desarrollo de su trabajo de grado, así como aceptamos su utilización con fines académicos y colocación en diversas bases de datos y/o concursos nacionales e internacionales, en formato digital y/o impreso.

Se firma el presente documento en señal de conformidad.

Callao, 04 de diciembre de 2019

Lic. Ismael Rosales Córdova

Director 